\title{
Formulas and Graphs for Representing the Interchange- ability of Fuel Gases
}

\author{
Elmer R. Weaver
}

\begin{abstract}
When gas-burning appliances have been adjusted to give satisfaction with a gas of one composition, and are then supplied with gas of a different composition, changes are usually noted in the characteristics of the flames produced. When no change can be seen or measured, the gases are said to be "exactly interchangeable." When undesirable changes do not occur to a greater extent than the person using the term thinks permissible, the gases are usually still called "interchangeable" with the omission of the adverb. No entirely satisfactory method has ever been found for predicting or representing the extent to which different gases depart from exact interchangeability. In this paper a set of six "indexes" is given for specifying and predicting from the composition of any two fuel gases the extent of the effects that occur when one is substituted for another. Four of these indexes are new. Their derivation is given, and their application is shown by comparison with the results of extensive experimentation of the American Gas Association. They are shown to represent the results of observation somewhat better than any method previously proposed.
\end{abstract}

\section{Introduction}

The problem of determining in advance the effect of changing the composition of the fuel gas supplied to a city on the operation of the many appliances in use is one of great practical importance. To this general problem have been devoted many extensive, expensive, and time-consuming studies based on experience, on theory, on laboratory observation, and on combinations of them. The various reports dealing with the problem would fill several volumes, yet no entirely satisfactory answer of general applicability has been obtained.

It will make the subject more tangible to cite some actual cases. About the year 1930 a supply of natural gas became available to the Washington Gas Light Co. At that time, the Company was delivering to the city a carburetted water-gas of $600 \mathrm{Btu} / \mathrm{cu}$ ft. Natural gas promised economies, but natural gas simply could not have been burned in existing appliances without a difficult period of readjustment and redrilling or replacement of burners and appliances. Accordingly, the Company set itself the problem of modifying the natural gas by mixing it with gases it could manufacture from coke, coal, and oil or from the natural gas itself to obtain a product that could be substituted for the carburetted watergas without adversely affecting the use of a million or more burners of every conceivable design and purpose. To avoid complications in connection with the selling price of the gas, the Company chose the limitation that the new supply should have the same heating value as the old. With some guidance from the experience of others, but mainly by the empirical method of trying many mixtures made in numerous ways with appliances of many types, the Company succeeded admirably in its purpose. However the solution applied only to the set of conditions existing in Washington and not generally to the replacing or mixing of gases of other types. Had satisfactory formulas been available to represent "interchangeability," most of the time and cost of the experimental investigation could have been saved.
Recently, the Company that supplies Milwaukee with a mixture of coke-oven and carburetted watergas found itself without plant capacity to meet winter peaks at a time when a transmission line to deliver natural gas from the Texas fields was nearing completion. It was not economical to build additional machinery to serve only as a supplementary source of supply during a few days, or at most a few months of a year or two while the natural gas line was being completed. Propane or butane were available, but the problem arose as to whether they could be safely introduced during peak loads, and in what quantity and with what other practicable modifications of the gas supply. Similar problems are faced by the gas companies in many localities.

The term interchangeability has come to represent the degree to which the operation of gas appliances is affected by substituting one gas for another. If no difference in the service rendered can be observed or measured, if flames on all burners are equally stable (that is, do not tend more or less to flash back or to "lift" from the burners), if there is no more tendency for carbon monoxide or soot to be liberated from one gas than from the other, the gases may be said to be exactly interchangeable. It is necessary to use the adverb if this ideal condition is to be indicated, for the term interchangeable is also applied to pairs of gases that do not give identical results but cause no more change of one kind or another than the user of the term thinks permissible.

Because service can be unsatisfactory in one or more of several ways, gases may be interchangeable in one respect but not in another. They are usually interchangeable, in the practical sense of causing no serious trouble, with some appliances but not with others; and they may be practically interchangeable in one direction but not in the reverse. For example, appliances that have been given ordinary adjustments while supplied with natural gas usually have a rather wide margin of safety from flash back (burning with primary air inside the burner) but a narrow margin of safety from "lifting" (blowing of the flames away from the burner ports). Hence, 


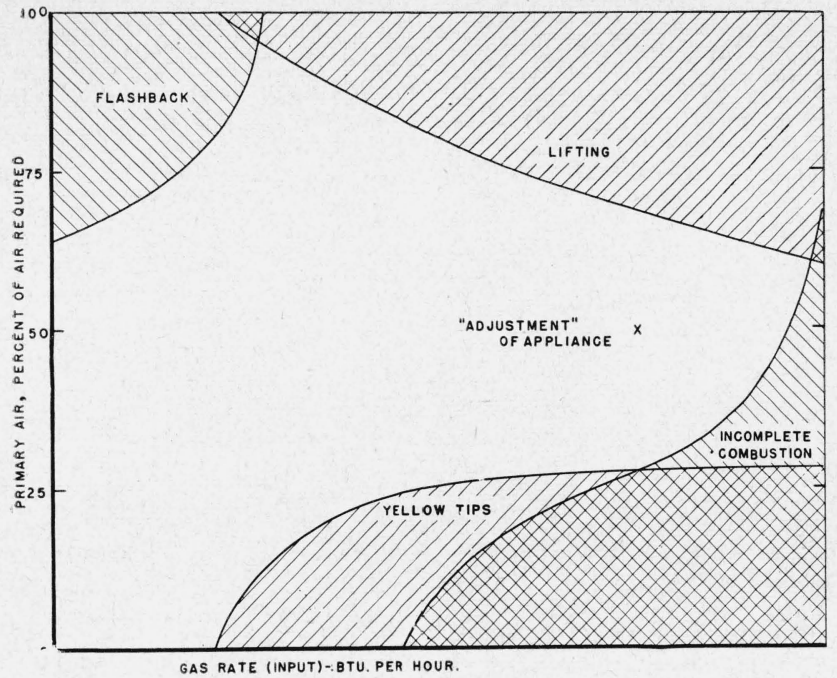

Ficure 1. Conventional diagram to show appliance "adjustment" in relation to limits of satisfactory operation.

When the point representing adjustment is within the unshaded area, the operation of the appliance is considered "satisfactory".

appliances that have been using a slow-burning natural gas will usually give no trouble if a considerably more rapidly burning gas, such as a mixture of the natural gas with 25 percent of coke-oven gas, is substituted; but if appliances should be adjusted for the second gas and the first were then supplied, a great deal of trouble from lifting might be anticipated.

In the course of an investigation of domestic gasburning appliances begun at this Bureau in 1915, the relations between the design of appliances, the composition of the gas supplied to them, and their performance in service were approximately determined. It was found that, in addition to the primary requirement that the burning gas produce as much heat as is wanted, there are four conditions, already mentioned and usually referred to as "limiting" conditions, that must always be met if service is to be satisfactory or even safe. They are: Flames must not (1) lift, (2) flash back, (3) liberate carbon as indicated by yellow tips, or (4) burn incompletely with the liberation of carbon monoxide. In order to describe the conditions under which failures occur in one or more of these respects, a diagram was devised that has since become conventional in the fuel gas industry. One such diagram is shown in figure 1 .

In this figure the point $X$ represents the rate at which heat is produced by combustion (commonly called the "input" of the burner to distinguish it from the "output" of heat in hot water or other material leaving the appliance) and the rate at which primary air enters the burner of an individual appliance under a particular set of conditions of gas supply and mechanical setting. These two rates are subject to easy mechanical adjustments of valves, orifices, and air shutters, and they are conveniently referred to collectively as "the adjustment" of the appliance. On the same diagram the four "limiting conditions" are represented by curves, the positions of which depend on the composition of the gas and on details of burner design not easily changed, such as the size and number of ports. For a given appliance the limiting curves are changed only by a change of composition of the gas, not by changes of orifice, air-shutter, or gas pressure; these affect the "adjustment" only. The position with respect to these limiting curves of a point representing the existing adjustment of an appliance shows whether the appliance is safe from each of the four hazards and by how wide a margin. A mechanical model of this diagram was constructed and exhibited by this Bureau at the 1925 convention of the American Gas Association. On this model a "point" (a small black disk) moved automatically to represent accurately the effects of any change in the proportions of the eleven most common constituents of fuel gases on the rate of liberation of heat and on the entrainment of primary air into the burner. The curves representing the limiting conditions also moved to show the effects of every change of composition of the gas supplied to a typical appliance, but the representation was only approximate. Because different appliances show very different limiting curves it was considered impracticable to represent all of them satisfactorily by a single diagram or a single mathematical formula without extensive additional research involving observations of many appliances with a large number of gas mixtures. Plans were made to conduct such a research at the Bureau and much of the necessary equipment had been purchased, but the project had to be abandoned for lack of funds.

In 1927 the American Gas Association (abbreviated AGA) began a 6-year study of interchangeability called the Mixed Gas Reserach, of which it was said in the final report, [1] ${ }^{1}$ that "detailed results *** are contained in twenty-five progress reports of the Testing Laboratory comprising nearly 2,000 typewritten pages * * * Approximately 175,000 separate tests and examinations were conducted during this study, involving the preparation and examination of more than 250 different gas mixtures". The investigation resulted in the development of a general formula, called " $\mathrm{C}=$ the index of change in performance of appliances," which was first made public in 1936 during the Federal Trade Commission's investigation of public utilities. This index will be referred to in the present paper as "AGA Index C." Its derivation and significance will be discussed in the following section.

It is easily shown (1) that at a constant pressure the heat "input" into an appliance is determined by a characteristic of the appliance and by $H / \sqrt{\bar{D}}$, where $H$ is the heating value, and $D$ is the density of the gas usually expressed as specific gravity, and (2) that the fraction of the air required for complete combustion, ${ }^{2}$ which is introduced as primary air is

${ }_{1}^{1}$ Figures in brackets indicate the literature references at the end of the paper. 2 By the "air required for complete combustion" is meant the number of cubic feet of air that contains just enough oxygen to combine chemically with the comfeet of air that contains just enough oxygen to combine chemically with the comand water. This number will be briefly called the "air requirement" of the gas and be represented by the symbol $A$. 
proportional to $\sqrt{D} / A$. For most gases there is a nearly constant relation between air requirement and heating value (approximately $9 \mathrm{cu} \mathrm{ft}$ of air is required per $1,000 \mathrm{Btu}$ ). Heating values and specific gravities of gases are commonly reported, air requirements rarely. Hence it is often convenient to substitute $H$ for $A$ and to consider $H / \sqrt{D}$ (or its reciprocal) a measure of two of the most important properties which determine interchangeability. (Of course, the more accurate $A / \sqrt{D}$ should be substituted when primary air is considered, if the necessary data are available). In 1934 in Bureau Circular 405 [2], the significance of $H / \sqrt{D}$ as a partial measure of interchangeability was pointed out. In the same publication it was shown that at least one additional factor, the "ignition velocity" or "speed of flame propagation," which can be represented approximately by a number $S^{3}$ must be considered in any decision regarding interchangeability. However, no attempt was made to combine $S$ and $H / \sqrt{D}$ into any general formula for interchangeability such as $\mathrm{AGA}$ Index $\mathrm{C}$.

In 1938 an AGA committee made an investigation to select gases for appliance tests that would be representative of the gases in use throughout the United States. The results are described in Report 847 of the AGA Testing Laboratories [3]. Although the number of gases experimented with was small in comparison with the Mixed Gas Research or the investigations described hereafter, certain important data are given in more detail and will have use in this paper.

In 1941 Knoy [4], who was concerned primarily, with substitutions involving liquefied petroleum gases, published a formula for interchangeability that has received wide acceptance.

In 1946 the AGA Laboratories published, as Research Bulletin 36 [5], an account of an investigation of interchangeability, during which 18 appliances were adjusted successively with 3 natural gases of somewhat different characteristics, and after each adjustment were supplied with from 18 to 48 other gases of widely different compositions and properties. The results are reported in enough detail to make them much more valuable to a student of the subject than the available results of the Mixed Gas Research. By this time it was recognized that no one formula could represent accurately the interchangeability of gases with respect to all important properties, and three "interchangeability index" for "yellow tips," "lifting," and "flashback," designated $I_{Y}, I_{L}$, and $I_{F}$, respectively, were developed. Collectively these three indexes give an excellent representation of the effects observed. The very important question of whether an interchange of gases would result in "incomplete combustion", meaning the liberation of carbon monoxide, was answered by the observation that combustion was complete in all cases in which the gases were interchangeable with respect to each of the three properties represented by indexes. Hence, no formula for interchangeability with respect

3 The valuation of $S$ will be described later. to completeness of combustion was considered necessary. For brevity this report will be referred to simply as Bulletin 36.

In the spring of 1948 a preliminary report of a somewhat similar investigation of the results of supplying a wide variety of gases to 28 burners was made [6] by J. F. Anthes, Chairman of the Committee in charge of the investigation. When the observed results were compared with the predictions of the previously evolved formulas, the agreements were not very satisfactory. In his presentation of the report Anthes called attention to this fact and expressed the hope that even more satisfactory formulas would be developed in the future. For brevity, reference [6] will be called the Anthes Report.

Accepting Anthes' statement as a broad invitation to anyone to try to develop more useful formulas, the writer undertook to repair the omission of a quantitative connection between the partial formulas $H / \sqrt{D}$ (or $A / \sqrt{D}$ ) and $S$ of Circular 405 and to see whether they could be made to predict quantitatively the probable interchangeability with respect to flashback and lifting as judged by all data easily available. The first application of a new index to lifting among the gases described in the Anthes Report, was more successful than anticipated; and while less success was met in dealing with Bulletin 36, the writer was encouraged to develop formulas for all four limiting conditions of service, lifting, flashback, yellow-tips, and incomplete combustion. The resulting formulas appeared to represent all available observations a little better than do the three indexes of Bulletin 36, and are simpler to apply.

However, at the time of the Anthes Report, the experimental study of the subject was being greatly extended by the American Gas Association, and many of the important details even of the first investigation remained to be published. It could not be certain that further work would not show the new formulas to be of limited application or unsatisfactory accuracy, in which case their premature publication would have resulted only in further confusion of an already tangled subject. Subsequently, the observations made in the AGA investigation were published in four reports designated Research Reports 1106 A, B, C, and D [7 to 10]. Comparisons of the formulas based initially on approximately 40 gas mixtures of the preliminary report with several hundred mixtures described in Bulletin 36 and the complete reports of the later work have shown their general applicability to the problems of interchangeability with enough certainty to merit the publication of a thorough analysis of the subject. The derivation of the new formulas will be explained and their relation to earlier formulas shown with the object of making the whole subject more understandable.

\section{Graphic Representation of the Perform- ance of Appliances and General Formulas for Interchangeability}

So many different symbols have been used for the same thing, and the same symbol has been used for 
so many different things in the numerous papers on interchangeability, that to use each in its original sense would be confusing unless accompanied by excessive explanation. An attempt has been made to simplify the use of symbols, as the result of which the discussion and even quotation of some work will not be in terms of the original symbols. For example, in the papers of the Bureau and in some of the AGA reports, heating value has been represented by $(H)$; in others it has been represented by $(h)$. In all AGA papers and in this paper also properties of the gas with which an appliance is adjusted are represented by the subscript $(a)$; but in some AGA reports the properties of gases subsequently supplied to the appliance are represented by the subscript $(t)$ for "test" gas, in others by $(s)$ for "substitute" gas. In this paper the last two subscripts have simply been omitted.

The following symbols are used in this paper:

$a=$ subscript used with another symbol to indicate a property of the gas with which an appliance was adjusted. The same symbol without subscript indicates the same property of a gas "substituted" for the adjustment gas.

$A=$ cubic feet of air required for the complete combustion of $1 \mathrm{cu}$. $\mathrm{ft}$. of gas.

$A_{F}=$ cubic feet of air required for the complete combustion of the gas that enters the burner in 1 hour.

$b, c, \ldots=$ fractions of given chemical constituents of a gas mixture.

$\boldsymbol{C}=$ a general "index of interchangeability". Usually identified as AGA Index $C$ or Knoy Index $C$.

$C=$ a constant. Used several times to represent different numbers.

$D=$ density of gas expressed as specific gravity referred to air as unity.

$\boldsymbol{E}, \boldsymbol{F}=$ factors used in computing $K$, the "chemical composition factor" in "AGA In$\operatorname{dex} C^{\prime 2}$.

$F=$ a factor used in computing flame speed $S$.

$H=$ heating value of gas in Btu per cubic foot.

$I=$ "input", or rate at which heat is produced in an appliance, in Btu per hour.

$k=\mathrm{a}$ "constant" representing the "adjustment" of an appliance that determines the rate of flow of gas into the burner. $k$ depends on the size and form of the "orifice."

$k^{\prime}=$ a second "constant" which represents the design and adjustment of the burner. Its value depends on the "air-shutter opening," the form of the "mixingtube," the size and number of the burner "ports" and some other things.

$K=$ a constant used in two of the AGA "indexes".

$\boldsymbol{K}=$ the "chemical composition factor" used in evaluating "AGA Index C".

$L=$ the "lifting constant" used in the AGA indexes. It is designated $\mathrm{F}$ in Bulletin 36.

$M=H_{a} D_{a} / H_{a} A_{a} D=\mathrm{AGA}$ "index representing change in performance of appliance with variations in heating value and/or specific gravity with no appreciable change in combustion characteristics".

$N=$ number of "readily liberated atoms" of carbon per hundred molecules of gas. All carbon atoms of unsaturated and cyclic hydrocarbons and all but one atom per molecule of saturated hydrocarbons are considered to be readily liberated. Hence, $N$ represents the number of carbon atoms in hydrocarbons minus the number of molecules of saturated hydrocarbons.

$p=$ gas pressure at the orifice.

$P=$ primary air in a burner expressed as a percentage of the air required for complete combustion.

$Q=$ percentage of oxygen in fuel gas. It is designated $\mathrm{O}_{2}$ in Bulletin 36 .

$R=$ ratio of number of atoms of hydrogen in all forms of combination in the fuel gas to the number of carbon atoms in the hydrocarbons (carbon monoxide is excluded).

$S=$ maximum flame speed in a mixture of the gas with air, expressed as a fraction of flame speed for hydrogen.

$T=$ the "yellow tip constant" used in computing the AGA index of interchangeability with respect to yellow tips.

$V=$ cubic feet of gas that enters the burner in 1 hour.

$Z=$ percentage of inert constituents (nitrogen and carbon dioxide) in fuel gas. It is designated $E$ in Bulletin 36.

$I_{F}=\mathrm{AGA}$ index for flashback. For gases that are exactly interchangeable with respect to flashback, $I_{F}=1$.

$I_{L}=\mathrm{AGA}$ index for lifting. For gases that are exactly interchangeable with respect to lifting, $I_{L}=1$.

$I_{Y}=\mathrm{AGA}$ index for yellow tips. For gases that are exactly interchangeable with respect to yellow tips, $I_{Y}=1$.

$J_{A}=A \sqrt{D_{a}} / A_{a} \sqrt{D}=$ index of interchangeability with respect to air supply. When $J_{A}=1$, the total quantity of air required to burn each gas is the same, the fraction of this introduced as primary air is the same, and, unless there are unusual convective effects, the excess oxygen in the flue products is the same, and there is the same hazard of liberation of large quantities of carbon monoxide through "smothering" of the flame.

$J_{F}=S / S_{a}-1.4 J_{A}+0.4=$ proposed index for flashback. For gases that are exactly 
interchangeable with respect to flashback, $J_{F}=0$.

$J_{H}=H \sqrt{D_{a}} / H_{a} \sqrt{D}=$ index of interchangeability with respect to rate at which heat is produced. For gases exactly interchangeable in this respect, $J_{H}=1$.

$J_{I}=J_{A}-0.366 R / R_{a}-0.634=$ proposed index for incomplete combustion. For gases exactly interchangeable in this respect, $J_{I}=0$.

$$
\begin{array}{r}
J_{L}=J_{A} \frac{S}{S_{a}} \frac{100-Q}{100-Q_{a}}=\text { proposed index of inter- } \\
\text { changeability with respect to lifting. }
\end{array}
$$
For gases that are exactly interchangeable with respect to lifting, $J_{L}=1$.

$J_{Y}=J_{A}-1+\left(N-N_{a}\right) / 110=$ proposed index for interchangeability with respect to yellow tips. For gases that are exactly interchangeable in this respect, $J_{Y}=0$.

The purpose of using fuel gas is always to heat something, and the first measure of service is the rate at which heat is supplied. Nearly all gas-burning appliances are given by their manufacturers an input rating, expressed in Btu per hour, at which the most favorable results are to be expected. The rate in cubic feet per hour at which gas flows through an orifice is equal to $k \sqrt{p / D}$, where $k$ is a constant for the orifice involving its form and area, $D$ is the density of the gas, usually expressed as specific gravity referred to air, and $p$ is the pressure at the orifice. The rate at which heat is supplied, in Btu per hour, commonly referred to as the "input", $I$, is the product of the rate of flow and the heating value of the gas, $I$, that is, $I=k \sqrt{p} \times H / \sqrt{D}$. The equation is written in this way to distinguish $E I / \sqrt{ } \bar{D}$, which is a characteristic of the gas, from the pressure, $p$, and from $k$, which is a characteristic of the mechanical construction and adjustment of the appliance. If an appliance is adjusted to give the desired heating effect with a gas of heating value $H_{a}$ and specific gravity $D_{a}$ and, without changing anything else, is then supplied with another gas of heating value $I$ and specific gravity $D$, then

$$
\frac{I}{I_{a}}=\frac{H \sqrt{D_{a}}}{H_{a} \sqrt{D}}
$$

where $I_{a}$ and $I$ are the inputs or the rates at which heat is produced when burning the adjustment gas and the substitute gas, respectively. The quantity $H \sqrt{D}_{a} / H_{a} \sqrt{D}$ is thus a measure or, to use the term favored in the AGA reports, an index, of interchangeability of the two gases with respect to the rate at which heat is produced when the two gases are delivered to an appliance at the same pressure. If the gases are exactly interchangeable, the index is unity. ${ }^{4}$

The satisfactory application of the heat depends not only on its rate of supply but on what is loosely

\footnotetext{
"In order to conform to the type of symbols to be used later for other "indexes" of performance $H \sqrt{D}_{a} / H_{a} \sqrt{D}$ will also be called $J_{H}$. $J$ will be used, in general, to indicate indexes derived in this paper and to distinguish them from the indexes derived by the American Gas Association, which has similarly employed $I$.
}

called the type of flame, which is often described qualitatively in the gas industry as "hard" or "soft". Perhaps the most tangible effects of practical importance connected with the type of flame are the space within which combustion is completed, and the relation of this space to efficiency and completeness of combustion. The amount of heat liberated in a given space is sometimes called the intensity of the flame and is important in many industrial and laboratory applications but not very significant in most domestic uses.

With most gases, when the flame is too soft, hydrocarbons are decomposed to produce solid carbon, which gives a yellow color to the flame. The solid particles of carbon are harder to oxidize completely than are gases and tend to escape from the flame as soot and discolor nearby objects. This is the reason for the desire to avoid yellow tips, the appearance of which is usually taken as one of the limits of satisfactory operation of appliances.

The principal factor in determining the degree of hardness of a flame is the fraction of the air required for complete combustion that is introduced as primary air. The higher this is the "harder" is the flame; in fact, this fraction is the usual quantitative measure of hardness used in the study and testing of appliances. An alternative measure sometimes used is the heating value of the primary mixture (gas and air within the burner). With the gases usually encountered in public supplies, from cokeoven gas to butane, there is little difference in the appearance or useful properties of flames produced with equal percentages of primary air (referred to total air required), provided the flames are stable and not very close to the yellow-tip limit.

The number of cubic feet of primary air injected into a burner by $1 \mathrm{cu} \mathrm{ft}$ of gas is directly proportional to the square root of the specific gravity of the gas. Hence, the ratio of primary air to total air required is $k^{\prime} \sqrt{D} / A$, where $A$ is the number of cubic feet of air required for the combustion of $1 \mathrm{cu} \mathrm{ft}$ of gas, and $k^{\prime}$ is a constant characteristic of the appliance. If an appliance is adjusted to have a desirable flame with one gas of specific gravity $D_{a}$ and air requirement $A_{a}$, the flame of another gas of specific gravity $D$ and air requirement $A$ will have the same percentage of primary air and the same desirable qualities (to the extent that primary air determines them) if $A \sqrt{D}_{a} / A_{a} \sqrt{D}=1$. If this expression, which will be called an index of interchangeability with respect to the injection of primary air, is less than one, the substituted gas will produce a harder flame, if greater than one, a softer flame than the gas with which the adjustment was made. We will call the expression $J_{A}$.

In almost every case in which an interchange of gases is otherwise practicable, the air required per heat unit is nearly identical for the two gases. For example, AGA Report No. 487 lists 16 natural gases with heating values from 705 to $1,260 \mathrm{Btu} / \mathrm{cu} \mathrm{ft}$ and 20 manufactured gases from 400 to $600 \mathrm{Btu} / \mathrm{cu} \mathrm{ft}$ as representative of all the gases of the two types supplied to the public in 1938 ("mixed gases", 
usually mixtures of the two types were placed in another category). All the natural gases required from 9.3 to $9.5 \mathrm{cu} \mathrm{ft}$ of air per $1,000 \mathrm{Btu}$. The extreme variation among manufactured gases was between 8.3 and $9.0 \mathrm{cu} \mathrm{ft} / 1,000 \mathrm{Btu}$ with only 3 of the 20 gases outside the range of 8.5 to 8.8. As interchange without readjustment of appliances is far from feasible between gases as different as those in the two groups, a practical problem of interchangeability rarely arises in which the air required per 1,000 Btu of the gases involved differs by more than 2 or 3 percent. Hence, within this rather small margin we can consider air required as proportional to heating value and write

$$
\frac{A_{a} \sqrt{D}}{A \sqrt{D_{a}}}=\frac{H_{a} \sqrt{D}}{H \sqrt{D_{a}}} \quad \text { (approx.) }
$$

which makes the index of interchangeability with respect to the injection of primary air the same as the index of interchangeability with respect to the rate of heat supply.

There is not only some gain in convenience from reducing the two indexes to one; a more important consideration is that the approximate heating values and specific gravities of gases from various sources or distributed in different places are commonly reported, but air requirements are not. For example, an appliance manufacturer who supplies different orifices or other burner parts for such widely different gases as coal gas, natural gas, and propane, and who knows the range of good adjustment with each, should have no difficulty in learning the heating value and specific gravity of the gas in a certain city nor in determining from them with what combination of parts an appliance may be expected to give satisfactory service.

It was mentioned in the introduction that in the study and testing of appliances it has long been cus-

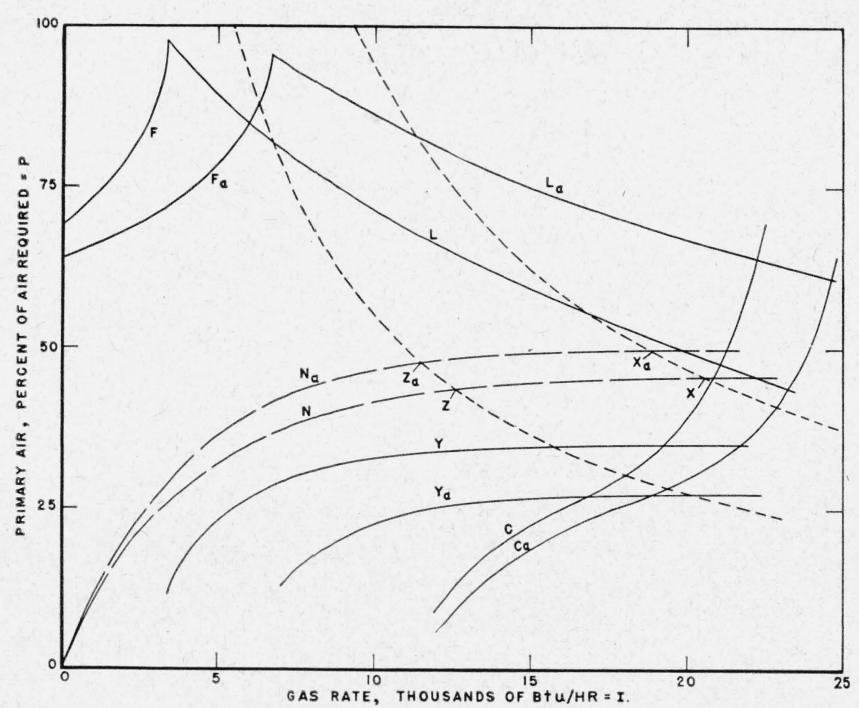

Figure 2. Conventional diagram of appliance adjustment and performance showing changes in the diagram to represent the effects of a change in the composition of the gas supplied. tomary to represent diagrammatically the two major variables, primary air and "input," in the performance of appliances. It will be desirable to develop this idea more fully than was done in connection with figure 1 . In figure 2 heat input $(I)$, expressed in Btu per hour, is plotted with respect to primary air $(P)$, expressed again as a percentage of total air required. Suppose an appliance is adjusted, with burner valve wide open, to produce the conditions indicated by the point marked $X_{a}$ when burning gas (a). If the pressure at the orifice is gradually reduced, by closing the burner value or otherwise, the changing conditions can be represented by a series of points along the line $N_{a}$, which represents the "normal injection" of primary air by gas (a) at any rate of input. If we partially close the air-shutter, the change of conditions will be represented by moving vertically downward from point $X_{i}$. Other changes in the appliance itself that will affect gas flow or the entrainment of air are easily pictured. If we control the entry of both gas and air into the burner, it is possible to observe experimentally conditions under which flames lift from the ports or flash back, become yellow, or liberate carbon monoxide.

The conditions under which these failures occur can be separated on the diagram from those under which they do not occur by curves such as $L_{a}, F_{a}$, $Y_{a}$, and $C_{a}$. Under all conditions above and to the right of the lifting curve $L_{a}$, flames may be expected to blow from the ports. Points above and to the left of $F_{a}$ represent conditions under which flash back occurs. Those below $Y_{a}$ represent conditions under which yellow tips appear, and those below and to the right of $C_{a}$ represent conditions under which combustion is incomplete and carbon moxoxide appears.

If without changing the pressure or any of the mechanical adjustments of the appliances we substitute another gas for $(a)$, the point on the diagram representing the input and type of flame is shifted from $X_{a}$ to another position $X$, the coordinates of which are given by multiplying or dividing, those of $X_{a}$ by the appropriate indexes.

$$
\begin{aligned}
& I=I_{a} \frac{H \sqrt{D_{a}}}{H_{a} \sqrt{D}}=I_{a} J_{H} . \\
& P=P_{a} \frac{A_{a} \sqrt{D}}{A \sqrt{D}_{a}}=\frac{P_{a}}{J_{a}}
\end{aligned}
$$

As a step in preparing a general expression for interchangeability, the committee in charge of the Mixed Gas Research decided to make use of the quotient $I / P$. It was explained that: "Examination of this ratio shows that as its value is increased either by increasing $I$ or reducing $P$ the tendency will be toward incomplete combustion. As the value of $I / P$ is lowered, the tendency will be toward faulty burner performance as evidenced by noisy operation, noisy flame extinction or flashback." It was not stated that increasing the value of $I / P$ by increasing $I$ and by decreasing $P$ have opposite tendencies so 
far as lifting is concerned, as can be seen readily from the diagram.

When comparing two gases,

$$
\frac{I}{P}=\frac{I_{a}}{P_{a}} \cdot \frac{H \sqrt{D_{a}}}{H_{a} \sqrt{D}} \cdot \frac{A \sqrt{D_{a}}}{A_{a} \sqrt{D}}=\frac{I_{a}}{P_{a}} \frac{H A D_{a}}{H_{a} A_{a} D} \cdot
$$

$M=H A D_{a} / H_{a} A_{a} D$ was called the "index representing change in performance of appliance with variations in heating value and/or specific gravity with no appreciable change in combustion characteristics." For the usual case, in which heating value is propor tional to air requirement or nearly so, $M$ is substantially equal to the square of $H \sqrt{D_{a}} / H_{a} \sqrt{D}$ and has the same significance as a means of judging the performance of appliances. If cases occurred in which the proportionality between heating value and air required did not hold and there were no complications, $M$ should be a slightly better index of interchangeability with respect to lifting and incomplete combustion than $H \sqrt{D_{a}} / H_{a} \sqrt{D}$ but not as good as $A \sqrt{D_{a}} / A_{a} \sqrt{D}$. As an index for flashback the reverse should be true. Actually, however, other factors complicate the problem so much that the three indexes, without further modification, are equivalent for practical purposes. They show well enough the effect of the change of gas supply on the heat input and the primary air; on the diagram they locate the point $X$ with respect to the coordinate axes. However, we are often more concerned in avoiding the dangerous or disagreeable results of lifting, flashback, and liberation of carbon monoxide and soot than with the rate and intensity of heating. The danger of encountering these difficulties is represented on the diagram by the relation of the point $X$ to the several limiting curves, the positions of which shift with changes of the gas supply typically as representing by limiting curves $L, F, Y$, and $C$. The initial positions of the limiting curves and the shifts that occur when the gas is changed depend to some extent on the design of the appliances and make accurate generalization difficult; but, in any case, we are concerned with the sum of the shift of point $X$ toward the limiting curve and of the curve toward $X$.

What has here been explained graphically was stated in algebraic form in the Mixed Gas Research Report as follows: ". . . The effect of variations in chemical composition and superimposed on changes in heating value and/or specific gravity could be accounted for by

where

$$
\boldsymbol{C}=\boldsymbol{M}+\left(\boldsymbol{K}_{\boldsymbol{a}}-\boldsymbol{K}\right),
$$

$$
\begin{aligned}
& \boldsymbol{C}=\text { index indicating change in performance of } \\
& \text { appliances, and } \\
& \boldsymbol{K}=\text { a factor depending on chemical composi- }
\end{aligned}
$$
tion."

In our diagram $\left(\boldsymbol{K}_{\boldsymbol{a}}-\boldsymbol{K}\right)$ should be represented by the displacement of the limiting curve. Actually the displacements of the several curves are of different magnitudes and, as will be shown later, appear to depend on different functions of composition. the case of flashback and lifting they are even in opposite directions. The impossibility of representing these divergent effects by a single expression is the reason why $\boldsymbol{C}$, the general AGA "index in change of performance of appliances", has not been more successful.

In the attempt to find a suitable function of composition to represent the changes of limiting conditions "a large number of expressions were devised for $\boldsymbol{K}$ and subsequently discarded". The final selection, made by a combination of theory and observation, was

$$
\boldsymbol{K}=H A / 5000 \boldsymbol{E F},
$$

in which $H$ and $A$ have their previous significance, $\boldsymbol{E}$ is the heat capacity, between $60^{\circ}$ and $1,600^{\circ} \mathrm{F}$ of the "theoretical products of combustion" of $1 \mathrm{cu} \mathrm{ft}$ of the gas, and $\boldsymbol{F}$ is the summation of the product of the fraction by volume of each chemical constituent and a constant characteristic of that constituent. This constant is proportional to the heat capacity of the products of combustion of the gas divided by the velocity of flame in a mixture of the gas with the amount of air required for complete combustion. For a pure gas $\boldsymbol{K}$ would simplify to the product of heating value, air required for combustion, flame velocity, and an arbitrary constant divided by the square of the heat capacity of the products of combustion. The heat capacity of the products of combustion is nearly proportional to the air required and to heating value; hence, these factors tend to cancel and to leave the "chemical composition factor" roughly proportional to flame velocity in a mixture of gas with the air required for complete combustion. The cancellation is not complete, however, and a plot of $\boldsymbol{K}$ with respect to flame speed only for various gases shows a nonlinear relation with considerable scattering.

In the Knoy formula interchangeability is judged from relative values of $(H-175) / \sqrt{D}$ instead of the expression $H / \sqrt{D}$ previously discussed. The expression was derived by considering the heating value of the primary mixture of gas and air in the burner, rather than the ratio of primary air to air required, to be the measure of good adjustment. It was further assumed that the primary mixture should normally have a heating value of $175 \mathrm{Btu} / \mathrm{cu} \mathrm{ft}$ and that air required is proportional to heating value, an assumption previously discussed. For further details of the derivation, the original article should be consulted.

\section{Data Available for the Study of Inter- changeability}

It was stated in the Report of the Mixed Gas Research that "while certain assumptions have been necessary the value of the final formula depends not so much on the correctness of these assumptions or hypotheses as the degree to which it satisfactorily serves to yield results that are in agreement with those actually obtained by careful experimentation". 
With this statement the writer is in complete agreement; it applies equally to all formulas that have been or may be developed.

The only data at present available to the author that show the results of a sufficiently numerous and varied lot of interchanges in enough detail to make the empirical evaluation of the formulas satisfactorily are those in Bulletin 36 and Research Reports No. $1106 \mathrm{~A}, \mathrm{~B}, \mathrm{C}$, and D, of the American Gas Assoc.

In the work reported in Bulletin 36, 18 appliance burners were adjusted to burn a "high Btu natural gas." Then 23 "supplemental" gases of varied types were supplied to the same burners at the same pressure and without readjustment of the appliances. Most of the supplemental gases were also mixed with the adjustment gas to give 25 additional "substitute" gases ${ }^{5}$ making 48 substitutions in all. With each of the substitute gases observations were made of lifting, flashback, and yellow tips, and the number of burners that failed in each respect was recorded.

Two similar series of observations were made with a "high methane natural gas" and a "high inert natural gas" as the adjustment gas. The second series involved eight supplemental gases and 10 additional mixtures with the adjustment gas. The third series included 14 original substitute gases and 8 additional mixtures. In all, there were 88 substitutions of another gas for an adjustment gas and, in effect, $88 \times 18 \times 3=5,742$ observations that an individual appliance did or did not fail with respect to one of three limiting conditions when one gas was substituted for another.

The tests recorded in Research Reports 1106-A, B, $\mathrm{C}$, and $\mathrm{D}$ were similar but much more extensive. The number of appliance burners was increased to 28 . There were six adjustment gases that were compared with $98,65,57,72,94$, and 13 substitute gases, of which $29,30,23,27,33$, and 13 , respectively, were unmixed supplemental gases. Instead of giving each appliance a single adjustment, supplying all gases at a single pressure, and reporting only one degree of failure with respect to three limiting conditions, appliances were given three successive adjustments, and supplied with gas at three different pressures; and failures were recorded for four limiting conditions. Moreover, the degree of failure with respect to lifting and yellow tips was recorded in two categories.

\footnotetext{
${ }^{5}$ The term "supplemental" gas reflects the principal purpose of the AGA investigation, which was to determine to what extent gas from the regular source of supply (the adjustment gas) could be supplemented when necessary with gas $f$ different characteristics from another source. The term will be retained to distinguish gas of the second type from its mixtures with the adjustment gas, made to determine how much of the supplemental gas could be used. Exce t when this distinction is to be made, both the supplemental gases and their mixtures will continue to be referred to as "substitute" gases, meaning, merely th t they are the gases substituted for the adjustment gas after the appliances were they are the gases substituted for the adjustment gas after the appliances were
adjusted. In Research Report 1106, the adjustment gases are given numbers less adjusted. In Research Report 1106, the adjustment gases are given numbers less
than 10. Supplemental gases are numbered from 11 upward. Their mixtures than 10 . Supplemental gases are numbered from 11 upward. Their mixtures with the adjustment gases were indicated by the percentage of the supplemental
gas in the mixture. No numbers were assigned to the gases in Bulletin 36, but it will be convenient in mentioning individual gases to use the same system, will be convenient in mentioning individual gases to use the same system,
numbering the adjustment gases 1,2 , and 3 , and the supplemental gases 11 to 37 numbering the adjustment gases 1,2 , and 3 , and the supplemental gases 11 to 37
in the order in which they appear in the tables showing the results of experiments. Combining the numbers with a letter, N (for natural gas) for those given in Bulletin 36, or A, B, C, or D for the various sections of Report 1106 permit unambiguous reference to any one of the large numbers of gases used or to any observation recorded during the study. Thus, N3-12-60 represents the comparison of the third adjustment gas referred to in Bulletin 36 with a mixture of 60 percent of supplemental gas 12 with 40 percent of adjustment gas 3 . B2 represent the adjustment gas 2 used in the tests recorded in Section B of Research Report 1106, and A1-19-20 represents a mixture containing 20 percent of gas 19 and 80 percent of gas 1 , as recorded in Research Report 1106-A.
}

In order to specify the kind of adjustment given appliances and the extent of the failures observed, flame characteristics were given the following designations:

-5 flames: Distinct yellow in outer mantles, or large volumes of luminous yellow tips on inner cones. Flames deposit soot on impingement.

-4 flames: Slight yellow streaming in the outer mantles, or yellow fringes on tops of inner cones. Flames deposit no soot on impingement.

-3 flames: Inner cones broken at top, lazy wavering flames.

-2 flames: Faint inner cone.

-1 flames: Inner cone visible, very soft tips.

0 flames: Inner cones rounded, soft tips.

+1 flames: Inner cones and tips distinct.

+2 flames: Inner cones distinct and pointed.

+3 flames: Short inner cones, flames may be noisy.

+4 flames: Flames tend to lift from ports, but become stable after short period of operation.

+5 flames: Flames lifting from ports, with no flame on 25 percent or more of the ports.

FB: Flames flash back through the ports.

Observations were made with appliances that had been adjusted to have flames of the types - 2, 0 , and +2 . All of these are within the range of what we would normally consider good adjustment. Actually, in any large number of homes the range of appliance adjustment will be found to include many cases of -3 and +3 flames and some -4 and +4 flames. The pressures employed were $2.5,5$, and 7.5 in. of water column, a range that is to be encountered in most localities. These pressures are referred to, respectively, as 0.5 normal, normal, and 1.5 normal. With some appliances when testing for completeness of combustion, the maximum pressure employed was $6.25 \mathrm{in}$. of water column (1.25 normal).

It may be helpful to represent these conditions of adjustment on the conventional diagram. If we define our limit of operation with respect to lifting as that at which flames lift from 25 percent of the ports and our yellow tip limit as that at which flames pass from the -4 to the -5 classification and assume that equal ranges in the percentage of primary air are represented by each of the specied flame characteristics, the initial adjustments of the appliances would be as shown in figure 3 . Each short, heavy line represents one set of conditions of pressure and adjustment with the adjustment gas.

It is the main purpose of this paper to show to what extent the proposed indexes of interchangeability will serve to predict what will happen when a gas supply is changed in a city with the usual range of pressures and existing appliance adjustments. As none of the initial conditions of pressure and adjustment employed in the AGA investigation are to be considered unusual, they will be treated alike in the statistical use of the information. Thus, if one burner flashed back under two conditions of adjustment and at each of two pressures, it will be recorded as four 


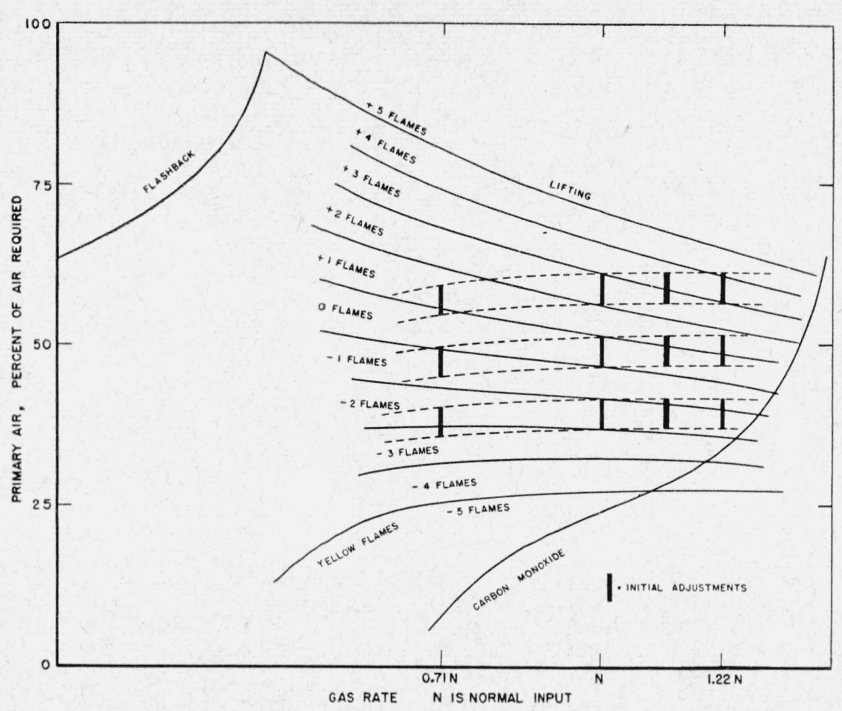

FIGURE 3. Initial adjustments of appliances in experiments described in Report 1106, as they would appear on the conventional diagram for a typical appliance.

failures just as though four burners had flashed back under one condition.

In the course of the experimental work it was found that certain appliances were much more prone to failures of certain types than other appliances. When several of these had been tested without failure it was considered unnecessary to test the others. The number of appliances tested, as well as the number of failures is scrupulously recorded; but for the purpose of this paper, no use can be made of the number of burners tested. Only the number of recorded failures will be used. In most cases this is probably the same number that would have been found had all the appliances been tested, but it is not necessarily so, and in some cases it is rather certainly not true. Had the purpose of the AGA investigation been to test existing or future formulas for interchangeability, it is probable that enough appliances would have been tested with each gas to make certain that no further failures would occur with the others; but the primary purpose seems to have been to establish the amount of "supplemental" gas that can be mixed with the base gas normally delivered without exceeding the limits of practical interchangeability. For this purpose, it was sufficient to know that so large a number of appliances had failed that the gas could not be considered even to approach interchangeability whatever the untested burners might have done. The result of this variation in the number of appliances tested will be discussed later in connection with the application of the data.

\section{Derivation of a New Index to Represent Lifting}

As explained in the introduction, the present attempt to derive improved formulas for representing the effects of changing the gas supplied to an appliance began with a combination of the two quan- tities represented by $(S)$ and $H / \sqrt{D}$, later changed to $A / \sqrt{D}$, to predict lifting and flash back.

The derivation of $(S)$, a coefficient intended to represent the approximate maximum velocity with which flame will travel in any mixture of the gas with air, is not fully explained in Circular 405 and has been changed a little. There are many obstacles in the way of computing flame speed simply and accurately; to avoid this several assumptions have been made. As the result is to be judged by the success of its application, no attempt will be made to justify them in detail. The principal assumption is that the maximum flame velocity in mixtures of two fuel gases is a linear function of the volumes obtained by adding to each gas in the mixture the volume of air required for its complete combustion. The assumptions made lead to the method for the calculation of $(S)$ which follows:

$$
S=\frac{a F_{a}+b F_{b}+c F_{c} \cdots}{A+5 Z-18.8 Q+1}
$$

in which $a, b, c, \ldots$ are the fractions by volume of various combustible constituents of the fuel gas, $F_{a}, F_{b}, F_{c}, \ldots$ are corresponding values of the coefficient $F$ listed in table $1, A$ has its usual meaning, the volume of air required to burn one volume of gas, and $Z$ and $Q$ are, respectively, the fraction by volume of inert gases, chiefly carbon dioxide and nitrogen, and of oxygen in the fuel. To obtain the factor, $F$, the recorded maximum ignition velocity in mixtures of the combustible with air was expressed as a percentage of the maximum ignition velocity of hydrogen with air and multiplied by 1 plus the number of cubic feet of air required to burn $1 \mathrm{cu} \mathrm{ft}$ of the gas. The coefficient 5 , by which the fraction of inert constituents in the gas mixture is multiplied, is larger than corresponds to the volume of inert as a fraction of ultimate products of combustion. The coefficient was obtained in trying to fit the formula to the results of appliance tests. It may be explained in part on the ground that usually we are

TABLE 1. Properties of gases used in computing interchangeability by the methods proposed in this paper

\begin{tabular}{|c|c|c|c|c|c|}
\hline Gas & $\begin{array}{l}\text { Chemical } \\
\text { formula }\end{array}$ & $\begin{array}{c}\text { Total } \\
\text { heating } \\
\text { value, } H\end{array}$ & $\begin{array}{c}\text { Specific } \\
\text { gravity, } \\
D\end{array}$ & $\begin{array}{c}\text { Air re- } \\
\text { quired } \\
\text { to burn, } \\
A\end{array}$ & $\begin{array}{c}\text { Flame } \\
\text { speed } \\
\text { factor, } \\
F^{\mathrm{a}}\end{array}$ \\
\hline Carbon monoxide. & $\mathrm{CO}$ & 315.3 & 0.97 & 2.39 & 61 \\
\hline Hydrogen & $\mathrm{H}_{2}$ & 318.5 & .07 & 2.39 & 339 \\
\hline Methane. & $\mathrm{CH}_{4}$ & 994.1 & .55 & 9.55 & 148 \\
\hline Ethane... & $\mathrm{C}_{2} \mathrm{H}_{6-}$ & 1757 & 1.04 & 16. 71 & 301 \\
\hline Propane. & $\mathrm{C}_{3} \mathrm{H}_{8}$ & 2535 & 1.56 & 23.87 & 398 \\
\hline Butane. & $\mathrm{C}_{4} \mathrm{H}_{10}$ & 3330 & 2.09 & 31.03 & 513 \\
\hline Ethylene & $\mathrm{C}_{2} \mathrm{H}_{4}$ & 1572 & 0.97 & 14.32 & 454 \\
\hline Propylene. & $\mathrm{C}_{3} \mathrm{H}_{6-}$ & 2337 & 1.45 & 21.48 & 674 \\
\hline Acetylene. & $\mathrm{C}_{2} \mathrm{H}_{2}$ & 1464 & 0.91 & 11.93 & 776 \\
\hline Benzene... & $\mathrm{C}_{6} \mathrm{H}_{6-}$ & 3700 & 2.70 & 35. 79 & 920 \\
\hline Atmospheric nitrogen & $\mathrm{N}_{2}$ & $\ldots$ & 0.97 & & \\
\hline Carbon dioxide & $\mathrm{CO}_{2-}$ & $\ldots$ & 1.53 & & .... \\
\hline Oxygen . . . . . . . & $\mathrm{O}_{2} \ldots \ldots$ & (n) & 1.11 & $(-4.78)$ & $\ldots$ \\
\hline Air... & & -.. & 1.00 & -..... & -..- \\
\hline
\end{tabular}

a $F=(A+1) S$, where $A+1$ is the number of cubic feet occupied by a mixture of $1 \mathrm{cu} \mathrm{ft}$ of gas with enough air for its complete combustion, and $S$ is the speed of flame in such a mixture in percentage of the speed in the corresponding mixture of hydrogen and air. 
really concerned with primary mixtures in the burners containing much less air than is required for complete combustion, so that inert in the gas constitutes a larger fraction of the total in the primary mixture than in a mixture containing all the air required for combustion. Partly it may result from the fact that we are usually working on a steep portion of the curve representing the relation of flame velocity to primary air, where the effect of added diluent is excessive. The factor for oxygen simply cancels as much nitrogen as is contained in an equivalent volume of air.

The two limits of appliance operation under consideration, lifting and flash back, are more closely related to the chemical reactions involved in combustion with primary and secondary air than to the quantity of heat liberated, and it is therefore more direct and may be more accurate to consider $A / \sqrt{D}$ rather than $H / \sqrt{D}$ as the major variable. To be consistent, the abscissa of a diagram such as figure 1 should be changed to represent the total volume of air required to burn the volume of gas supplied to the appliance rather than the "heat input". When nothing but the supply of gas is changed, the point $X$, determined by the previous mechanical adjustment of the appliance, will then follow accurately a reciprocal curve (i. e., the product of ordinate and abscissa is constant) instead of following such a curve only approximately. The principal reason for using $H / \sqrt{D}$ originally, that the heating value of a prospective gas supply is often known when its composition is not, is no longer of importance since $(S)$ cannot be computed unless the composition is known.

In order to find an experimental relation between $S$ and $A / \sqrt{D}$, it was necessary to consider the results of determining the lifting curves of a single appliance with each of a large number of gases. For this purpose AGA Report 847 [3] supplied the necessary data. The curves in Report 847 that represent the conditions under which lifting occurs with a given test burner have been replotted in figure 4 , with the volume of air required to burn all the gas supplied to the appliance as abscissa in place of heat input. Curves lettered $A$ through $P$ represent the lifting limits for gases identified by the same letters in Report 847. A reciprocal curve, $Y$, has been drawn to represent a fixed mechanical adjustment of an appliance, the condition assumed to exist in the definition of interchangeability. The fact that this adjustment remains unchanged gives us definite relations between gas and primary air, so that either can represent both when dealing with a third variable, such as flame speed $(S)$. The intersection of $Y$ with the lifting curve of one of the gases represents the flow of gas and primary air that would just produce incipient lifting if it occurred, not the flow that actually occurs. The difference between the two is the margin of safety against lifting. Hence, if we can determine a relation between $(S)$ and one of the coordinates of the intersection of $Y$ with the lifting curve, we will be in position to express the hazard of lifting quantitatively.

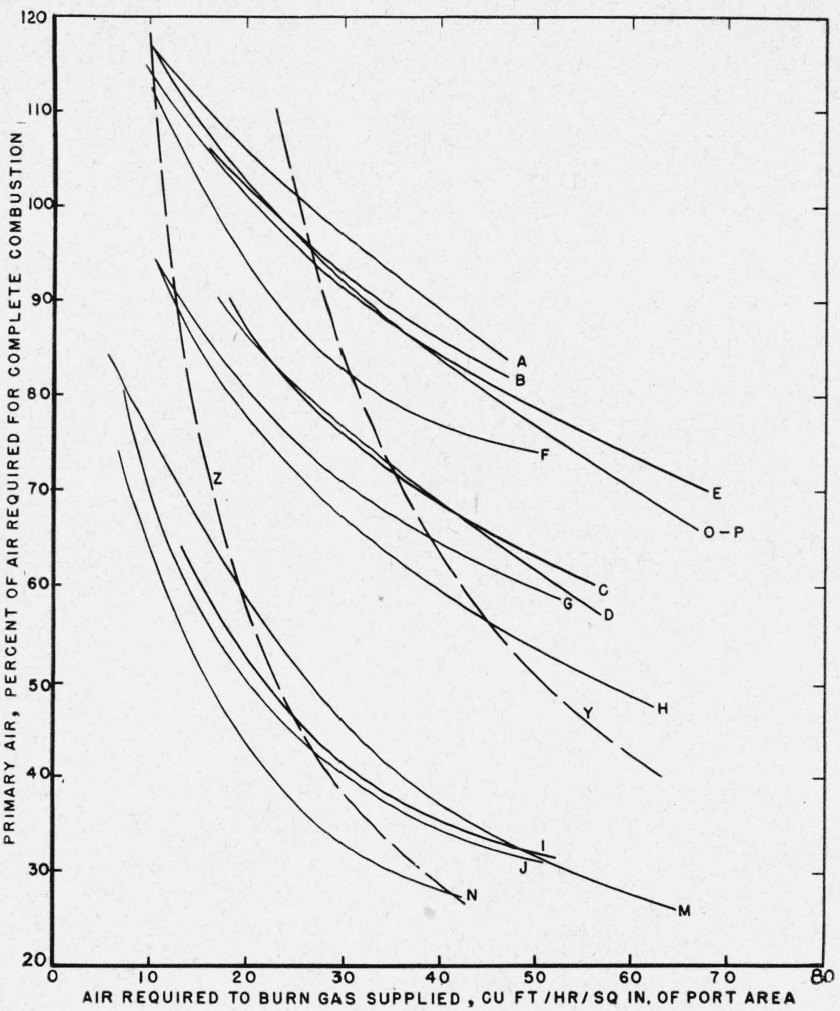

FIGURE 4. Lifting curves of AGA Report 847 replotted with rate of flow of primary air as abscissa.

Curves $\mathrm{Y}$ and $\mathrm{Z}$ represent constant mechanical adjustments.

The primary air at which lifting occurs with the adjustment represented by $Y$ is plotted with respect to flame-speed $(S)$ by the open circles of figure 5 . A straight line through the origin (the origin is not on the figure) represents the results about as well as they can be represented by any simple relation. To show the effect of a different adjustment of the appliance and to include the natural gases, another reciprocal curve $(Z)$ has been drawn in figure 4 . Its construction and significance are the same as those of $(Y)$, except that a very different mechanical adjustment of the appliance is represented. The intersections of curve $Z$ with the various lifting curves are shown on figure 5 by solid dots, which scatter rather widely from the simple relation of direct proportionality between $(S)$ and the percentage of primary air at which lifting occurs, represented by the broken line. Apparently they could be better represented by such a curve as the unbroken one.

It is our purpose, if possible, to choose a relationship through which interchangeability of various gases with respect to lifting can be represented by a single formula. If a different relation exists between the properties of the gases and the performance of a single appliance after a change of the size of orifice and perhaps of the primary air openings, we would wish to base our formula on the conditions most nearly representative of those existing in service. For the most numerous group of gases, this is undoubtedly the condition of adjustment represented 


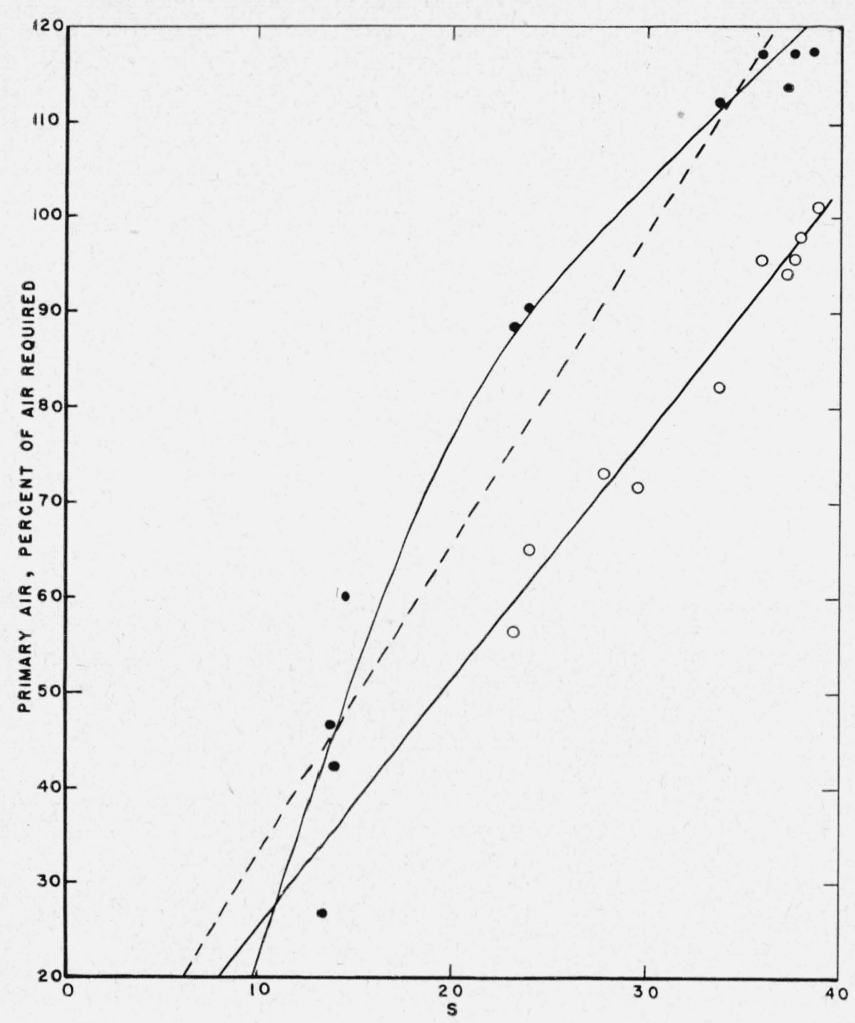

FIgURE 5. Primary air that would cause lifting at relative rates corresponding to fixed mechanical adjustments of burners.

Data from Figure 4.

by $(Y)$ rather than by $(Z)$. We do not often encounter in practice an appliance taking through the burner more than 100 percent of the air required for combustion, nor one with so low an input rating as $1,450 \mathrm{Btu}$ per hour per square inch of port area, the greatest input with adjustment $Z$ of any except the natural gases. It is not quite certain that the curvature of the solid curve is not the result of inaccuracies in either the values of $(S)$ or of the positions of the lifting curves intersected by line $(Z)$. The extreme ends of such curves are ordinarily of little interest and are determined only with considerable difficulty. The displacement to the right of the points at the upper end of the curve may also be explained by the fact that, as the percentage of primary air increases beyond that at which flame speed is a maximum, additional air slows down instead of accelerating the ignition velocity. A line drawn through the approximate average of points representing the more rapidly burning gases and the slow-burning natural gases passes close to the origin. Finally, the range of compositions covered by curve $(Z)$ is much greater than the range of practical interchangeability, and our formulas need cover only ranges within which interchange can generally be made. For all these reasons, as well as for simplicity, it was decided to represent practical interchangeability by direct proportionality between $(S)$ and the fraction of primary air at which lifting occurs.
An additional reason for this choice appears when we consider lifting, not among appliances supplied at constant pressure and without mechanical adjustment of any kind, but among those in which desired rates of heating are set at the time of use by means of the burner valve. They include top burners and broilers of cooking appliances and a majority of space heaters. With these appliances we have to consider whether lifting will occur at the maximum desired rate of heat input, which may be considered constant, To obtain an approximate answer to the problem, the lines representing a constant input of 4,000 Btu per hour per square inch of port area were drawn on the original figures of Report 847, and their intersections were plotted in figure 6 . An approximation to proportionality between $(S)$ and the fraction of the air that passes through the burner when lifting occurs is again apparent.

Expressing this proportional relation in terms of our symbols for gas properties,

$$
S=k \sqrt{D} / A \text { or } A S / \sqrt{D}=k,
$$

in which $k$ is a constant representing a characteristic of the appliance independent of the gas supplied to it. If we use letters with the subscript $(a)$ to represent properties of the gas with which the appliance was adjusted and letters without subscript to represent any other gas, exact interchangeability would be indicated if

$$
A S \sqrt{D_{a}} / A_{a} S_{a} \sqrt{D}=1
$$

and the degree of departure from exact interchangeability is indica ted by the coefficient $A S \sqrt{D_{a}} / A_{a} S_{a} \sqrt{D}$

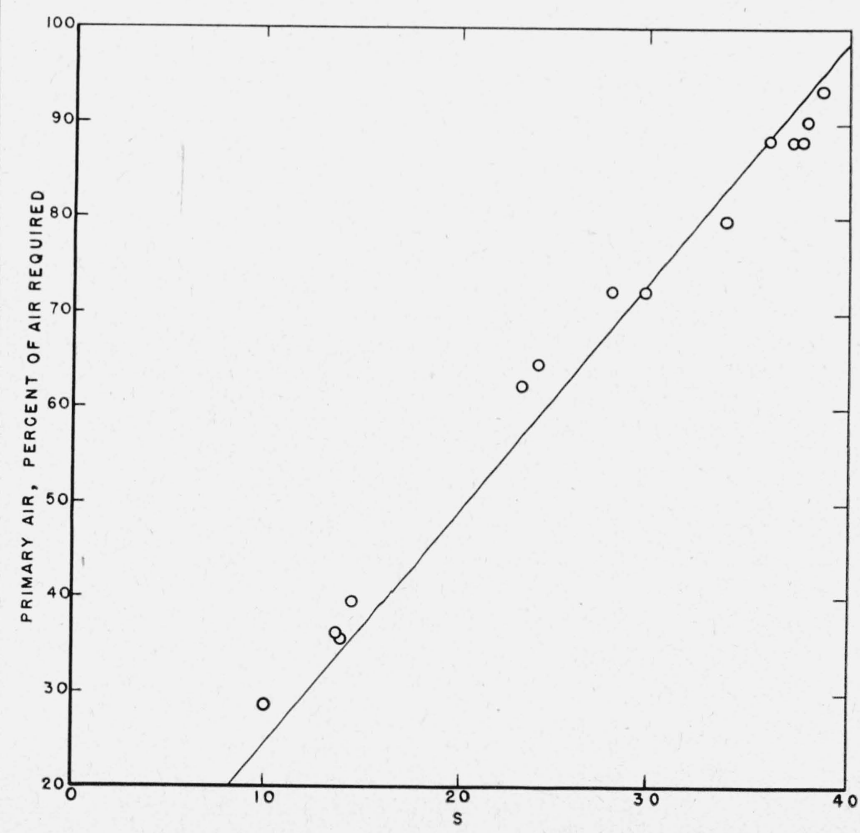

Figure 6. Primary air that would cause lifting from appliances with an input of 4,000 Btu per hour per square inch of port area.

Data from AGA Report 847. 
which, in conformity with AGA phraseology, may be called an index of interchangeability with respect to lifting. It will be designated $J_{L-1}$ to distinguish it from the corresponding AGA index $I_{L}$ and from a modification to be designated $J_{L}$.

The merits of the new index were first tested by plotting $S / S_{a}$ with respect to $A \sqrt{D}_{a} / A_{a} \sqrt{D}$ for the gases described in the Anthes Report. The result was figure 7 .

The Anthes report was a preliminary condensation of Research Report $1106 \mathrm{~A}$ and did not state the number or extent of failures (whether +4 or +5 flames) of appliances but only whether the unmixed supplementary gas was or was not considered by the investigators to be interchangeable with respect to each limiting condition, and, if not, what percentage of it could be mixed with the adjustment gas.

If the new index accurately indicates the behavior of all appliances, then in such a plot as figure 7 , the points representing any number of gases that are identical ("exactly interchangeable" among themselves) in their tendency to lift should lie on a reciprocal curve representing a constant value of the index. Such a curve is, of course, determined by any one point. The points representing every gas more susceptible to lifting should lie on one side of the curve, and those representing gases less susceptible to lifting should lie on the other side. In figure 7 , all supplemental gases that were reported as interchangeable with the adjustment gas with respect to lifting are represented by circles. All supplemental gases reported not interchangeable are represented by crosses. The adjustment gas itself is represented by

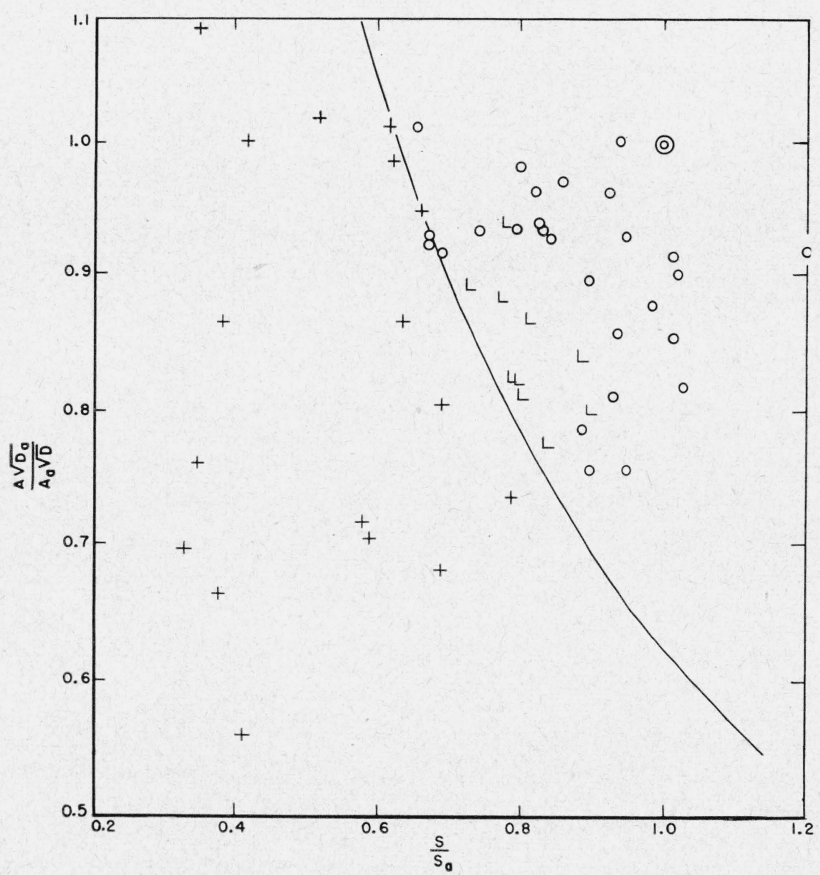

Figure 7. Observations of lifting and committee's estimates of limiting mixtures as recorded in the Anthes Report.

$(+)$ represents gases considered not interchangeable because of lifting: $(O)$ gases that were interchangeable, and (L) limiting mixtures. two concentric circles. As it could be assumed that any mixture of a supplemental gas with the adjustment gas would be interchangeable with the latter if the supplemental gas was itself interchangeable, the "limiting mixtures", the determination of which involved only conditions other than lifting were also represented by circles. When lifting was mentioned as one of the conditions that made the substitute gas noninterchangeable, the properties of the mixture regarded as "limiting" are represented by $L$. Points representing limiting mixtures should fall near to but on the safe side of a curve separating the gases which gave trouble from those which did not. Since lifting was the only limiting condition with five of the original substitute gases and was only one of two or more limiting conditions with the others, it should not be surprising to find that some of the limits were determined primarily by other factors, and that they are well on the safe side with respect to lifting.

Had some of the appliances been adjusted initially to incipient lifting, the curve separating the interchangeable from the noninterchangeable gases should have passed through or very close to the concentric circles that represent the adjustment gas.

It can be seen at a glance that, so far as this set of data is concerned, the index is in almost exact agreement with the reported observations. When the observations reported in Bulletin 36 were plotted in the same manner, the agreement with the formula was much less satisfactory. In Bulletin 36 the number of appliances that showed lifting with each gas was given. Figures 8 to 10 , representing the result of substitutions for each of the three adjustment gases, are like figure 7 except for a change of scale and the substitution of the number of appliances that failed for the crosses of the earlier figure. Had the index

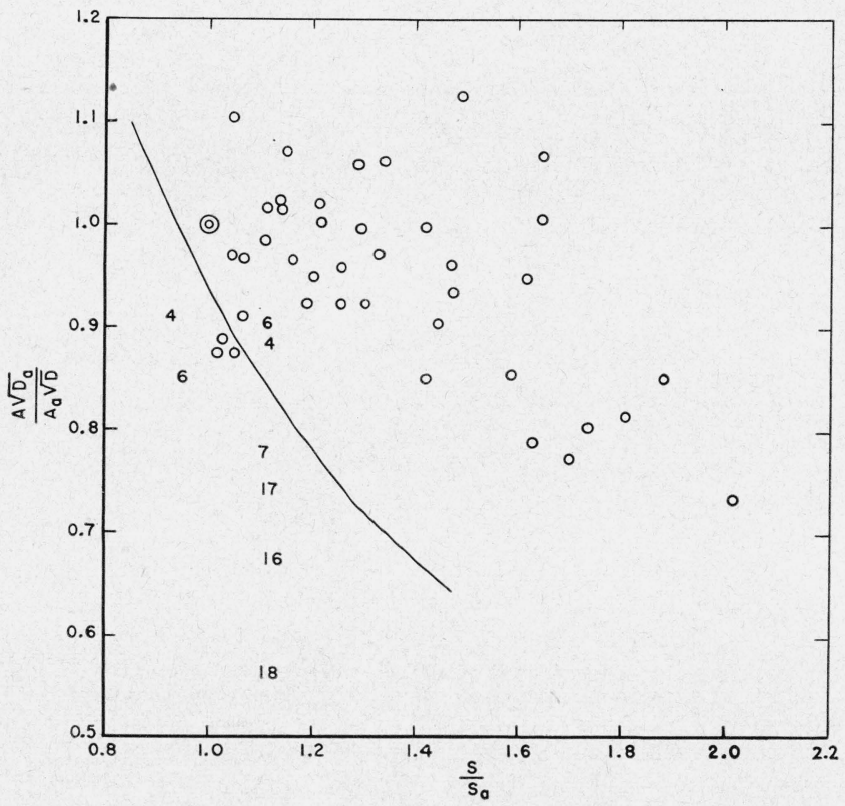

FIGURE 8. Observed lifting after appliances were adjusted with "high-Btu" natural gas.

From Bulletin 36, numbers represent number of recorded cases of lifting with substitute gas. 


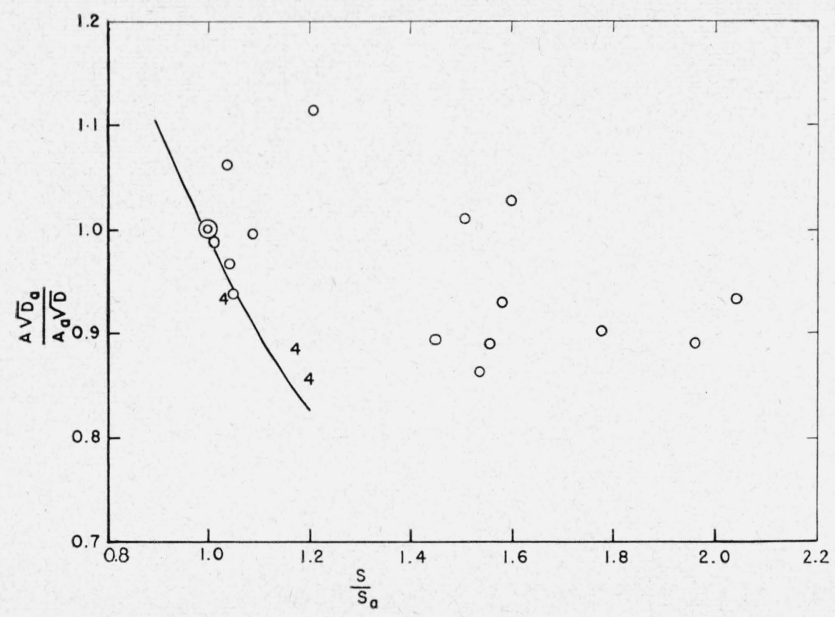

FIGURE 9. Observed lifting after appliances were adjusted with From Bulletin 36 . "high-methane" natural gas.

perfectly represented the observations in this case, not only should all zeros have fallen on one side of a single reciprocal curve and all other numbers on the other side, but of two numbers the greater should always have been farther from the curve.

Inspection showed that of the gases that produced lifting more readily than would have been predicted from their indexes, a large proportion contained butane and air. In cases in which air is present its amount is, of course, subtracted from the volume needed to burn the fuel portion when the "air required for complete combustion" is computed. With an appliance injecting just this amount of air the sum of the air injected and that already in the gas is the correct amount needed to meet the chemical requirements of combustion. However, few

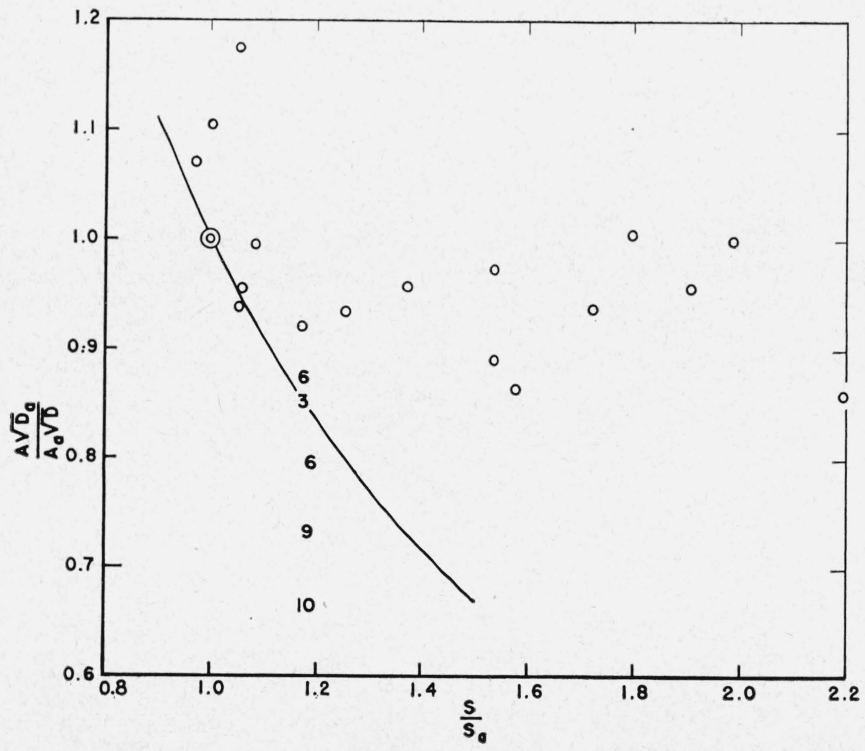

FIGURE 10. Observed lifting after appliances were adjusted with From Bulletin 36

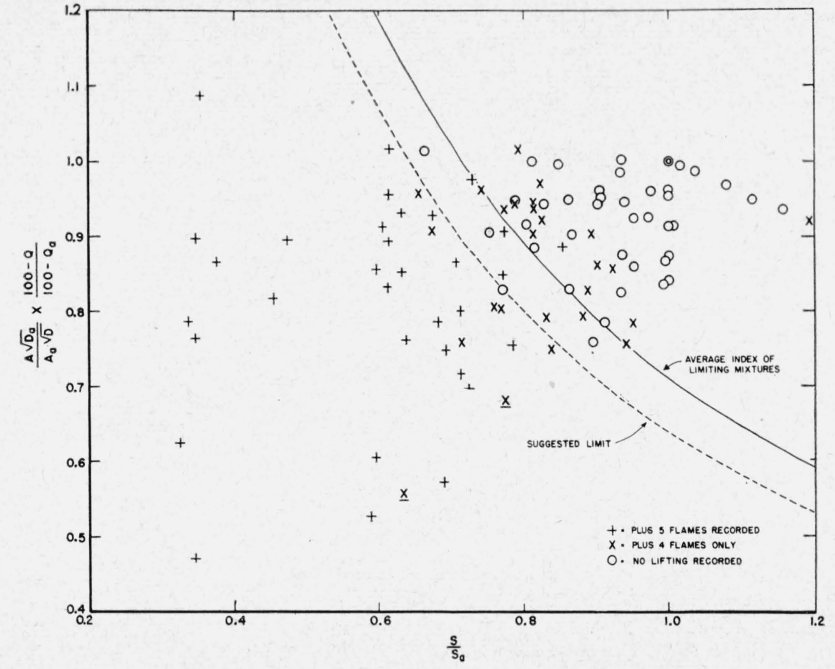

FIGURE 11. Observations of lifting recorded in AGA Report 1106-A.

Value of $J_{A}$ modified to take account of oxygen in the gas.

appliances are used with 100 percent of primary air. With a slow-burning gas, such as natural gas or butane, it is not uncommon for lifting to begin at 25 to 30 percent of primary air and, as failure is judged by the appearance of lifting from any of the burners under observation, it is with the lowest limits of lifting that we are really concerned. At these low percentages of primary air, the primary mixture is not correctly accounted for by the formula. For example, if a butane-air mixture of $1,000 \mathrm{Btu} / \mathrm{cu}$ ft injects just 100 percent of the "air required", about 8 percent of the air in the primary mixture enters the burner with the gas, and only 92 percent is injected. If the burner is now adjusted to take "25 percent of the air required", the air injected is actually 25 percent of 92 percent, or 23 percent of that needed to burn the fuel, but 8 percent enters with the gas, making a total of 31 percent instead of the 25 percent indicated by formula. The error involved in ignoring the oxygen in the gas is great enough to make a big difference in the usable gas rate, as will be appreciated after a glance at the gently sloping lifting curves at the bottom of figure 4 .

From this discussion it appears that a correction to the index for lifting may be needed when the gas contains much oxygen. An inspection of the data indicated that the trouble with the formula would be reduced if the value of $A / \sqrt{D}$ for each gas is multiplied by the fraction by volume of all constituents of the gas except oxygen. The index for lifting is then conveniently written

$$
J_{L}=\frac{S A \sqrt{D}_{a}(100-Q)}{S_{a} A_{a} \sqrt{D}\left(100-Q_{a}\right)},
$$

where $Q$ is the percentage by volume of oxygen in the gas.

To test the application of $J_{L}$, values of $\left[A \sqrt{D}_{a}\right.$ $(100-Q)] /\left[A_{a} \sqrt{D}\left(100-Q_{a}\right)\right]$ have been plotted with 
respect to $S / S_{a}$ for the data reported in Research Report $1106-\mathrm{A}$ in figure 11 , and for the data of Bulletin 36 in figure 12 . In figure 11, substitute gases that showed any +5 flames are marked + and those that produced +4 flames only are marked $X$. This seemed more informative than entering the number of "failures" of either type. The solid reciprocal curve represents the average values of $J_{L}$ for the mixtures considered "limiting" by the AGA committee in charge of the investigation. The broken line represents the present writer's judgment of a limiting value for the index in this case. Two points marked $X$ are underscored. They will be referred to later in a discussion of the reliability of the data.

In figure 12 the three plots corresponding to figures 8 to 11 have been superimposed. Dots have been placed below numbers representing observations made with "high methane" natural gas and above numbers representing "high inert" gas. The numbers representing adjustments with "high Btu" gas are without dots. The horizontal scale is the same for the three sets of data; the vertical scale has been shifted to bring the curves drawn to represent the limits of interchangeability into coincidence at the abscissa $S / S_{a}=1$. One of the more interesting things about the figure is that it shows rather clearly the different margins between lifting and the adjustments with the three different adjustment gases.

It may be of interest to compare the form of the new index $J_{L}$ with the AGA index for lifting $I_{L}$, which is defined in Bulletin 36 by the equation

$$
I_{L}=\frac{K_{a} / f_{a} a_{s}}{f_{s} a_{a}\left(K_{s}-\log \left(f_{a} / f_{s}\right)\right)}
$$

in which subscripts $a$ and $s$ represent properties of "adjustment" gas and "substitute" gas, respectively, and

$$
\begin{array}{ll}
K_{a}=F_{a} / D_{a} & K_{s}=F_{s} / D_{s} \\
f_{a}=1000 \sqrt{D_{a}} / H_{a} & f_{s}=1000 \sqrt{D_{s}} / H_{s} \\
a_{a}=100 A_{a} / H_{a} & a_{s}=100 A_{s} / H_{s} \\
F_{a}=F G_{a} & F_{s}=F G_{s}
\end{array}
$$

where $A, H$, and $D$ have the same significance given them throughout this paper, but $F_{a}$ and $F_{s}$ are obtained as summations of the products of the fractions by volume of each constituent $G$ of the gas mixtures and a factor $F$, called the "lifting constant" of the constituent. The constant $F$ was chosen empirically from a consideration of lifting curves, not of flame velocities, and is based on the effect of unit mass of each constituent of the gas mixture, which is the reason for the appearance of specific gravity in the denominator of the expression defining $K$. For further details of the derivation of $I_{L}$, Bulletin 36 must be consulted.

In comparing the new index, $J_{L}$, with $I_{L}$ it is first to be noted that one decreases while the other increases

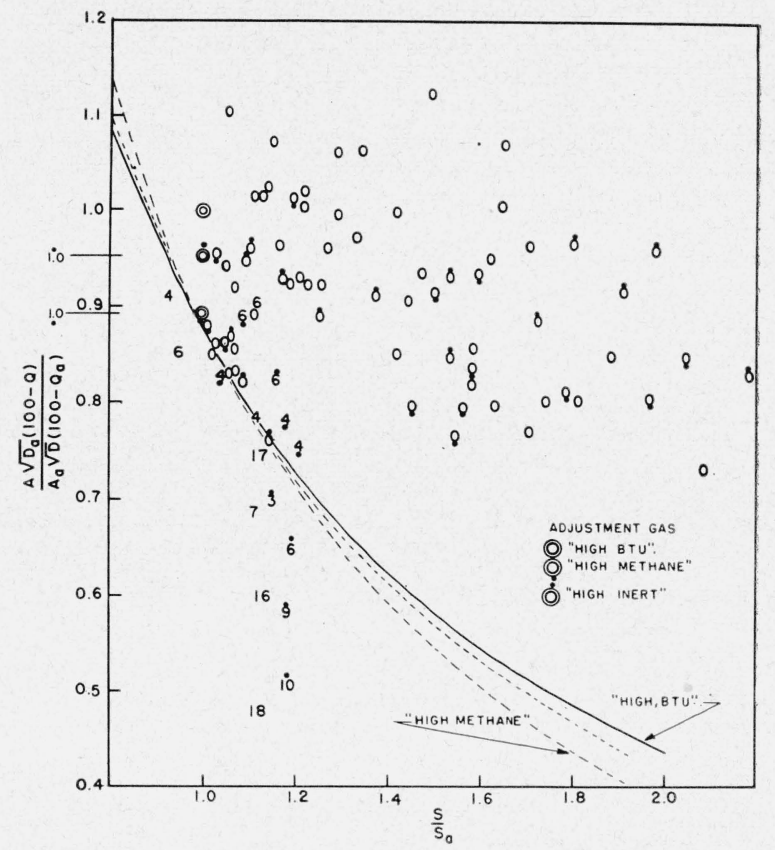

FIGURE 12. Observations of lifting with appliances adjusted for natural gases recorded in Bulletin 36.

Value of $J_{A}$ modified to take account of oxygen in the gas.

with increasing tendency of the gas to cause lifting. This amounts to saying that $A S \sqrt{D_{a}} / A_{a} S_{a} \sqrt{D}$ corresponds more nearly to the reciprocal of $I_{L}$, which we may write

$$
\frac{1}{I_{L}}=\frac{K_{s}}{K_{a}}\left\{\frac{f_{a} a_{s}}{f_{s} a_{a}}-\frac{1}{K_{s}} \log \frac{f_{a}}{f_{s}}\right\} .
$$

Making the various substitutions indicated above, simplifying, and dropping the subscript $(s)$ as in the remainder of this paper

$$
\frac{1}{I_{L}}=\frac{K A \sqrt{D_{a}}}{K_{a} A_{a} \sqrt{D}}\left\{1-\frac{1}{K_{a}} \log \frac{H \sqrt{D_{a}}}{H_{a} \sqrt{D}}\right\} .
$$

The term $1 / K_{a} \log H_{\sqrt{D_{a}}} / H_{a} \sqrt{\bar{D}}$ is found to be rather small in most cases. If we neglect it for the moment and assume that values of $K$ are proportional to values of $S$ in index $J_{L-1}$ one index becomes the reciprocal of the other. Next we should note that $I_{L}$ contains no term relating specifically to oxygen, but as this is rarely an important constituent of a gas, the omission is relatively unimportant.

As $K$ and $S$ are derived in very different ways from observations of different kinds, no theoretical relation between them can be stated. A comparison was made by plotting with respect to each other their numerical values for the experimental gases described in Bulletin 36 and Report 1106-A. The assumed proportionality was not closely approximated; nevertheless there is a general agreement as to the nature of the index needed to represent lifting, with the principal difference appearing in the values and methods of determining constants that are essentially similar functions of flame velocity. 


\section{Selection of the Best Index of Inter- changeability for Lifting}

Figures 11 and 12 give a good general picture both of the agreement of $J_{L}$ with observations and of the relations between the functions of composition of gas mixtures from which the index was derived, but they do not permit ready comparison of $J_{L}$ with $I_{L}$ or other indexes for predicting lifting based on different properties of the gases involved. Accordingly, the data of figure 11 are plotted in still a different manner in figures 13 and 14 . In figure 13 , the lifting index $J_{L}$ for each substitute gas is plotted with respect to the number of appliances for which any lifting ( +4 or +5 flames) was recorded. In figure 14, the abscissa is the number of burners with +5 flames only. The average index of limiting mixtures in each figure and the suggested limit of interchangeability correspond, respectively, to the solid and the dotted reciprocal curves of figure 11. Arrows at the edges of the figures indicate the direction of points off the figure, the inclusion of which would have unnecessarily reduced the scale used. Each of the two asterisks in the figures represents a substitute gas with which a single +4 flame was recorded. These points indicate the same gases (A1-32-90 and A1-32-55) that were represented by underlined $X$ in figure 11 . They appear to be quite anomalous; at least we should expect the gas represented by the lower point to produce many +5 flames. When the observations made with these two gases are plotted with respect to other functions of composition, $I_{L}$, AGA index C, Knoy Index $C, J_{H}, J_{A}$, the ratio of hydrogen to inert in the gas and to the observed adjustments of the Rochester Burner that produced lifting, they appear to be as much out of line as they are in figures 13 and 14 . They are also highly improbable merely when compared with the other

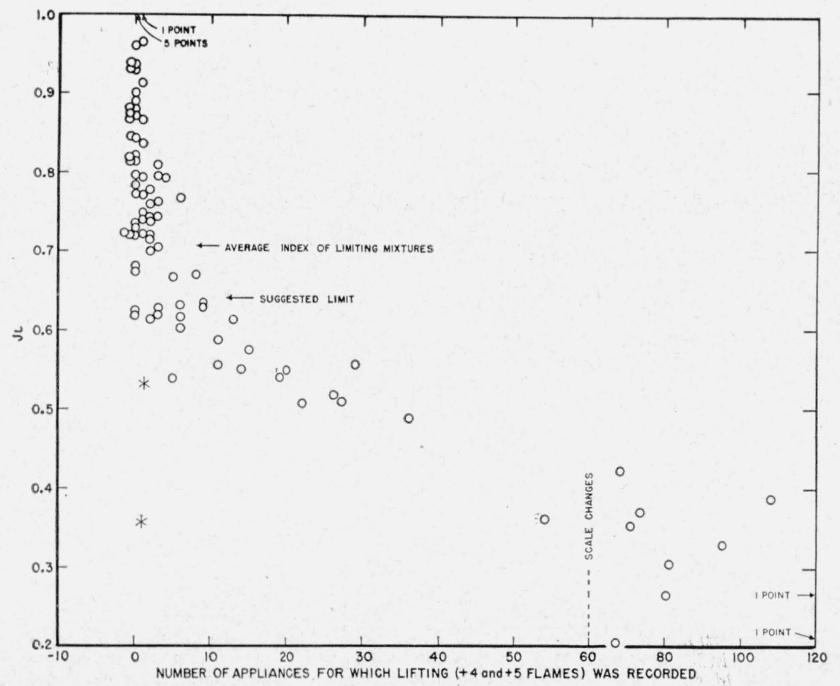

Figure 13. Number of appliances showing any lifting $(+4$ and +5 flames $)$ compared with values of $J_{L}$.

Data from Report 1106A.

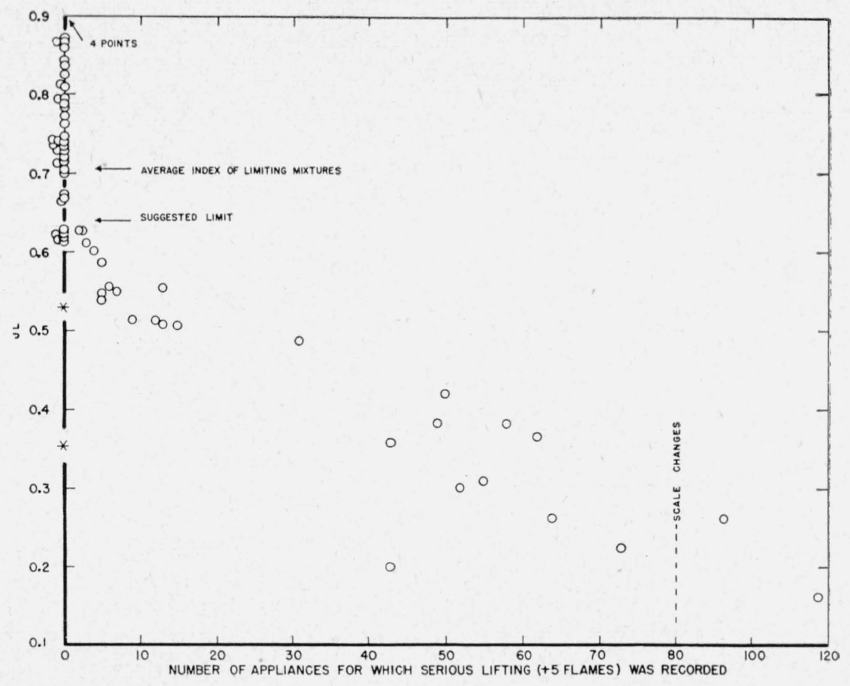

Figure 14. Number of cases of serious lifting $(+5$ flames $)$ compared with $J_{L}$.

Data from Report 1106A.

observations of mixtures with the same supplemental gas (A-32). This gas undiluted showed 71 cases of lifting, of which 55 were recorded as +5 flames, and the mixture of 40 percent of the gas with 60 percent of adjustment gas $\mathrm{A}-1$ caused nine cases of +4 flames, but the anomalous mixtures containing 90 and 55 percent, respectively, of gas A-32 showed only one case of +4 flames each. For these reasons it seemed desirable to omit these two gases from all comparisons between the various indexes.

In selecting the limits of mixing of supplemental with adjustment gases, the $\mathrm{AGA}$ committee permitted some +4 flames and even a few +5 flames. Taking the first gas substituted, A1-11 as an example, the committee decided that a mixture containing 30 percent of the supplemental gas was to be considered interchangeable with the adjustment gas, although it was recorded as having produced four +5 and two +4 flames. The number of cases of serious lifting ( +5 flames) therefore seems to be a more practical as well as an easier basis on which to compare various indexes than the number of cases of both +4 and +5 flames. Hence, only the more serious type of lifting will be included in most of the comparisons that follow.

In figure 15 , lifting is plotted with respect to the AGA index for lifting, $I_{L}$. In figure 16 , the same comparison is made with the AGA general index of interchangeability, $C$. Plots of the same kind were made for the Knoy index, for the ratio of hydrogen to inert, which is regarded as a general index of interchangeability by some operators, for several other functions of composition, and for comparisons of appliance burners with the Rochester test burner. The observations made after adjusting appliances with the other adjustment gases were treated in the same way. Then similar plots were made of the results of observations of the other types of appliance failure. In all, more than 100 plots were made to 


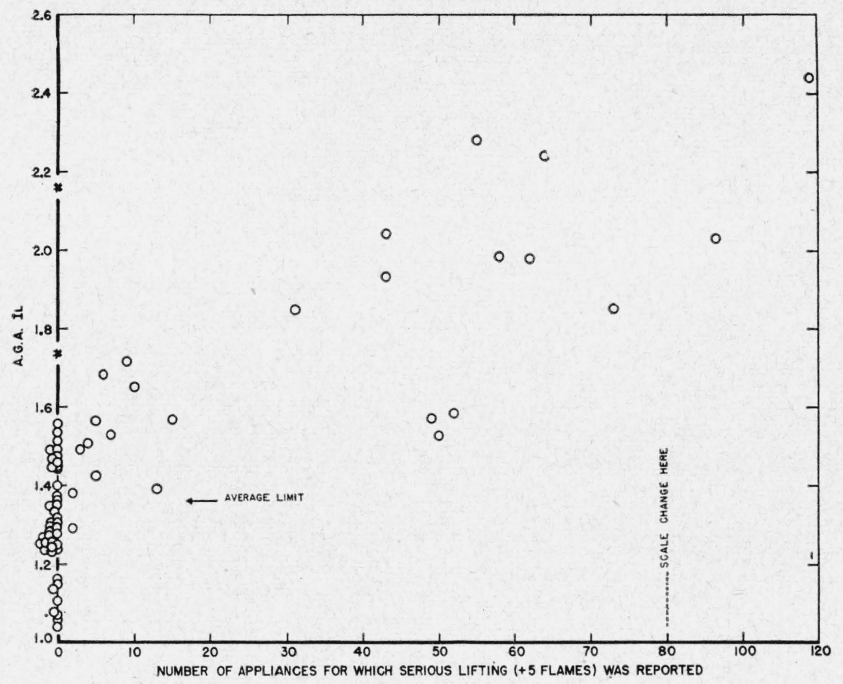

Figure 15. Number of cases of serious lifting ( +5 flames) compared with $A G A$ Index $\dot{I}_{L}$.

Data from Report $1106 \mathrm{~A}$.

show the frequency of appliance failure of one kind or another in relation to some computed or experimental means of predicting failure.

Some of the plots resulted in nothing of interest, but to reproduce all those that did would require too much space and would be more confusing than helpful. Some times it is hard to determine from casual inspection which of two indexes better represents the observations. A method of summarizing in numerical form the information available from one of the figures is needed. The method devised will be explained with the aid of figure 17, assumed to represent a simple hypothetical case. It is assumed that five gases, $A$ to $E$ were tested with the results indicated in the figure, that is one appliance showed lifting with gas A, two with gas B, six with gas E, etc.

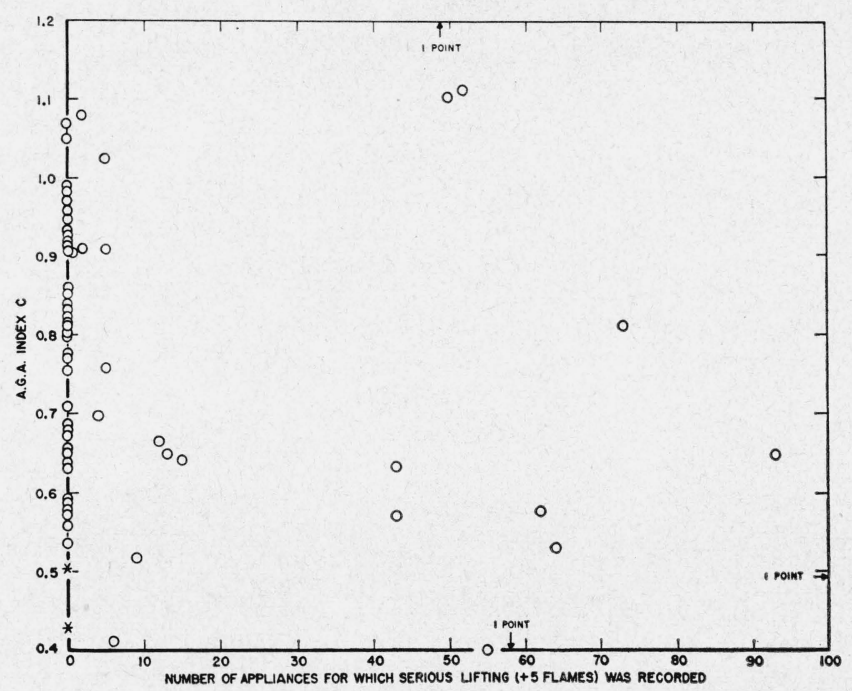

Figure 16. Number of cases of serious lifting ( +5 flames) Data from Report 1106A.

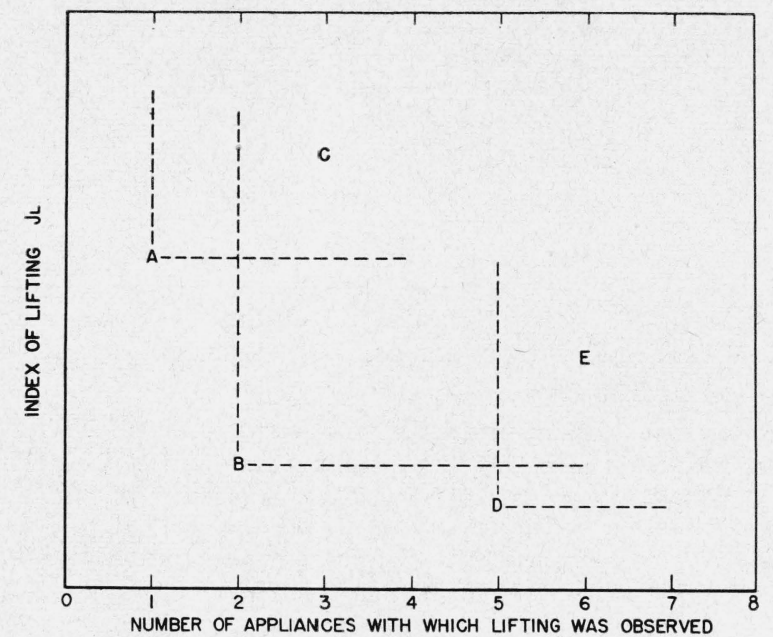

FIgURE 17. Figure representing the hypothetical case used to explain the method of "summations" employed for comparing various indexes.

We should expect the least appliance failures from $C$, because it has the highest index $J_{L}$, and the most failures from $D$ with the lowest index. Table 2 is prepared to show the exceptions to the predictions that would be made from a knowledge of the indexes. In the column headed "summation A", one is entered for each gas with which lifting was recorded less frequently than with one or more gases having higher values of the index. In the case of each of these mixtures, the number of mixtures of higher index that produced lifting more frequently is noted and added together in the column headed "summation B." From the total number of cases of observed lifting with the mixtures indicated in summation B is subtracted the total number of cases occurring with the mixtures indicated in summation $\mathrm{A}$. This gives "summation C", which is the total number of times lifting was observed from any appliance with any gas when it would not be expected to occur from the known extent of lifting with each of the other gases and the relative values of the indexes for the two gases.

The summations are easily made from the plotted data with the aid of a piece of transparent plastic

TABLE 2.-Hypothetical case showing application of method of summation from figure

\begin{tabular}{|c|c|c|c|}
\hline \multirow{2}{*}{$\begin{array}{l}\text { Gas with which other } \\
\text { gases are compared }\end{array}$} & \multicolumn{3}{|c|}{ Summation } \\
\hline & $A^{a}$ & $\mathrm{~B}$ & $\mathrm{C}$ \\
\hline $\begin{array}{l}\mathrm{A} \\
\mathrm{B} \\
\mathrm{C} \\
\mathrm{D}\end{array}$ & $\begin{array}{l}1 \\
1 \\
0 \\
1 \\
0\end{array}$ & $\begin{array}{l}1 \\
2 \\
0 \\
1 \\
0\end{array}$ & $\begin{array}{l}2 \\
5 \\
0 \\
1 \\
0\end{array}$ \\
\hline Total & 3 & 4 & 8 \\
\hline
\end{tabular}

a Summation A represents the number of times we would be in error if we predicted rom their indexes, whether each gas mixture would cause lifting with more appliances than would occur with any other one gas mixture. Summation $B$ represents the number of times we would be in error if we predicted from the index whether each gas mixture would cause more frequent lifting than each of the other gas mixtures. Summation $C$ represents the number of cases in which we would be in error if we predicted whether each appliance would show lifting with each gas from a comparison of the index for that gas with the index for each other gas. 
with one right angle, the apex of which is successively placed on each of the plotted points as represented by dotted lines in figure 17 . The numbers to be entered in each summation are then easily counted. In detail, mixture A has a lower value of $J_{L}$ than mixture $\mathrm{C}$, but caused lifting of two less appliances. Hence we enter 1 in summation $A$, one in summation B, and 2 in summation C. Mixture $\mathrm{B}$ has a lower value of the index than either $\mathrm{C}$ or $\mathrm{E}$, hence 1 is added to summation $\mathrm{A}$, and 2 to summation B. One more appliance lifted with $\mathrm{C}$ than with $\mathrm{B}$ and four more with $\mathrm{E}$ than with $\mathrm{B}$, hence the total, 5, is entered in summation C. There were less failures with gas $\mathrm{C}$ than with any gas of lower index not already compared with it; hence there are no exceptions to the rule and nothing to enter in any of the summations. Mixture D has a lower value of the index than $\mathrm{E}$, and one less appliance showed lifting with it than with $\mathrm{E}$, hence 1 is added to summations $\mathrm{A}, \mathrm{B}$, and $\mathrm{C}$.

The application of this method of descriptive summation to comparisons between indexes for other limiting conditions and the experimental observations should now be understandable. If the summation for one index results in smaller numbers than for another, the first is the better index because there are less exceptions to the predictions that can be made from its use.

The summations of observations made after adjustment with gas $A 1$ for several indexes are shown in table 3. The data are confined to the gases for which $I_{L}$ was given. The last series of numbers in the table, designated "possible", requires explanation. The AGA lifting index was given for 70 gases. If the one with the highest index had produced the most cases of lifting, the other 69 would have to be entered in summation $A$, and this in spite of the fact that the remainder of the observations might have been in perfect order. Hence summation $\mathrm{A}$ is not very significant. Summation B is prepared, in effect, by comparing the tests of each of the 70 gases with the tests of each of the remaining 69 gases, making a total of $70 \times 69 / 2=2,415$ comparisons. When there is a reversal of the anticipated relation, a unit is entered in summation B. Had all comparisons resulted in reversals, the fact would have represented a perfect inverse correlation between index and observation, that is a correlation that varied in the direction opposite to that anticipated. Had there been no correlation between the index and the number of appliance failures, we should expect about half this number in summation B. There were nine combinations of adjustment of each of 28 appliances, hence the possibility that in any one of the 2,415 possible reversals there would be $9 \times 28=252$ more failures with one gas than with the other. But this maximum difference could have existed in the maximum number of cases only had the gases been divided into a group each number of which produced 252 failures and an equal group that produced no failures. Comparisons between numbers of the same group would show no differences. The maximum number that could appear in summation $\mathrm{C}$ is
$35 \times 35 \times 252=308,700$, but this again could occur only if there were complete reversal of the predicted relation of index to appliance failures, as well as arrangement in two extreme groups. The number of failures that would have appeared in summation $\mathrm{C}$ had there been no correlation between the index and appliance failure cannot be stated, because it depends greatly on the distribution of tendencies to lift among the appliances used, but it is of the order of magnitude of $10^{5}$.

Table 3 shows that there is a strong correlation with the numerical value of the index even in the case of the worst one, which is AGA index C. We see at once that the number of times we would fail to predict lifting on individual appliances by the use of $I_{L}, J_{L}$, or $J_{L-1}$, indexes designed to show the tendency to lift only, is an order of magnitude less than the number of times we would fail when using any of the single expressions designed to show general interchangeability, except the ratio of hydrogen to inert which, for this set of data, is about as good as $I_{L}$. Index $J_{L}$ is shown to be much better than $I_{L}$ so far as this set of data is concerned, and the advan-

TABLE 3. Summations showing the application of various indexes to observations of lifting made after adjusting appliances with gas $A 1$.

(Only +5 flames and cases for which $I_{L}$ is given are included. Tests A1-32-90 and A1-32-55 omitted).

\begin{tabular}{|c|c|c|c|}
\hline \multirow{2}{*}{ Index } & \multicolumn{3}{|c|}{ Summation } \\
\hline & A & B & $\mathrm{C}$ \\
\hline $\begin{array}{l}J_{L} \\
J_{L}-1 \\
\mathrm{AGA} I_{L} \\
\text { AGA C } \\
\text { Knoy C } \\
\text { Hydrogen: inert } \\
J_{H}\end{array}$ & $\begin{array}{l}14 \\
22 \\
37 \\
57 \\
48 \\
39 \\
58\end{array}$ & $\begin{array}{r}36 \\
48 \\
120 \\
817 \\
451 \\
109 \\
429\end{array}$ & $\begin{array}{r}294 \\
339 \\
1,402 \\
12,614 \\
10,915 \\
1,112 \\
12,392\end{array}$ \\
\hline Possible & 69 & 2,415 & 308,700 \\
\hline
\end{tabular}

tage of correcting $J_{L-1}$ for the presence of oxygen in the gas is apparent.

The superiority of $J_{L}$ is even more evident if we omit from the summations the mixture A1-26-100, experimentation with which was on a different basis than with the other mixtures. This is explained in footnote in Report 1106-A as follows: "Data taken prior to the Committee's decision to adjust each burner for more than one kind of flame. First figure gives number of burners with unsatisfactory flames, second indicates the number of burners adjusted for the particular kind of flame". We find that of the seven, eight, or nine burners tested under five of the nine combinations of adjustment and pressure, all had +5 flames. We have no way of judging how many failures would have occurred had all 28 appliances been given all the adjustments. Omitting this gas gives the three lifting indexes with the summations listed in table 4.

Although data from the experiments with several adjustment gases have been plotted for various general indexes, the superiority of the lifting indexes $I_{L}$ and $J_{L}$ is so decisive that no further consideration 
TABLE 4. Summations of observations of lifting with appliances adjusted with gas A1.

Tests A1-26-100, A1-32-90, and A1-32-55 omitted from the comparison

\begin{tabular}{|c|c|c|c|}
\hline \multirow{2}{*}{ Index } & \multicolumn{3}{|c|}{ Summation } \\
\hline & A & B & C \\
\hline $\begin{array}{l}J_{L} \\
J_{L-1 \ldots} \\
I_{L}\end{array}$ & $\begin{array}{l}13 \\
21 \\
36\end{array}$ & $\begin{array}{r}27 \\
39 \\
113\end{array}$ & $\begin{array}{r}125 \\
17 \Theta \\
1,101\end{array}$ \\
\hline
\end{tabular}

need be given to AGA index C, Knoy index C, etc. Summations for the comparisons with natural gases are given in table 5. In this set of comparisons $I_{L}$ certainly has the advantage. It might be concluded that $J_{L}$ is generally unsuitable for use when burners have been adjusted with natural gases, but such a conclusion is probably not warranted by the experimental data, which show that $J_{L}$ applied very well to all tests except those involving a single producer gas and its mixtures. Further work may be needed to establish the value of $J_{L}$ when applied to very slow-burning gases, however. Again $J_{L}$ appears to be superior to $J_{L-1}$ by a margin wide enough to warrant dropping the latter from further discussion.

The interpretation of the experiments recorded in Research Report 1106, parts B, C, and D is affected by the fact, earlier mentioned, that varying numbers of appliances were actually tested with the different conditions of adjustment and gas supply. Usually the burners most susceptible to lifting were tested first. When enough of them had been tested without lifting to make it probable that most of those not tested would not show lifting, testing was discontinued. In these cases it is not likely that the number of failures would have increased greatly had all the appliances been tested; but there were other cases in which all appliances tested showed +5 flames, and it appears that testing was discontinued because the noninterchangeability of the substitute gas with the adjustment gas had been shown decisively and further experimentation seemed unnecessary for the original purpose of the investigation.

Even had the appliances been arranged as well as practicable in the order of susceptibility and had testing been continued with each gas until some of

TABLE 5. Summations of observations of lifting with appliances adjusted with natural gases

\begin{tabular}{|c|c|c|c|c|}
\hline \multirow{2}{*}{ Adjustment gas } & \multirow{2}{*}{ Index } & \multicolumn{3}{|c|}{ Summation } \\
\hline & & A & B & $\mathrm{C}$ \\
\hline "High Btu". - & $\left\{\begin{array}{l}J_{L} \ldots \\
J_{L-1} \\
I_{L-\ldots}\end{array}\right.$ & $\begin{array}{l}9 \\
8 \\
3\end{array}$ & $\begin{array}{r}9 \\
12 \\
3\end{array}$ & $\begin{array}{l}47 \\
64 \\
22\end{array}$ \\
\hline "High methane".. & $\left\{\begin{array}{l}J_{L \ldots} \ldots \\
J_{L-1} \\
I_{L-\ldots}\end{array}\right.$ & $\begin{array}{l}1 \\
3 \\
0\end{array}$ & $\begin{array}{l}1 \\
6 \\
0\end{array}$ & $\begin{array}{r}2 \\
24 \\
0\end{array}$ \\
\hline "High inert". & $\left\{\begin{array}{l}J_{L-\ldots} \\
J_{L-1-} \\
J_{L-\ldots}\end{array}\right.$ & $\begin{array}{l}4 \\
4 \\
1\end{array}$ & $\begin{array}{l}4 \\
8 \\
1\end{array}$ & $\begin{array}{r}21 \\
30 \\
2\end{array}$ \\
\hline
\end{tabular}

the burners had not shown lifting, there must have been some uncertainty as to the number that might have failed, for the order of susceptibility was by no means constant. When, under a given condition of adjustment and gas supply, no more than three appliances showed either +4 or +5 flames, they were designated by their identifying letters. In table 6 is a summary of the entries of this kind in Report 1106-A. When a given burner was the only one that showed +5 flames or the only one that showed +4 flames when none showed +5 flames, it was considered "most susceptible" to lifting and entered in column (A). If its greater tendency to lift was shared by one or two other burners, it is entered in column B, etc. Rated like an athletic event, a first in susceptibility to lifting is represented in column $\mathrm{A}$, a tie for first with not more than two others in column B, second or a tie for second with not more than two others in $\mathrm{C}$, third or a tie for third with not more than two others in D. Columns $\mathrm{E}$ and $\mathrm{F}$ merely show that the burner was not first or second, while the entries under G show definitely that the burner was often far less susceptible than numerous others. The burners are listed in order of the number of times they appeared to be most susceptible or among the two or three most susceptible, and 19 of 28 were in this position under at least one condition, but those most susceptible in many cases were as low as 16th in order of susceptibility in other cases.

If such variations appear in the relative susceptibility to lifting, we cannot expect greater regularity in their absolute susceptibilities, which determine the number of appliances on which lifting should occur with a given gas. Even if the index were the

TABLE 6. Relative tendency to lift shown by certain burners as recorded by burner designations in table 7 of Report 1106-A

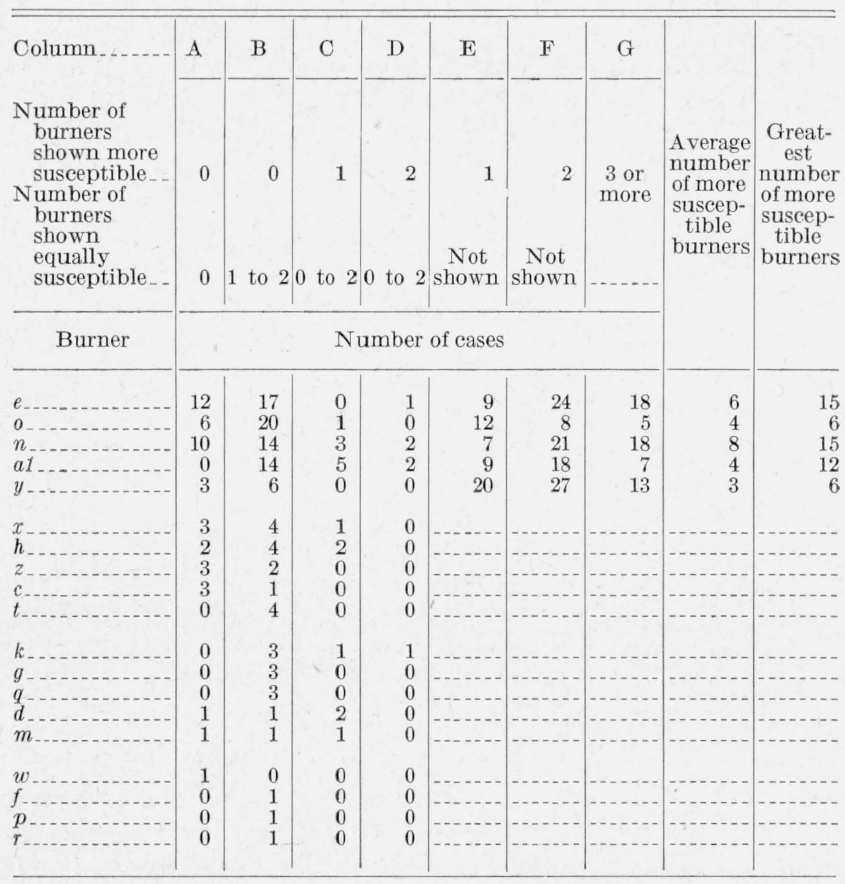


TABLE 7. Summations of all tests for lifting compared with $I_{L}$ and $J_{L}$ (comparisons with adjustment gas A1 limited to those for which $I_{L}$ had been computed)

\begin{tabular}{|c|c|c|c|c|c|c|c|c|c|}
\hline \multirow{2}{*}{$\begin{array}{l}\text { Adjust- } \\
\text { ment gas }\end{array}$} & \multicolumn{3}{|c|}{$\begin{array}{l}\text { Index } I_{L} \text { sum- } \\
\text { mations }\end{array}$} & \multicolumn{3}{|c|}{$\begin{array}{l}\text { Index } J_{L} \text { sum- } \\
\text { mations }\end{array}$} & \multicolumn{3}{|c|}{$\begin{array}{l}\text { Maximum possible } \\
\text { summations }\end{array}$} \\
\hline & A & B & C & A & B & C & A & B & C \\
\hline A1 & 37 & 120 & 1. 402 & 14 & 36 & 294 & 69 & 2,415 & 308,700 \\
\hline B1 & 23 & 76 & 601 & 20 & 77 & 44 & 64 & & 112 \\
\hline B2 & 14 & 44 & 18 & 17 & 35 & 9 & 56 & $\begin{array}{l}1,596 \\
1,50\end{array}$ & 204,624 \\
\hline B3 & 15 & 48 & 201 & 24 & $\begin{array}{l}35 \\
35\end{array}$ & 5 & 72 & $\begin{array}{l}2,628 \\
2,620\end{array}$ & 326,59 \\
\hline & 32 & 105 & 611 & 30 & 42 & 258 & 93 & 4,418 & 344,824 \\
\hline D1. & 7 & 11 & 6 & 2 & 3 & 4 & 11 & 6 & 7 \\
\hline & 3 & 3 & 22 & 9 & 9 & 47 & 47 & 1.128 & 145,15 \\
\hline & 0 & 0 & 0 & 1 & 1 & 2 & 17 & 153 & 20,412 \\
\hline $\mathrm{N} 3 \ldots$ & 1 & 1 & 2 & 4 & 4 & 21 & 21 & 231 & 30,492 \\
\hline Total & 132 & 408 & 3,087 & 121 & 242 & 1,222 & 450 & 14,715 & $1,654,468$ \\
\hline
\end{tabular}

best possible guide in predicting appliance failure, and if all appliances had been tested with every gas, we should expect considerable irregularity among the results, because table 6 shows the variations to be unpredictable. When a varying number of appliances is tested, the scrambling of the results is much greater. Nevertheless, we have no alternative to using the data available. The apparent value of any index must be unfavorably affected by such irregularities as the variable number of appliances tested, but these variations are not too great to leave a high degree of correlation between the number of appliance failures and the properties of the gas supply, and the index that most perfectly represents these properties should still show the better correlation with the number of appliance failures.

It would be possible to omit from consideration certain results in Reports $1106-\mathrm{B}, \mathrm{C}$, and D, for the same reasons given in the case of tests $\mathrm{A} 1-32-90, \mathrm{~A} 1-32-55$, and A1-26-100, but their individual discussion would not be worth while. Accordingly, all the results recorded in these reports have been included in the "summations" made of them. The AGA index $I_{L}$ was reported for only 57 of 65 gases for which tests were recorded with $\dot{B} 1$ as the adjustment gas, but all tests are included in the summations for $J_{L}$, although the larger number of gases leads necessarily to somewhat larger summations. In spite of this handicap, $J_{L}$ shows the higher degree of correlation in this as in all other cases, except the tests reported in Bulletin 36. The summations for each group, including those previously discussed, are given in table 7 . There is no room for uncertainty that $J_{L}$ represents the results of this huge group of tests materially better than does $I_{L}$.

The Rochester Test Burner is a simple single-port burner with a graduated means of adjusting the primary air opening. When used to measure the lifting properties of a gas, a normal rate of gas flow is set with an adjustment gas, and with each substitute gas in turn the air shutter is opened until lifting occurs. A graduated scale attached to the air shutter provides a numerical reading that is taken to be the desired measure of the tendency of the substitute gas to produce lifting. The readings of the Rochester burner were not included in table 3 with the indexes, because neither they nor index $I_{L}$ was applied to all the gases substituted for $A 1$, and the ones omitted were not the same. Index $J_{L}$ was plotted for the same gases used with the Rochester burner, however, and the usual summations taken. Including +4 and +5 flames, they were as follows: for $J_{L}, \mathrm{~A}=25, \mathrm{~B}=72, \mathrm{C}=481$. For the Rochester-Burner Index, $A=33, B=108$, $\mathrm{C}=1,331$. It appears that observations with the Rochester burner would have provided a more accurate means of predicting lifting than $I_{L}$ but not as accurate a means as $J_{L}$. The same appeared to be true in plots of tests involving other adjustment gases, but summations were not made.

\section{Derivation of a New Index to Repre- sent Flashback, and its Comparison With AGA Index $I_{F}$}

The flashback curves shown in Report 847 are not complete enough, nor do they cover a sufficiently varied lot of gases to be of much use in preparing a formula for predicting flashback. It was therefore necessary to go much farther back, to 1922 and the Bureau's Technologic Paper 222 [11], which dealt with a considerable variety of rapidly burning gases and two range burners. The observations were made before methods of testing appliances were well developed and leave much to be desired in the way of completeness and accuracy, but they still represent the best data for this purpose available to the writer.

Essentially the same method was employed as in the preparation of the formula for lifting. Curves were replotted from the original figures to show the average rate of gas supply (in terms of the air required to burn it) at which the two appliances flashed back with each gas and at each of several percentages of primary air. Only a part of the 10 resulting flashback curves, for gases designated 103-106, are shown by heavy lines in figure 18; the

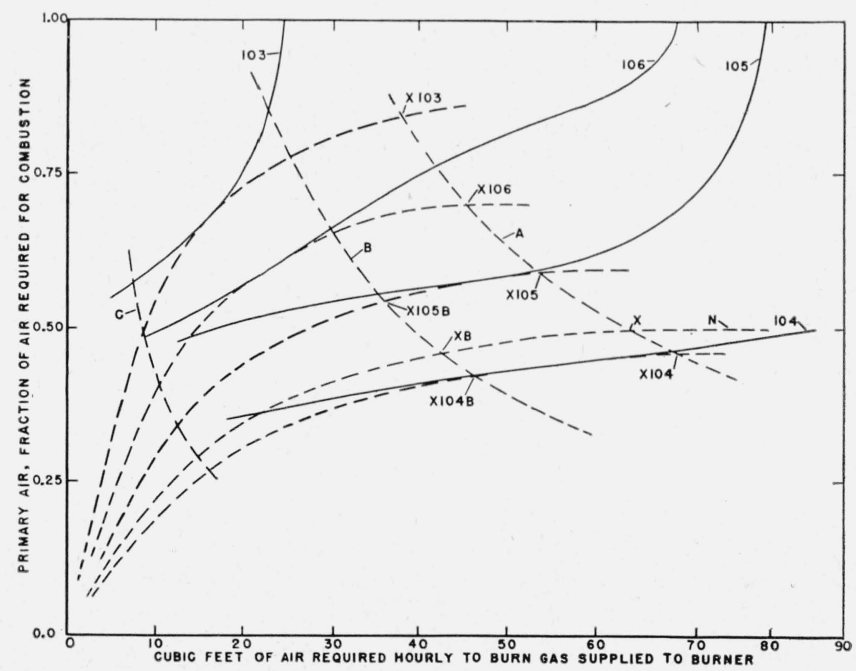

Figure 18. Average flashback curves for four gases, and changes that occur in tendency to flash back when pressures and mechanical adjustments are changed. 
others are omitted to make the figure less confusing. In the case of lifting we were concerned only with what would happen when the gas-supply valve of an appliance is wide open. If lifting does not occur under that condition, it does not occur when the gas is turned down. The case of flashback is entirely different. Ranges and space heaters are usually manually controlled to whatever rate the user desires, and many appliances of other types have graduating thermostats that effect similar control automatically. Safety from flashback therefore requires that it shall not occur under any conditions produced by gradually reducing the pressure at the burner orifice, by closing a valve in the supply line or otherwise. What happens to the input of gas and the injection of primary air when this occurs is represented on the basic diagram by "normal injection curves," of which curves $N_{a}$ and $N$ of figure 2 are examples. Normal injection curves in figure 18 are broken curves converging at the origin. The point representing the operation of an appliance at its normal input rating may seem remote from flashback, but if the normal injection curve connecting it with the origin intersects the flashback curve, the appliance is subject to that hazard. The changes that take place in the flow of gas and primary air when one gas after another is supplied to an appliance with unchanged mechanical adjustments, including the burner valve, is again represented by a reciprocal curve $(A)$.

The solution of our problem begins with the construction of a normal injection curve for a typical appliance, marked $N$ in figure 18 . Such curves differ somewhat from one appliance to another, but are enough alike to permit almost any one to represent appliances in general. Other normal injection curves to be used in the same problem must be related to the others as shown by the method of deriving one from another which follows. The intersection of curves $A$ and $N$ is marked $X$. From another point on curve $A$, say $X-105$, a normal injection curve is constructed in the following manner. Other reciprocal curves, of which $B$ and $C$ are shown, are constructed. Each represents a different pressure at the orifice. Curve $N$ intersects curve $B$ at a point marked $X-B$. The normal injection curve through point $X-105$ will intersect curve $B$ at a point $X-105-B$, whose abscissa has the same ratio to that of $X-105$ as the abscissa of point $X-B$ has to the abscissa of $X$. In this manner any number of points on the normal injection curve through $X-105$ can be located, and any number of other normal injection curves can be drawn.

By trial and error, normal injection curves tangent to the experimental flash back curves were constructed in the manner described. Their intersections with curve $A$ are marked $X-103, X-104$, . . and have the same significance with respect to flashback as did the intersections of reciprocal curve $Y$ with the lifting curves of figure 4 . The abscissas of points $X-101, \ldots, X-110$ are plotted with respect to flame speed $(S)$ in figure 19. The gas rate in terms of air required to burn it will be designated $A_{F}$. It was plotted in preference to its reciprocal, primary air, because a simpler relation was expected to appear. Actually, the points scatter badly, but they can be represented by a straight line as well as by any other simple function. The straight line obviously does not pass through the origin and the still simpler relation of direct proportionality does not exist. As each abscissa of a point of figure 19 is that of a point on the same reciprocal curve of figure 18 ,

$$
A_{F}=k A / \sqrt{D}
$$

and the equation of the straight line of figure 19 can be written

$$
S-k A / \sqrt{D}+C=0
$$

in which $k$ and $C$ are constants. The significance of the equation is that, with single values of the constants, it represents in terms of three properties of the gas $A, D$, and $S$, and with as much accuracy as the accuracy of the observations and assumptions will permit, all gases that are equally susceptible to flashback.

The observations of flashback recorded in Report 1106-A are plotted in figure 20 with the coordinates used in figure 7 . When flashbacks were reported without a qualifying note for any appliance, the point corresponding to the gas used is marked + , and when no flashback occurred, it is marked 0 . When flashback was noted for a single appliance but marked "tendency" or "occasionally," the corresponding point was omitted from the figure as indeterminate. The diagonal straight line does not make a perfect separation of gases with which flashback was recorded from those with which it was not, but points very far on the wrong side of the line are not numerous.

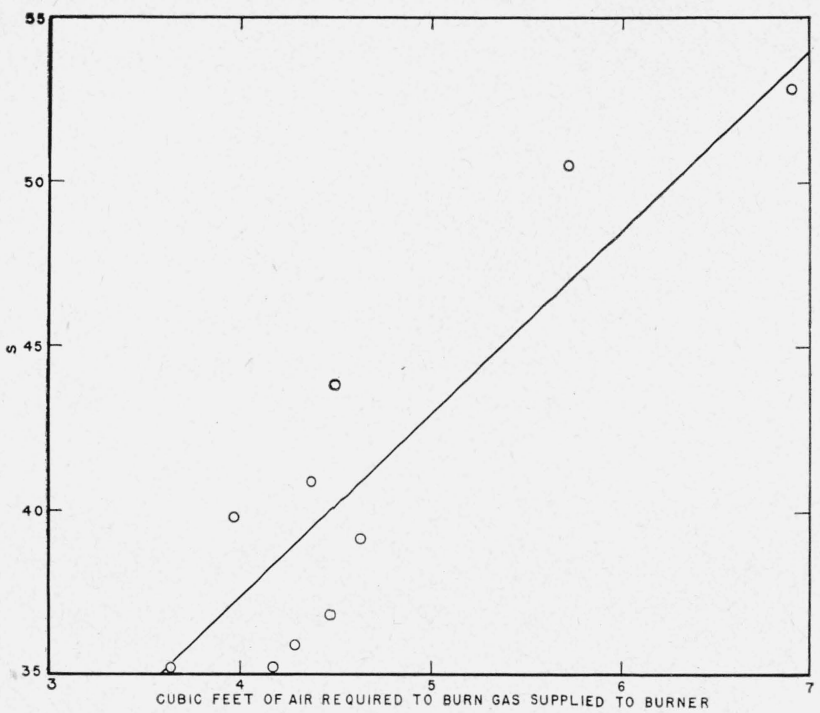

Figure 19. Relation between flame speed (S) and rate of gas supply (in terms of air required to burn it) at initial adjustments of appliance with each gas such that flashback will just occur when pressure is gradually reduced. 


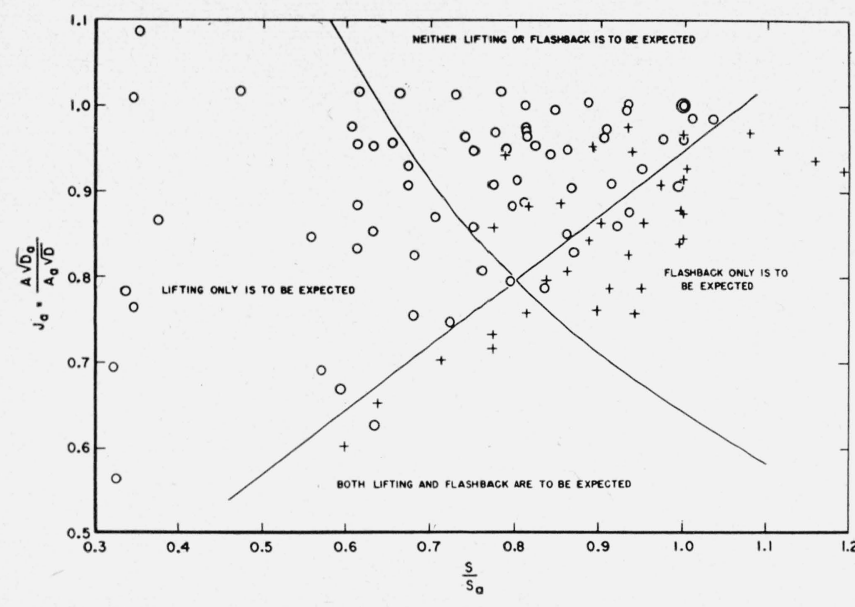

Figure 20. Observations of flashback from Report 1106-A. Added curve for lifting shows generally the conditions for stable and unstable flames.

Actually, the line was drawn, in the first place, from the undetailed but considered data of the Anthes Report, with which it was in excellent agreement.

It is of interest to add, to the line indicating the limit of interchangeability with respect to flashback, the reciprocal curve indicating the limit of interchangeability with respect to lifting previously found. The curve in figure 20 corresponds to the "suggested limit" of figures 11, 13, and 14. Figure 20 is thus divided roughly into quadrants, only one of which represents gases with which flames may be expected to be stable (subject to neither lifting nor flashback).

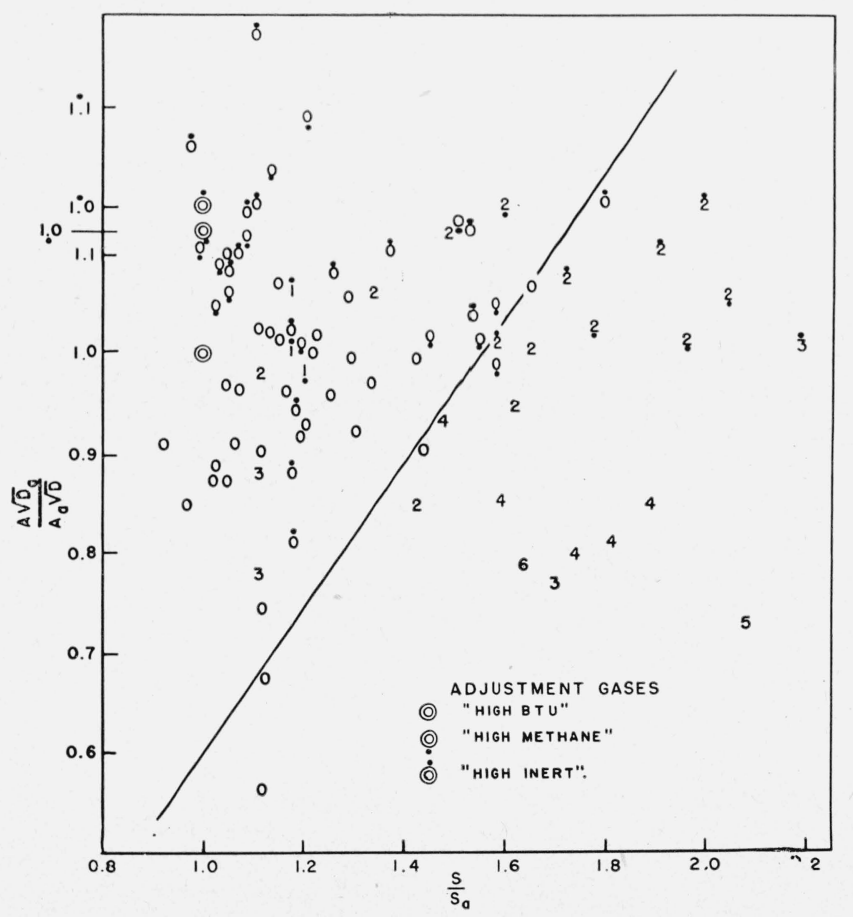

Figure 21. Observations of flashback with appliances adjusted From Bulletin 36
In figure 21 , three plots showing the results of flashback tests with appliances adjusted for the three natural gases of Bulletin 36 are superposed. The figure is like figure 12 except that the numbers represent the number of appliances that flashed back with each gas instead of the number that showed lifting. The three figures that are combined in figure 21 were drawn separately, a line was drawn on each to represent what was considered to be the permissible limit of interchangeability with respect to flashback, and the three figures were superposed by sliding vertically (adjusting the ordinates) until the limiting curves coincided.

The slopes of the lines representing limits of interchangeability in figures 20 and 21 are identical, although they may not appear to be so because of a difference of scale. They may both be represented by the equation

$$
S / S_{a}-1.4 A \sqrt{D}_{a} / A_{a} \sqrt{D}=C,
$$

in which 1.4 is also the value of $k$ in eq 3 derived from figure $19 .^{6}$ Assuming the relation to be quite general, gases that are identical ("exactly interchangeable") in their tendency to cause flashback will always be represented by points on a line parallel to those in figures 19 and 20 . Then the "index," or measure of departure from exact interchangeability between two gases, can be taken as the difference between the final constants of the equations of the lines on which they lie, that is,

$$
J_{F}=C-C_{a}=S / S_{a}-1.4 A \sqrt{D_{a}} / A_{a} \sqrt{D}+0.4,
$$

where $J_{F}$ is the new index for susceptibility to flashback.

It is again of interest to examine the relation of the new formula to the corresponding AGA index defined by the equation $I_{F}=K_{s} F_{s} / K_{a} f_{a} \sqrt{h_{s} / 1000}$. The various symbols have the same meaning as in the earlier equation defining $I_{L}$. By substituting the symbols used in this paper, simplifying, and rearranging terms to put those depending primarily on speed of combustion on one side of the equation and those having to do with "inputs" of gas and primary air on the other, this becomes $K / K_{a}=I_{F}\left(H \sqrt{D_{a}} / H_{a} \sqrt{D}\right) \sqrt{1000 / H}$, or making the now familiar approximate assumption that heating value and air requirement are proportional, $K / K_{a}=I_{F}\left(A \sqrt{D}_{a} / A_{a} \sqrt{D}\right) \sqrt{1000 / H}$.

The new expression for interchangeability put in the corresponding form becomes

$$
S / S_{a}=1.4\left(A \sqrt{D}_{a} / A_{a} \sqrt{D}\right)-\mathrm{C} .
$$

Each of these equations is designed to represent a set of gases, all of which would be equally susceptible to flashback. Hence $I_{F}$ is a constant for such a set. A fairly close relation between the two formulas is

${ }^{6}$ Of course this equality was obtained by adjusting the slopes of the lines a little at the time the figures were drawn, but it is difficult to say that the agreement of the line with the points it represents could be improved by a change of slope in any of the figures. 
now apparent, but there are important differences. When we change to another set of gases all interchangeable among themselves, the values of $I_{F}$ and $C$ change. The formulas also differ because of the introduction of $\sqrt{H}$ as a factor in the denominator of the AGA expression. If several sets of mutually interchangeable gases are represented geometrically in terms of the AGA formula, the result is a series of curved lines passing through the origin with different slopes. The new formula results in a series of parallel straight lines.

The value of the new formula $J_{F}$ was examined in the same manner as that of $J_{L}$ by plotting it and other indexes with respect to the frequency of reported failures of appliances. It was found that, as in the case of the indexes for lifting, both $I_{F}$ and $J_{F}$ were decisively better for judging interchangeability with respect to the property in question than is any of the general indexes. The ratio of hydrogen to inert was considerably less closely related to recorded flashbacks than to recorded lifting. Accordingly, only $I_{F}$ and $J_{F}$ will be discussed. In figure 22 , the number of appliances that flashed back with each gas is plotted with respect to $J_{F}$. As in figure 20, mixtures for which there were recorded flashbacks of a single burner marked "tendency" or "occasionally" have been omitted. Figure 23 shows similar data plotted with respect to $I_{F}$, but, as in the case of lifting, $I_{F}$ was not recorded for all the substitute gases. Figure 24 shows $J_{F}$ for only those mixtures for which $I_{F}$ was reported.

The point that is most noticeable when comparing figures 23 and 24 is that when using $I_{F}$ and either the adjustment gas (with which flashback did not occur) or the average of the gases selected by the investigators as limiting mixtures, there are many more flashbacks that would not be predicted than when $J_{F}$ is used. Thus, 19 flashbacks were recorded for eight mixtures that had lower values of $I_{F}$ than the adjustment gas, and only seven flashbacks in three mixtures that had lower values of $J_{F}$. The usual

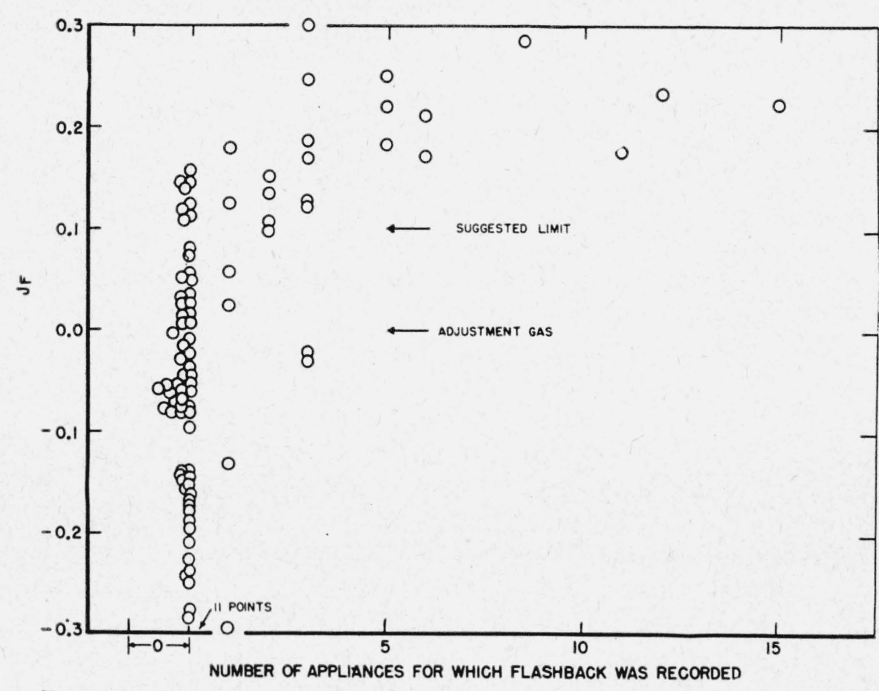

Figure 22. Number of cases of observed flashback from Report 1106-A compared with the index for flashback $J_{F}$.

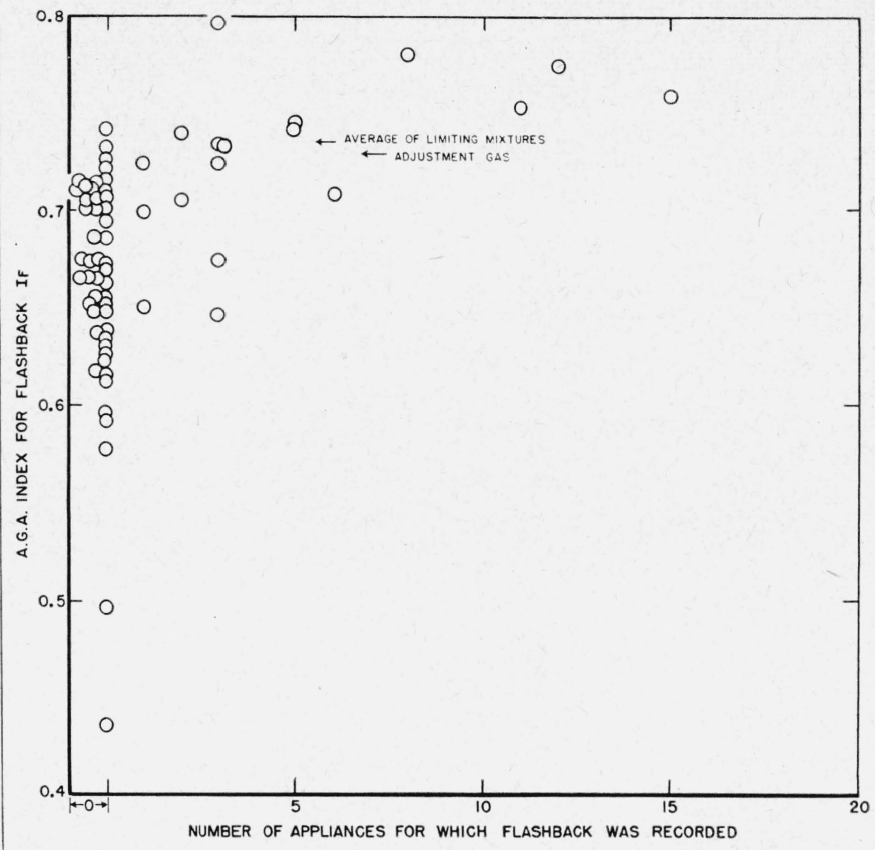

FIgURE 23. Number of cases of observed flashback from Report 1106-A compared with the AGA Index for flashback. $I_{F}$.

summations are given in table 8 . As in table 4, the summations relating to comparisons with adjustment gas $A-1$ are limited to those for which values of $I_{F}$ are given in the report. In the other summations, all recorded results are included. Data from report 1106-B are not included because practically all the substitute gases were less subject to flashback than the adjustment gas, and the number of failures that occurred was too small to be significant.

The Rochester Test Burner could not be adjusted to flash back with four of the gases described in report 1106-A that did flashback in the appliance

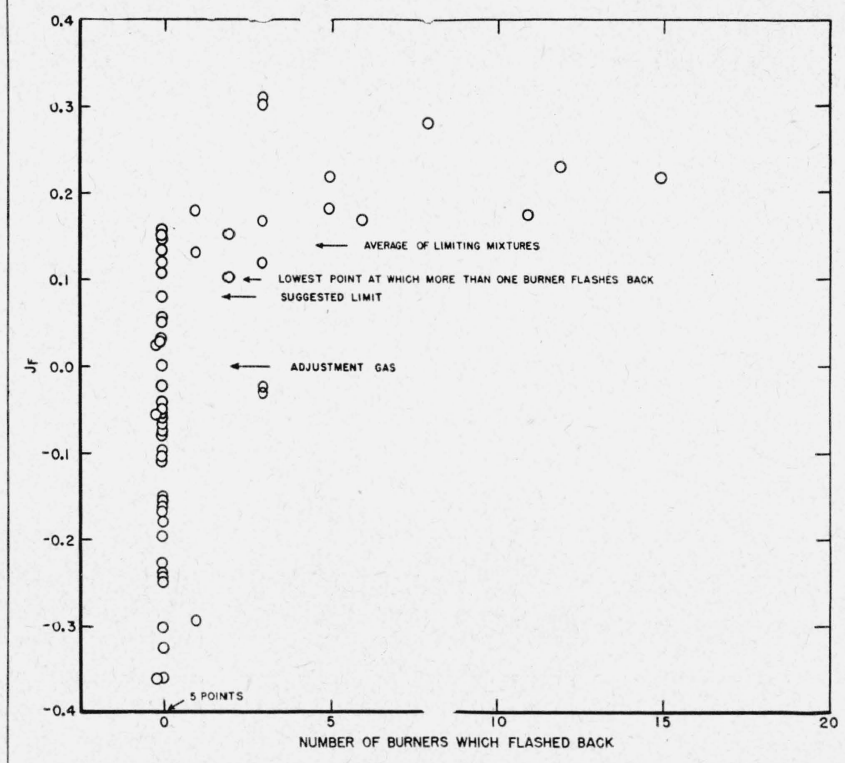

Figure 24. Number of cases of observed flashback for the gases represented in figure 23 compared with $J_{F}$. 
TABLE 8. Summations of tests for flashback compared with $I_{F}$ and $J_{F}$

\begin{tabular}{|c|c|c|c|c|c|c|}
\hline \multirow{2}{*}{ Adjustment gas } & \multicolumn{3}{|c|}{$\begin{array}{c}\text { Index } I_{\mu} \\
\text { Summations }\end{array}$} & \multicolumn{3}{|c|}{$\begin{array}{c}\text { Index } J_{F} \\
\text { Summations }\end{array}$} \\
\hline & A & B & $\mathrm{C}$ & A & B & $\mathrm{C}$ \\
\hline $\begin{array}{l}\mathrm{A} 1 \\
\mathrm{C} 1 \\
\mathrm{~N} 1 \\
\mathrm{~N} 2 \\
\mathrm{~N} 3\end{array}$ & $\begin{array}{r}48 \\
53 \\
12 \\
1 \\
6\end{array}$ & $\begin{array}{r}168 \\
115 \\
56 \\
2 \\
18\end{array}$ & $\begin{array}{r}437 \\
337 \\
120 \\
2 \\
27\end{array}$ & $\begin{array}{r}44 \\
22 \\
32 \\
5 \\
8\end{array}$ & $\begin{array}{r}107 \\
73 \\
78 \\
10 \\
15\end{array}$ & $\begin{array}{r}261 \\
186 \\
197 \\
15 \\
16\end{array}$ \\
\hline Total & 120 & 359 & 923 & 111 & 283 & 675 \\
\hline
\end{tabular}

burners; and there were 11 gases, including the adjustment gas, that did flash back with the Rochester Burner but not with any of the appliance burners. Summations of the readings for the gases that could be made to flash back in the Rochester burner and of $J_{F}$ for the same gases gave the results in table 9. The two means of predicting flashback appear to be about equally good if the figures in the table only are considered, but it must be remembered that the Rochester burner was favored in the selection of these data because those gases that could not be made to flash back with it where the tests with the other burners would have led us to think that it could, have been eliminated from consideration. It is probably safe to conclude that flashback of appliances in service can be predicted with a little more certainty from a knowledge of the composition of two gases and the use of the index than from tests of the gases with the Rochester burner.

TABLE 9. Summations comparing the readings of the Rochester Test Burner with $J_{F}$ as means for estimating the probability of flashback

Tests summarized are those with gases that could be made to flash back in the Rochester burner

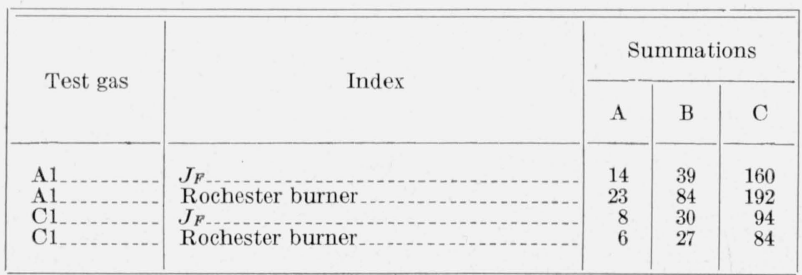

\section{Interchangeability With Respect to Yellow Tips}

Much the greater part of the heat of combustion of practically all gases distributed as public supplies comes from hydrocarbons. These compounds tend to be decomposed in the zone of primary reaction according to the chemical equation

$$
C_{n} H_{m}+\frac{n}{2} 0_{2}=n \mathrm{CO}+\frac{m}{2} \mathrm{H}_{2} .
$$

Although some of the carbon monoxide and hydrogen are oxidized at the same time to carbon dioxide and water, the amount is relatively small as long as an appreciable excess of hydrocarbon remains.
If there is enough oxygen in the primary air to satisfy the equation, an insignificant quantity of hydrocarbon or none at all passes through the primary zone. Any hydrocarbon that does get through the zone is surrounded by an atmosphere devoid of oxygen and at a temperature high enough for the thermal decomposition of most hydrocarbons, but not high enough for methane, which is a particularly stable compound. The carbon formed by decomposition in the flame is in the solid form and imparts a yellow color to it. The carbon is most apparent near the tip of the flame. Once the solid carbon is formed, its reaction in the secondary zone of combustion is much slower than that of gases in the same region, and some of it usually escapes to form eventually a discoloring smudge of soot on nearby surfaces even when the amount is too small to produce a visibly smoky flame. This is the reason we wish to avoid "yellow tips."

The "yellow tip limit", expressing the quantity of primary air needed to avoid yellow tips, is usually near that which would be calculated from eq 4 including methane among the hydrocarbons, but since we get little or no carbon from methane itself, other hydrocarbons must be present also. Then we might expect any formula for interchangeability with respect to yellow tips to involve the amount of primary air injected, the air requirement of the gas, the total carbon in the hydrocarbons, the quantities of hydrocarbons other than methane, and their stability toward heat. Approximately a dozen different formulas involving combinations of these factors were tried, and three or four of them gave pretty good results for the data of Bulletin 36 and Report 1106-A. To make a long story short, it was found that a function of the familiar $A / \sqrt{D}$ and an easily found number $N$ would give results as good as and more simply than anything else tried. $N$ is the number of carbon atoms in the hydrocarbons of 100 molecules of gas minus the number of molecules of saturated hydrocarbons (methane, ethane, propane, butane, etc.) in the same.

The form of the function relating $N$ and $A / \sqrt{D}$ had to be determined from the observations of Bulletin 36 and the Anthes Report because there were no adequate data from another source as for lifting and flashback. The data were plotted in figure 25 with $J_{A}$ as ordinate and $N$ as abscissa. $N / N_{a}$ was not used because $N_{a}$ may be close enough to zero to make the ratio embarrassingly large. In each case a straight line was drawn to divide as well as practicable the gases that produced yellow tips from those that did not. In figure 25 the AGA Committee's judgment of the interchangeability of the gases substituted for gas $A 1$ as stated in the Anthes Report is given. The meaning of the symbols is the same as in figure 7 , that is, + represents gases considered not interchangeable, $\mathrm{O}$ gases that were interchangeable, $L$ limiting mixtures of supplemental gases for which yellow tips was one of the limiting conditions, and the concentric circles represent the adjustment gas. Figure 26 represents in more detail the experimental results from Report $1106-\mathrm{A}$ on which the 


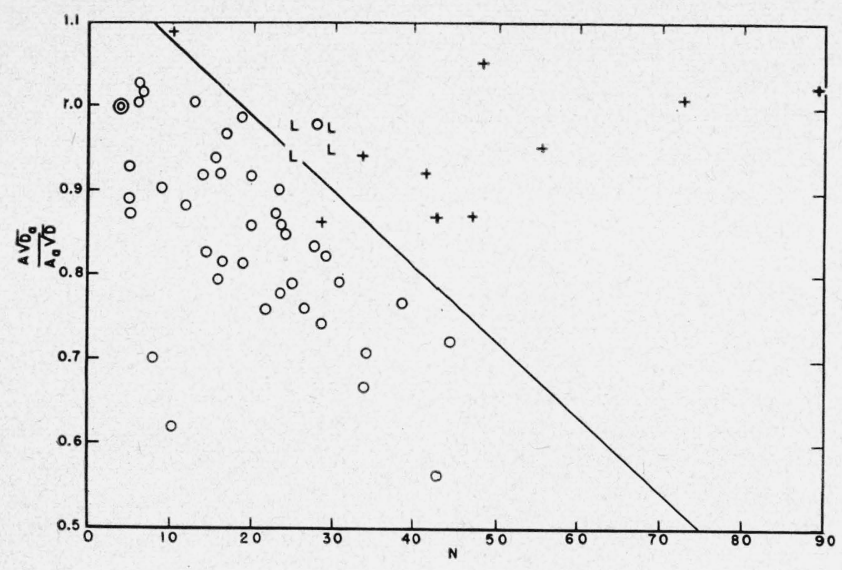

FiguRE 25. Interchangeability of gases with respect to yellow tips as shown in the Anthes Report.

Committee's decision as to interchangeability was based. In this figure + represents the occurrence, with some of the applicances tested, of -5 flames, $X$ represents the appearance of -4 flames only, and $\mathrm{O}$ represents gases in whose flames no yellow was reported. Figure 27 again combines the data on the three sets of tests with different adjustment gases reported in Bulletin 36. In this case the data did not distinguish between degrees of yellow tips. Once more, the slopes of the lines in the three figures are the same, and again they separate satisfactory from unsatisfactory performance reasonably well.

The results can be expressed by the general equation

$$
\frac{A \sqrt{D_{a}}}{A_{a} \sqrt{D}}+\frac{N}{110}=C
$$

in which $C$ is a constant for any group of gases that are equally liable to produce yellow tips. As with

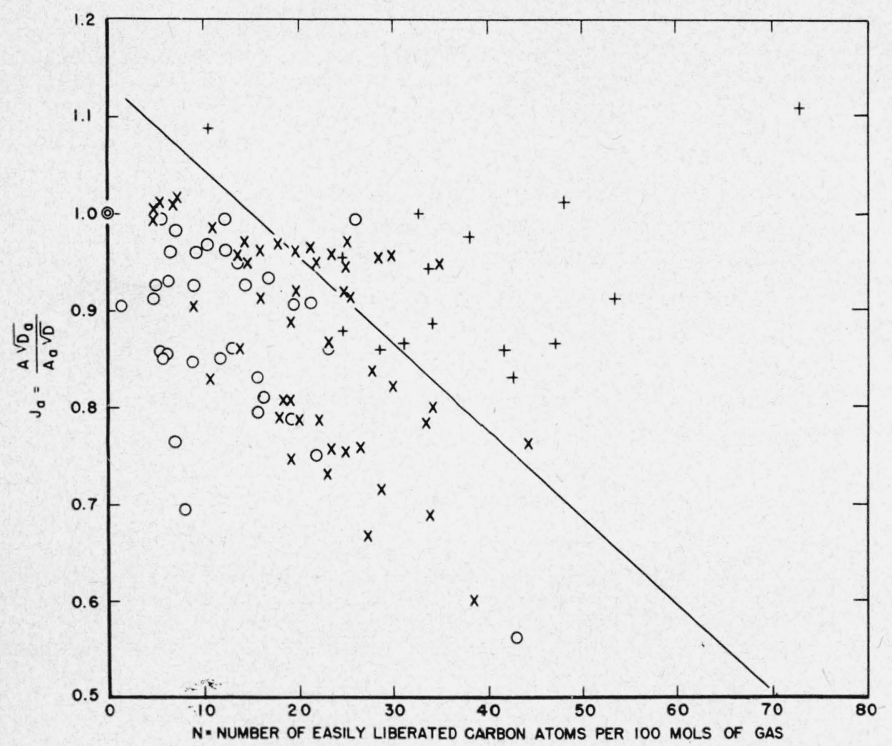

Figure 26. Observations of yellow tips from Report 1106-A. + Indicates -5 flames reported on some appliances, $X$ only -4 flames reported,
$O$ no yellow reported in flames.

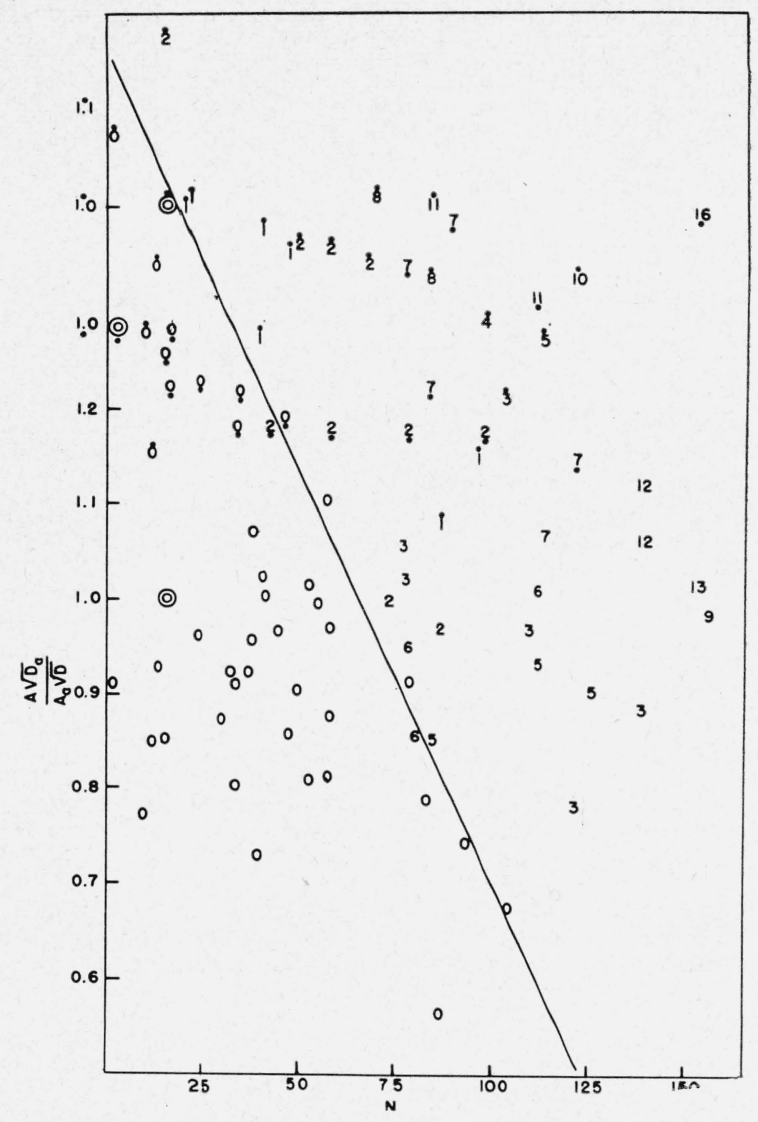

Figure 27. Observations of yellow tips with appliances adjusted for natural gases as reported in Bulletin 36 .

the flashback formula, the value of $C$ is different for another group of mutually interchangeable gases, and the difference between two values of $C$ for two gases is a measure of their approach to interchangeability. Hence the index of interchangeability with respect to yellow tips is

$$
J_{Y}=C-C_{a}=\frac{A \sqrt{D_{a}}}{A_{a} \sqrt{D}}-1+\frac{N-N_{a}}{110} .
$$

The definition of the AGA index for Interchangeability with respect to yellow tips is

in which

$$
I_{Y}=\frac{f_{s} a_{s} Y_{a}}{f_{a} a_{a} Y_{s}}
$$

$$
Y=\frac{100 T}{A+7 E-26.3 O_{2}} .
$$

The factor $T$ is the experimentally observed number of cubic feet of primary air required to eliminate yellow tips per cubic foot of gas. It is tabulated for various constituents in Bulletin 36 . Substituting the symbols of the present paper and simplifying

$$
I_{Y}=\frac{A \sqrt{D_{a}}}{A_{a} \sqrt{D}} \frac{T_{a}}{T} \quad \frac{A+7 Z-26.3 Q}{A_{a}+7 Z_{a}-26.3 Q_{a}},
$$


in which $Z$ is the volume of inert and $Q$ the volume of oxygen in the gas.

To show more clearly the relation between the two formulas, they may be put in the forms

$$
\begin{aligned}
& \frac{A \sqrt{D_{a}}}{A_{a} \sqrt{D}}=\frac{N_{a}-N}{110}+J_{Y}+1, \\
& \frac{A_{\sqrt{D_{a}}}}{A_{a} \sqrt{D}}=I_{Y} \frac{Y}{Y_{A}},
\end{aligned}
$$

in which the factors representing the flow of gas and air into the burner are on one side of each equation, and those representing the chemical property of forming carbon in the flame are on the other. If $A \sqrt{D_{a}} / A_{a} \sqrt{D}$ is plotted with respect to $N_{a}-N$, the equation represents a series of parallel lines, one for each value of $J_{Y}$. For the second formula, $A \sqrt{D_{a} \text { ! }}$ $A_{a} \sqrt{D}$ is to be plotted against the ratio rather than the difference of quantities representing the chemical property of readiness to decompose when heated, and gives a series of lines, one for each value of $I_{Y}$ converging at the origin. These differences between the treatment of the same phenomena by the two formulas is nearly the same as in the case of the formulas for flashback.

The indexes $I_{Y}$ and $J_{Y}$ were plotted with respect to the number of appliances for which yellow tips were recorded with each of the nine adjustment gases of Bulletin 36 and Reports 1106 A-D. Again, it would take too much space to display all these figures, and they will be represented only by the now familiar summations, which are given in table 10. In Bulletin 36 no distinction is made between -4 and -5 flames, and in Reports 1106-B, C, and $\mathrm{D},-5$ flames were not prevalent, hence the table represents all burners which showed yellow tips of any kind. For report $1106 \mathrm{~A}$, the entries are limited to gases for which $I_{Y}$ was reported however. In the other cases, in which $I_{Y}$ was reported for nearly

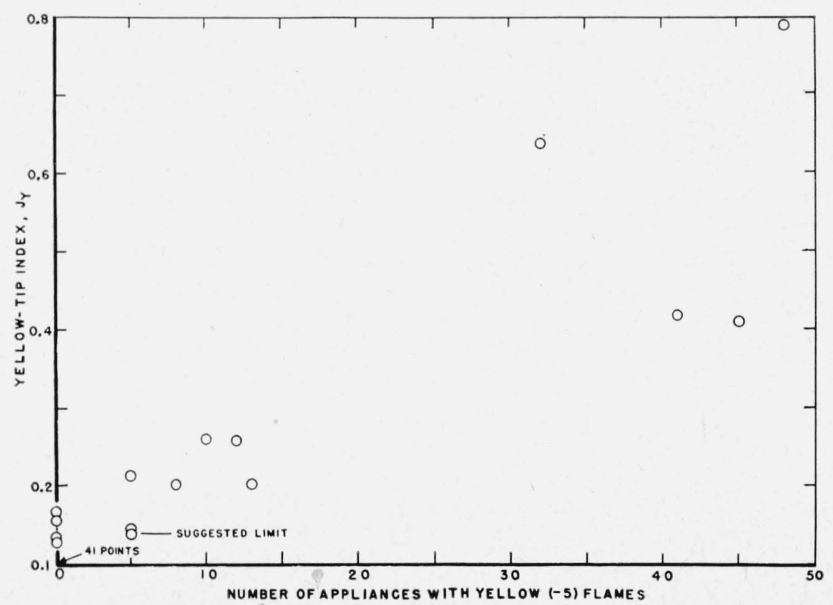

Figure 28. Yellow (-5) flames recorded in Report 1106-A compared with yellow-tip index $J_{Y}$.

Only cases for which $I_{Y}$ was also given.

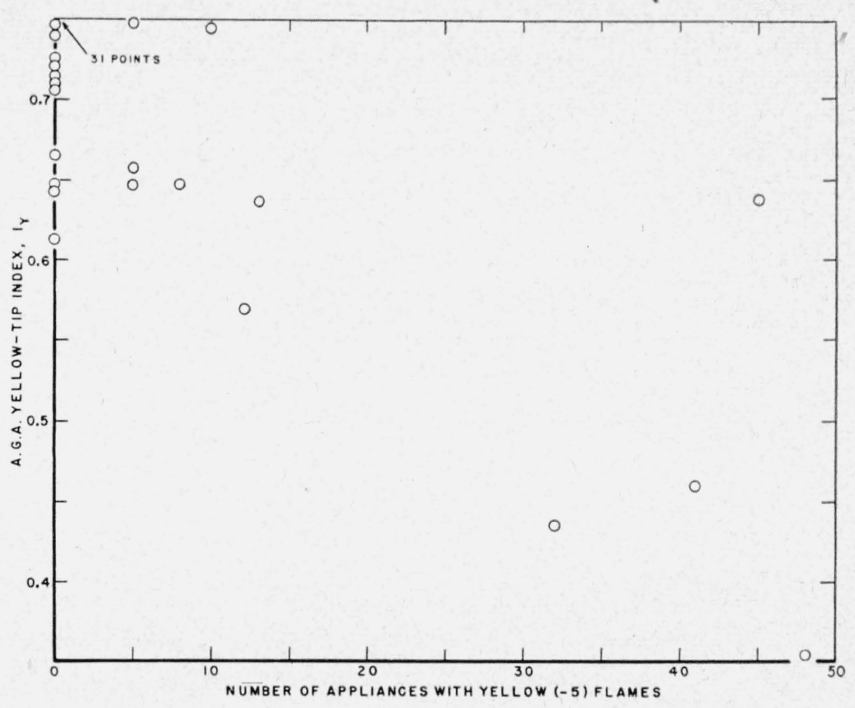

Figure 29. Yellow (-5) flames recorded in Report 1106-A compared with $A G A$ index $I_{Y}$.

all mixtures, this distinction was not made, and the comparison is a little unfavorable to $J_{Y}$ for this reason.

Actually, the appearance of a little yellow in a flame cannot be considered a serious failure of an appliance in the sense that lifting, flashback, and the liberation of carbon monoxide are; and this was evidently the opinion of the AGA Committee in charge of the investigation, for the gases selected as interchangeable included many that produced some -4 flames. It is of interest, therefore, to consider only those appliances that produced -5 flames. Figures 28 and 29 show plots of the two indexes with respect to the number of recorded cases of -5 flames among the gases of Report $1106 \mathrm{~A}$ for which $I_{Y}$ was recorded. Their summations are given in table 11, together with the summations for the observations made with the Rochester Test Burner and the Caloroptic.

TABLE 10. Summation of observations of yellow tips ( -4 and

\begin{tabular}{|c|c|c|c|c|c|c|}
\hline \multirow{2}{*}{ Adjustment gas } & \multicolumn{3}{|c|}{$\stackrel{I_{Y}}{\text { Summations }}$} & \multicolumn{3}{|c|}{$\frac{J_{Y}}{\text { Summations }}$} \\
\hline & A & B & $\mathrm{C}$ & A & B & $\mathrm{C}$ \\
\hline $\begin{array}{l}\text { A1 } 1 \\
\text { B1 } 2 \\
\text { B3 } 1 \\
\text { D1 } 1 \\
\text { N1 } 2 \\
\text { N2 } 3\end{array}$ & $\begin{array}{r}42 \\
38 \\
32 \\
40 \\
60 \\
7 \\
11 \\
0 \\
6\end{array}$ & $\begin{array}{r}210 \\
134 \\
153 \\
288 \\
461 \\
11 \\
21 \\
0 \\
13\end{array}$ & $\begin{array}{r}1,200 \\
402 \\
535 \\
1,351 \\
1,763 \\
60 \\
50 \\
0 \\
22\end{array}$ & $\begin{array}{r}38 \\
22 \\
33 \\
37 \\
55 \\
3 \\
17 \\
1 \\
8\end{array}$ & $\begin{array}{r}203 \\
76 \\
110 \\
185 \\
379 \\
4 \\
31 \\
1 \\
16\end{array}$ & $\begin{array}{r}1,082 \\
253 \\
485 \\
1,102 \\
1,253 \\
6 \\
84 \\
1 \\
52\end{array}$ \\
\hline Totals & 236 & 1,291 & 5,383 & 214 & 1,005 & 4,318 \\
\hline
\end{tabular}
- 5 flames) compared with indexes $I_{Y}$ and $J_{Y}$

The table shows a very definite advantage of the new index, both over the old one and the test burners in predicting serious cases of failure for the group of gases considered. The new index again does not agree as well as the old with the observations recorded 
in Bulletin 36, but on the whole it appears to be the better for general use.

TABLE 11. Summation of observations of yellow (-5) flames compared with indexes $I_{Y}, J_{Y}$, and the settings of the caloroptic and Rochester Burners

For adjustment gas $\mathbf{A} 1$ and all substitute gases for which all the data are recorded

\begin{tabular}{|c|r|r|r|}
\hline \multirow{2}{*}{ Index } & \multicolumn{3}{|c|}{ Summation } \\
\cline { 2 - 4 } & A & \multicolumn{1}{|c|}{ B } & \multicolumn{1}{|c|}{ C } \\
\hline & & & \\
\hline$I_{Y}$ & 18 & 39 & 356 \\
$J_{Y}$ & 6 & 11 & 59 \\
Rochester burner & 32 & 39 & 221 \\
Caloroptic & 32 & 29 & 161 \\
\hline
\end{tabular}

\section{Interchangeability With Respect to Completeness of Combustion}

The most important potential hazard in connection with the use of gas is that of the liberation of carbon monoxide through incomplete combustion. Where there is a uniform supply of gas, this hazard has been almost eliminated by the testing of appliances under American Standard approval requirements, the designing of appliances to meet the requirements, the assignment of safe "input ratings," and the training of service men to adjust burners to their ratings and to "normal" supplies of primary air. When the gas supply is changed, the rating in general is no longer normal, and the effect of the change on possible release of carbon monoxide must be given the most careful consideration.

It was mentioned previously that the important chemical reactions in the Bunsen flame are concentrated in two thin zones, the inner cone in which the principal reaction is usually the formation of hydrogen and carbon monoxide and the outer cone, or mantle, in which the carbon monoxide and hydrogen react with secondary air, usually completely. The size and shape of the zone of primary reaction are determined by the flame speed, or ignition velocity, with which the flame front moves into the streaming mixture of gas and primary air. The location of the secondary zone is determined by the interdiffusion of the surrounding air and the gases within or produced by the flame. If we were to plot the concentration of oxygen with respect to distance as we approach the flame surface from the outside, we would find a steadily falling curve dropping suddenly to zero at the flame surface. The concentration of carbon monoxide, hydrogen, and any hydrocarbons not already decomposed declines in the same manner as the outer cone is approached from the inside. The very thin zone of reaction itself is always located just where the concentrations of oxygen and combustible gas are exactly chemically equivalent. That this is true is easily seen if we think of how promptly any combustible gas that got into the hot, relatively concentrated oxygen just outside the zone would burn, or the speed with which oxygen would react in the concentrated fuel just inside it.
When a flame burns in the open, provided it is not too much disturbed by air currents, the zone of secondary reaction is a continuous surface, and there is no chance for carbon monoxide to escape from the region of the flame without passing through it, which it cannot do. If we thrust a cold object into the flame, the zone of secondary reaction spreads out to the extent necessary for the fuel gases to find their chemical equivalent of oxygen, and generally the surface of the solid seems to cut the flame cone sharply. Just at the cold surface, however, there is a zone in which the temperature is too low for combustion so that the continuity of the flame is broken, and through the gap a little carbon monoxide can escape. As the temperature of the solid increases, the width of the gap narrows and finally disappears entirely. The amount of carbon monoxide liberated in a case of flame impingement obviously depends on the temperature of the solid object and the length of the line of intersection between it and the flame surface. An increase in the size of the flame may lead to a greatly increased area of escape for the unburned gas, but generally the amount of carbon monoxide that gets away is not dangerous unless the flame is inclosed by solid walls, which prevent the access of as much secondary air as is needed. In this case the flame fills the combustion space and the gases that cannot be burned for lack of secondary air are too cold to burn by the time they escape from the confining walls and have access to adequate secondary air. Hence, we have two cases to consider (1) that of flame impingement in open space with adequate access of secondary air to the boundaries of the flame, which usually results in the release of measurable but not dangerous amounts of carbon monoxide, and (2) that of inclosure, which excludes the secondary air needed. In the first case, an increase in the size of the flame, whether produced by burning more gas or otherwise, has only a minor and gradual effect on the liberation of carbon monoxide; in the second case, increasing the size of the flame has no effect until the capacity of the combustion chamber and flue passages to take secondary air is almost reached, but beyond that point carbon monoxide is suddenly liberated in dangerous quantity. There are appliances in which the two effects of flame impingement and exclusion of secondary air are somewhat merged and hard to distinguish. The burning of gas in and around the glowers of radiant heaters is an example.

The case of insufficient secondary air is most important and easiest to deal with when considering interchangeability of gases. In most appliances the hydrocarbons are pretty completely decomposed in the primary cones so that only carbon monoxide and hydrogen remain to be burned. Moreover, these two gases have nearly the same heating value and exactly the same air requirement, though both they and their products of combustion, carbon dioxide and water vapor, have different rates of diffusion that affect the size of the flame appreciably. It follows that if the volume of air required, in cubic feet per hour, to burn two gases supplied to 
the same appliance is the same, and if the same percentage of it is entrained as primary air, the same quantity of secondary air is also involved in the final combustion. Both these conditions are met if $A / \sqrt{D}$ is the same for the two gases. Moreover, because heating value is nearly proportional to air requirement, nearly the same total heat is produced, and the volume of secondary air, which depends on thermal convection, is nearly the same in the two cases. The result is that we can predict from basic relations that $A \sqrt{D_{a}} / A_{a} \sqrt{D}$ will be a fairly good index of interchangeability for the important case of incomplete combustion because of a lack of secondary air.

This is well confirmed by observation. It was found in the early work at the National Bureau of Standards that the curve showing the limit of complete combustion on a diagram like figure 1 was displaced much less by moderate changes in the composition of gases than were the lifting and flashback curves. Additional evidence comes from the fact that the manufacturers of many appliances wish to "rate" them as high as possible and that the upper limit is usually determined by completeness of combustion. When the rating in Btu per hour has been pushed to the limit, it has usually been necessary to assign a rating for natural gas a little lower than for manufactured gas, but the ratio about corresponds to the difference in the air requirement of the two gases. The same conclusion can be reached from several statements in the Report of the Mixed Gas Research.

The degree to which impingement occurs in an appliance depends on the size of the flame, and this is affected by the completeness of decomposition of the hydrocarbons in the primary zone and the proportions of hydrogen and carbon monoxide that result. Carbon monoxide diffuses more slowly than hydrogen, carbon dioxide more slowly than water vapor. The result is that when carbon monoxide rather than hydrogen is burned the concentrations of the reactants fall more slowly, and the position of the zone in which they are equivalent is moved outward. Of course more carbon monoxide also escapes through a gap in the zone of reaction if the concentration inside is higher. The general result may be expected to be a function of the relative amounts of carbon monoxide and hydrogen in the mixture that leaves the primary zone. It was first assumed that this could be represented by the ratio of the total number of hydrogen atoms to carbon atoms in all constituents of the gas, and this ratio was plotted with respect to $A \sqrt{D}$, but gases with large initial contents of carbon monoxide appeared from the diagram to be more susceptible to incomplete combustion than from the results of observation. If we were dealing with a gas containing no hydrocarbon, primary air would react in the primary zone to oxidize carbon monoxide; when much hydrocarbon is present it serves to produce carbon monoxide in that zone. It seems reasonable, therefore, to differentiate between the carbon in hydrocarbons and that initially present as carbon monoxide, and the ratio of the total hydrogen in the gas to the carbon in hydrocarbons only, designated $R$, was substituted for the previous ratio.

When $A \sqrt{D_{a}} / A_{a} \sqrt{D}$ is plotted with respect to $R / R_{a}$ for appliances adjusted with gas $A 1$, the result is figure 30. Gases with which incomplete combustion was reported are marked $(+)$, those which burned completely in all appliances are marked (O). If $A \sqrt{D_{a}} / A_{a} \sqrt{D}$ which we previously called $J_{a}$ were the sole determining factor in incomplete combustion, the best line we could draw to separate the two symbols of figure 30 should be a horizontal line. Apparently it is not. Similar figures were drawn for each of the sets of observations with other gases, and the slope of the limiting straight line that would give the best general separation was chosen by considering all the figures.

If the relation represented by the straight line chosen is right, equal susceptibility of gases to produce carbon monoxide occurs when

$$
\frac{A \sqrt{D_{a}}}{A_{a} \sqrt{D}}-0.366 \frac{R}{R_{a}}=C,
$$

where $R$ and $R_{a}$ are the ratios of the number of hydrogen atoms in all forms of combination to carbon in hydrocarbons only, and $C$ is a constant that is the same for all exactly interchangeable gases.

Again we can take as the index of interchangeability the difference between the values of $C$ for two gases when the properties of the two gases represented by $A, D$, and $R$ are put into the equation, that is,

$$
J_{I}=\frac{A \sqrt{ } \overline{D_{a}}}{A_{a} \sqrt{D}}-0.366 \frac{R}{R_{a}}-0.634
$$

When the substitute gas is exactly interchangeable with the adjustment gas, $J_{I}=0$.

No coefficient of interchangeability for incomplete combustion was considered necessary by the authors

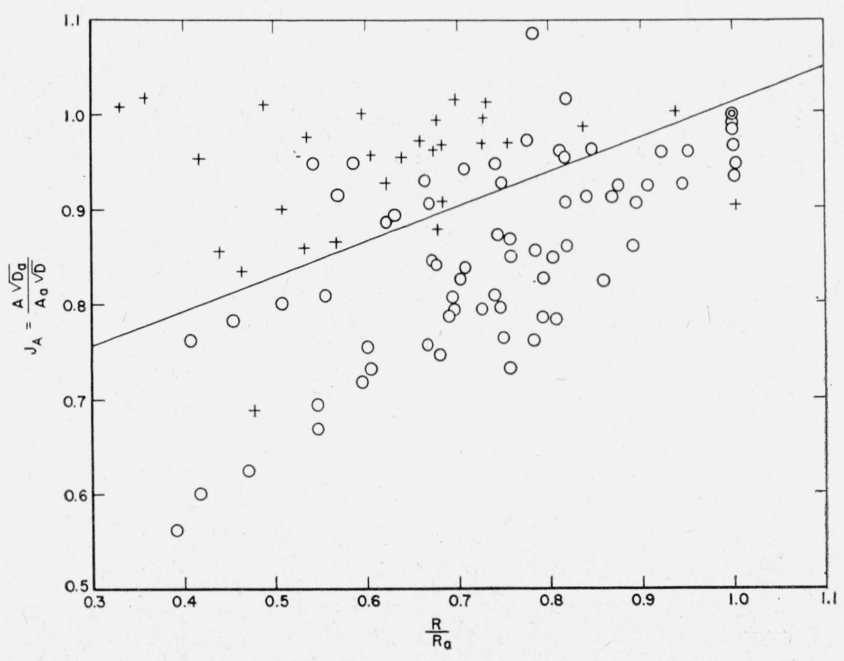

Figure 30. Observations of incomplete combustion from Relation to $J_{A}$ and $R / R_{a}$. Report $1106-A$. 
of Bulletin 36 because it was found that gases interchangeable with respect to the other limiting conditions were interchangeable with respect to completeness of combustion also. This was by no means always true of the observations recorded in Reports 1106-A-D. This is not hard to explain by reference to figures 2 and 3.

The adjustment gases of Bulletin 36 were all slow-burning natural gases, and at least some of the appliarices were adjusted rather close to the condition of lifting. In most cases the substitute gases were of faster-burning types (with shorter flames and less chance for impingement) which, tend to produce less carbon monoxide unless the input to the burner is greatly increased. With most of the substitutions, the displacement of the limit of complete combustion was therefore in the direction of safety, and the imminence of lifting prevented too great an increase of input. The only substitute gases for which the shift of the limit of complete combustion could have been away from safety were those containing a considerable amount of inert. Because inerts inject air without "requiring" any for chemical reaction and increase the velocity of flow through the ports without increasing the heat liberated, they affect the tendency of the flame to lift more than the tendency to burn the gas incompletely. The substitute gases also generally contained higher percentages of easily decomposed hydrocarbons than the adjustment gases, so that any displacement of the "adjustment" toward less primary air, which might have precluded danger from lifting, caused the higher yellow-tip limit to be encountered.

The case was quite different with the gases covered by Report 1106. The adjustment gases were all of rapid-burning types; they contained readily decomposed hydrocarbons; and the adjustments were nearly all rather far from lifting conditions. Introducing natural gas or even propane or butane into these burners, tended to reduce the input at which incomplete combustion is encountered without adversely affecting the yellow-tip limit and often without crossing the initially wide margin of safety from lifting. Therefore the fact that an index relating to completeness of combustion was not needed when considering the tests recorded in Bulletin 36 does not mean that such an index is not needed in general.

Table 12 shows this rather clearly. In it are listed the number of substitute gases for which only one type of failure was recorded in Report 1106, the number of times the AGA Committee attributed to only one limiting condition the amount of a supplementary gas that could be satisfactorily added to the base gas, and the total number of times a given type of failure was said to be one "reason for limiting further addition of the supplemental gas".

In figure 31, the numbers of appliances reported in Report 1106-A to have burned the gases incompletely are plotted with respect to $J_{I}$. The most notable thing about the figure is that a relatively large number of appliances begin to show failure at approximately the same value of the index, and this
TABLE 12. Importance of various types of failure in determining interchangeability

\begin{tabular}{|c|c|c|c|c|}
\hline \multirow{4}{*}{$\begin{array}{l}\text { Number of substitute gases with which } \\
\text { only one type of failure was reported } \\
\text { Number of supplementary gases the } \\
\text { limit of interchangeability of which } \\
\text { was attributed to only one type of } \\
\text { failure. } \\
\text { Number of times a type of failure was } \\
\text { stated as one reason for limiting "the } \\
\text { further addition of a supplemental } \\
\text { gas"- }\end{array}$} & \multicolumn{4}{|c|}{ Type of failure } \\
\hline & $\begin{array}{l}\text { Lift- } \\
\text { ing }\end{array}$ & $\begin{array}{c}\text { Yellow } \\
\text { tips }\end{array}$ & $\begin{array}{l}\text { Flash } \\
\text { back }\end{array}$ & $\begin{array}{l}\text { Incom- } \\
\text { plete } \\
\text { com- } \\
\text { bustion }\end{array}$ \\
\hline & 35 & 59 & 24 & 12 \\
\hline & 69 & 46 & 13 & 40 \\
\hline
\end{tabular}

index is nearly that of the adjustment gas. The same statement applies also to the data of reports $1106-\mathrm{B}-\mathrm{D}$. The reason is not hard to find. An inspection of figure 2 shows that in a typical appliance the normal injection curve, $N$, along which the point representing the adjustment of an appliance moves when pressure is increased, is nearly parallel to the yellowtip limit and approaches the lifting curve only at a sharp angle but is nearly perpendicular to the limit of complete combustion, $C$. Moreover the typical appliance is safest and most efficient when it is adjusted to take just a little more primary air than is necessary to avoid yellow tips. The only reason for supplying still more primary air is to permit more gas to be burned completely. Hence the danger of incomplete combustion is the usual reason for limiting the input of an appliance. The general method of increasing the amount of gas that can be burned is to increase the size of the appliance, giving it more ports, a larger combustion chamber, larger flue passages, etc.; but this costs money. At the time it is approved under ASA standards every appliance is assigned an "input rating" in Btu per hour, and when adjusted to this rating during testing it must take a 50 -percent increase of pressure $(25 \%$ in the case of range burners and some others) without incomplete

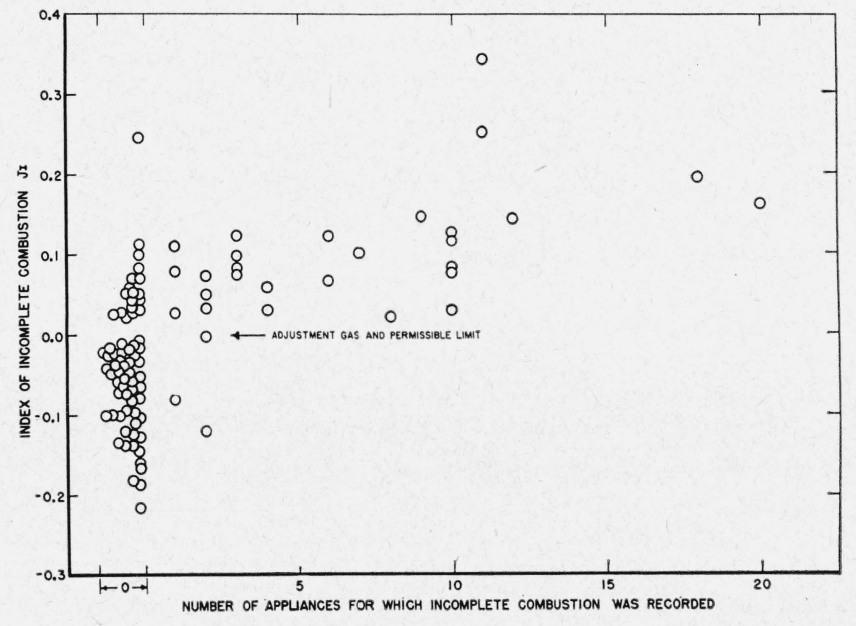

FIGURE 31. Number of appliances for which incomplete combustion was recorded in Report 1106-A compared with $J_{I}$. 
combustion. As appliances of increasing input rating command increasing prices, manufacturers tend to rate their appliances as high as they can and still meet the combustion requirement. When the tests of Report 1106 were made, each appliance was given. its normal adjustment, which includes the "rated input." Because this rating probably was usually determined as just described, we should expect the burner to approach closely the limit of complete combustion if the pressure of the adjustment gas were increased 50 percent (range burners, $25 \%$ ). If the substitute gas then had only a slightly higher index of complete combustion than the adjustment gas, we should expect incomplete combustion with most of the appliances when the substitute gas is supplied at a pressure 50 percent above normal. This is precisely what happened. The much greater dependence on pressure of incomplete combustion than of other types of failure and the fact that substituting other gases rarely resulted in incomplete combustion except at the higher pressures are clearly shown in table 13.

TABLE 13. Number of failures recorded in Report 1106-A at different pressures

\begin{tabular}{|c|c|c|c|}
\hline Type of failure & $\begin{array}{c}\text { Pressure } \\
0.5 \mathrm{~N}\end{array}$ & $N$ & $\begin{array}{l}1.25 \mathrm{~N} \\
\text { or } \\
1.5 \mathrm{~N}\end{array}$ \\
\hline Lifting. & 239 & 519 & 732 \\
\hline $\begin{array}{l}\text { Flashbac } \\
\text { Yellow t }\end{array}$ & 84 & $\begin{array}{r}51 \\
288\end{array}$ & $\begin{array}{r}21 \\
307\end{array}$ \\
\hline $\begin{array}{l}\text { Yellow thps } \\
\text { Incomplete combustion }\end{array}$ & 0 & 9 & 173 \\
\hline
\end{tabular}

a 1.25 times normal pressure with range burners, $1.50 \mathrm{~N}$ with others.

Another feature of figure 31 is the wider spread of the index corresponding to the same number of appliance failures than is the case with other indexes, and this in spite of a more definite limit at which failures begin. This is probably the result of the fact that, as already explained, failure to burn gas completely results from two independent conditions, lack of enough secondary air, and cooling of flames by impingement. Since we know that $J_{A}=$ $A \sqrt{D_{a}} / A_{a} \sqrt{D}$ should be a good index for the first (and much the most dangerous) condition, it is probable that we should give as much weight to it as to $J_{I}$ when predicting interchangeability. If this is done, a better index for cases of severe flame impingement could probably be worked out. The coefficient of $R / R_{a}$ in the expression for $J_{I}$ should probably be increased if the two indexes are used.

\section{Application of Indexes of Inter- changeability}

If we had to decide whether a plank would be long enough to span a brook, we would have two things to consider, the length of the plank, which we could measure accurately, and the width of the brook at which we might have to guess. A gas company or a public utility commission that must decide what modification of a gas supply to make or to permit has a very similar problem. The several indexes of interchangeability supply a means of measuring the length of the plank (the effect of a change of composition of the gas supply on the operation of any one appliance with a definite adjustment). The width of the brook corresponds to the existing adjustments of all or a great proportion of the appliances in service. The figure of speech may be carried even further. If the margins of the brook are muddy, we may know that the plank will not reach to solid ground and that we will have an unsatisfactory bridge, but it may be better than no bridge at all. Correspondingly, we may be sure that a given change of the gas supply will cause trouble with some appliances; whether they will be too numerous and the trouble of too serious a nature to justify the change can only be estimated. So far in this paper only the easy part of the problem has been discussed; unfortunately, the difficult part will have to be left almost entirely to the observation, ingenuity, and judgment of those immediately concerned. Some discussion of this may, however, be helpful.

The most obvious thing is that not all brooks are of the same width and that not all groups of gas appliances will tolerate, without readjustment, the same change in, let us say, the index for lifting. If appliances in service have been adjusted to burn natural gas, it is probable that nearly all of them have been set very close to lifting in order to burn the gas completely at a rate to supply a satisfactory amount of heat. Probably many of them are also on the verge of incomplete combustion, but they have a wide margin of safety from flashback and a reasonable one from yellow tips. Bulletin 36 probably gives us a fair guide in deciding how wide these margins are.

Similarly, a community that has been burning a by-product oil gas is likely to have appliances most of which are adjusted as close as permissible to flashback in order to have primary air enough to prevent smoking; but because of the large percentage of hydrogen present, they are remote from lifting and have at least the usual margin of safety from incomplete combustion. If it has been the gas company's policy to adjust appliances in a given district only when the pressure is near its maximum and has trained its employees to adhere closely to the input rating of the appliance, a gas with a value of $J_{I}$ of 0.10 or 0.15 when the adjustment gas is the customary supply, may be introduced with reasonable safety. But a company with many unvented space heaters on its system, which has adjusted appliances without much regard to the momentary stage of a variable pressure, and has tended to leave appliances with more than their normal input rating because its customers like it that way, may risk the lives of some of those customers if it increases $J_{I}$ by even a small amount. Of course it is impossible to set a positive limit to any change of properties of the gas on one side of which is safety and on the other danger. We have no sharp-edged precipice, but we do have a much narrower margin of uncertainty than in many other things that have to be 
decided for the sake of safety, the permissible speed of automobile traffic, for example, or the safe spacing between a heated chimney and wooden building materials.

The method of using the indexes in determining the composition of a gas supply, after the margins of safety of existing adjustments have been estimated, will be illustrated by the following problem.

Problem: A company distributing a coke oven gas of the composition of gas A1 wishes to supplement its supply as much as permissible during peak loads by mixing in propane and air. How much propane can be and how much air should be used?

The first step is, if possible, to assign permissible limits to the various indexes; the second is to make a quick estimate, by means of a few preliminary calculations, to determine which conditions may be limiting factors and to obtain some idea of the permissible changes; and the final step is to compute the indexes that may determine the limit with as much accuracy as the available data seem to justify.

For the difficult first task of assigning permissible limits to the indexes, we have a much better basis in the experiments of Report $1106 \mathrm{~A}$ than will usually be available to a gas company or a regulatory body. Permissible limits for appliances adjusted with gas A1 have already been assigned in the various figures. They are:

The lifting index, $J_{L}$, should not be less than 0.64 .

The flashback index, $J_{F}$, should not be greater than 0.08 .

The yellow tip index, $J_{Y}$, should not be greater than 0.14 .

The index for incomplete combustion, $J_{I}$, should not be greater than zero.

For the second step it will probably be sufficient to assume that all the indexes are linear functions of composition. After computing the indexes for changes from the adjustment gas to propane and to propane with 50 percent of air, one can quickly determine by linear interpolation (if one did not already know it) that the addition of propane will produce values of $J_{F}$ less than zero unless a very large amount of air is added, and that lifting will result from the addition of much less air, so that flashback is entirely eliminated from consideration. It will be found that incomplete combustion will not permit much propane to be used unless at least an equal volume of air accompanies it, and that if four times as much air as propane is used, very little of the mixture can be used without producing lifting. Yellow tips are found to be indicated under about the conditions that produce incomplete combustion. It is rather quickly found that we cannot hope to use more than about one-fourth as large a volume of propane as of the coke oven gas, and that something between one volume and four volumes of air will have to accompany each volume of propane.

The third step is to compute accurately and plot the indexes for several mixtures of air with propane in the range of interest outlined by the preliminary survey and for several mixtures of these mixtures with the coke oven gas. The plots obtained are

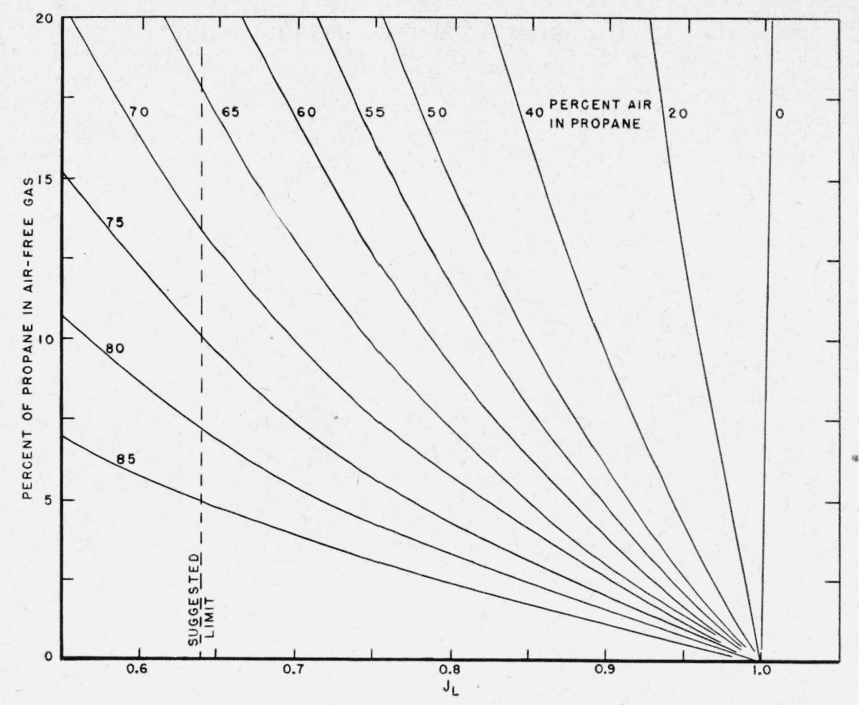

Figure 32. Values of index $J_{L}$ for mextures of propane and air with coke oven gas.

shown in figures 32 to 34 , and should be understandable without further explanation. The intersections of the lines representing suggested limits with the curves representing definite percentages of air in propane are plotted in figure 35 . From this figure, the permissible quantity of propane, if our preselected limits are not to be violated in any respect, is shown to be 16 percent by volume of the air-free gases, an increase in the amount of fuel that can be sent out of about 87 percent, as shown by the right hand scale of ordinates. The optimum percentage of air to be mixed with the propane is 67 percent. If during an emergency we are willing to tolerate some yellow flames but no carbon monoxide, we can use 18 percent of propane in the air-free fuel, but to avoid lifting we must reduce the amount of air mixed with the propane to 64.5 percent.

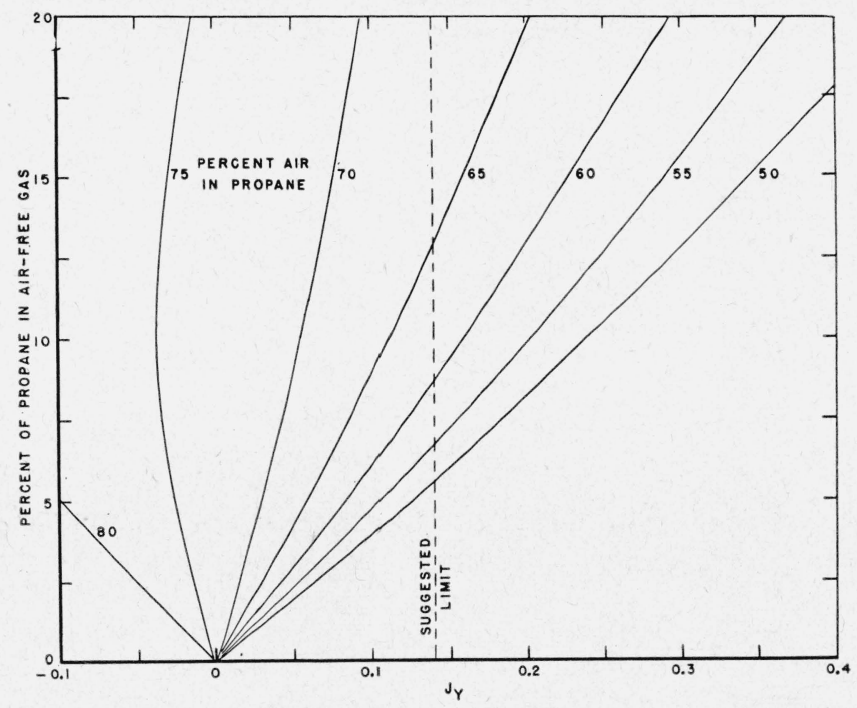

FiguRE 33. Values of index $J_{Y}$ for mixtures of propane and air with coke-oven gas. 


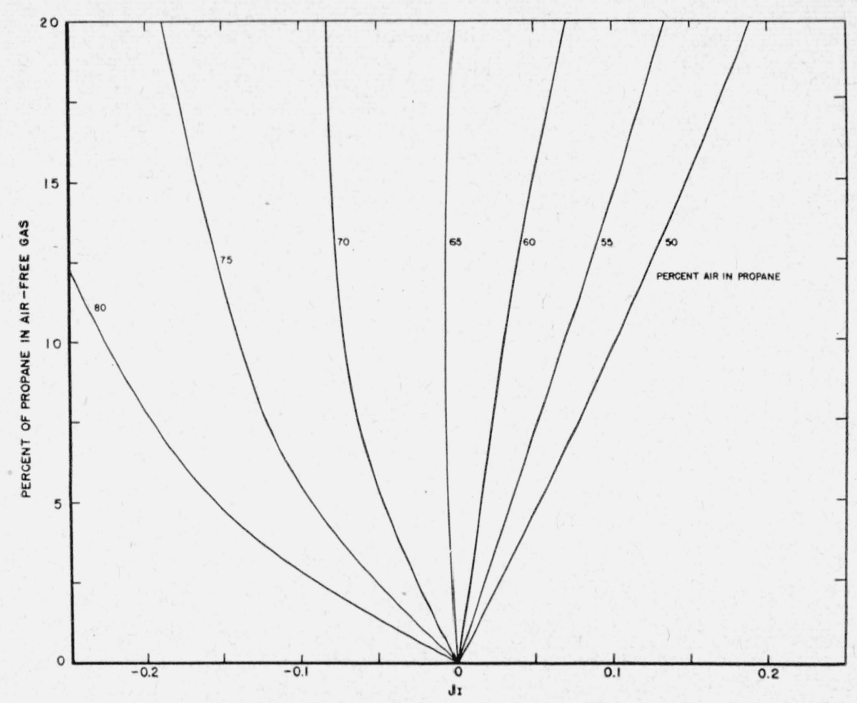

Figure 34. Values of index $J_{I}$ for mixtures of propane and air with coke-oven gas.

It is interesting to check this diagram with the direct results of the observations of propane-air mixtures recorded in Report 1106-A. It may seem that this is reasoning in a circle since the "suggested permissible limits" were based on the report. To some extent the objection is valid, but the general expression for $J_{L}$ was derived without the use of data from Report 1106-A, the expressions for $J_{Y}$ and $J_{I}$ were based on the whole group of about 400 experimental gases covered in the five reports of experimental work, and the selection of permissible limits for the indexes was made by considering all the 97 "substitute" gases of the Report 1106-A without special consideration being given to the mixtures of propane and air.

Two mixtures of propane and air were used as supplemental gases. Gas A1-11-100 contained 78.2

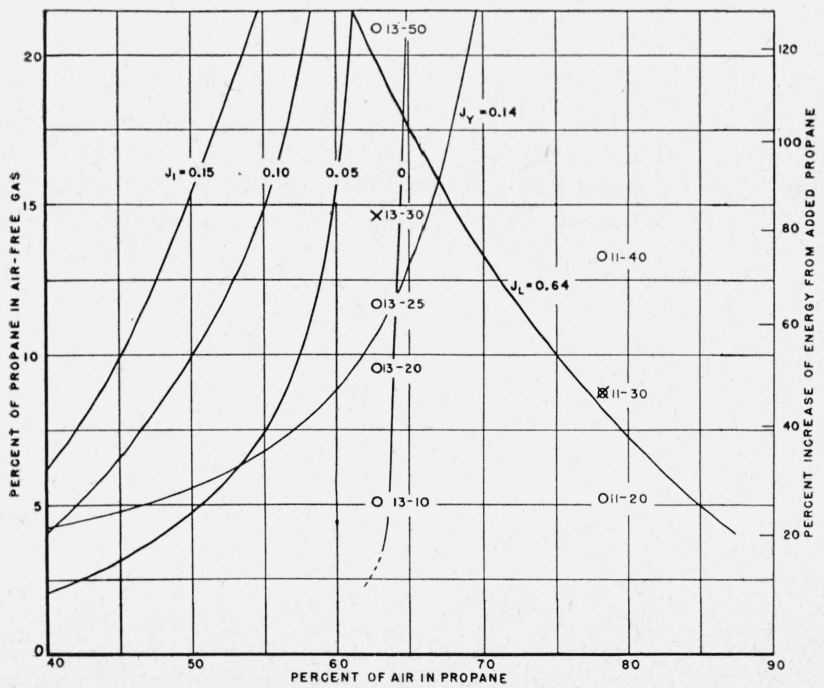

FIGURE 35. General diagram showing the amounts of propane that can be used to supplement coke-oven gas when mixed with any quantity of air. percent of air and had the same heating value as the adjustment gas. Gas A1-13-100 contained 62.8 percent of air. Each was mixed in several proportions with the adjustment gas to make substitute gases, the compositions of which are represented in the figure by circles and by numbers from which the initial A1 has been omitted. In both cases the AGA Committee decided that 30 percent of the substitute gases was the limit of practicable interchangeability. These mixtures are represented by the $\mathrm{X}$ marks labeled $11-30$ and $13-30$, respectively. In the first case the limiting mixture was tried experimentally; in the second it was estimated from observations of 25- and 50-percent mixtures of the supplemental gas with the adjustment gas.

We will now compare, point by point, the predictions that might have been made from the chart with the actual observations. From the chart we could predict that neither incomplete combustion nor yellow tips would occur with supplemental gas 11 , either when mixed with the adjustment gas in the proportions shown or when used alone. The record shows no incomplete combustion and no yellow tip for the unmixed supplemental gas and only one appliance with a -4 flame (slight yellow tip) at the softest adjustment with 40 and 60 percent of the supplemental gas in the mixture. We should predict severe lifting for the mixture containing 40 percent of supplemental gas and none with the mixture containing 20 percent. There were 22 recorded cases of failure, of which 15 involved +5 flames, with the 40-percent mixture and none with the 20-percent mixture. We should predict some show of lifting with the 30 percent mixture, because the point 11-30 is a little over the line, and we find six cases of which four involved +5 flames. These were considered by the Committee not severe enough to make a reduction of the limit necessary, however.

With supplemental gas 13 , we should predict that the 50-percent mixture, marked $13-50$, would produce yellow tips, with a little lifting and some incomplete combustion. We find 37 recorded cases of yellow tips of which 12 were -5 flames, 20 cases of lifting of which only five involved +5 flames, and 12 cases of incomplete combustion. It was previously pointed out that the +5 flames more sharply define lifting conditions than the +4 flames. The five cases of +5 flames in a total of 20 with the 13-50 mixture checks rather well with the four +5 flames in a total of six with the 11-30 mixture, combined with the fact that the point $13-50$ is a little farther inside the lifting limit than the point $11-30$.

We should predict no trouble from lifting with the experimental mixture containing less than 50 percent of supplemental gas 13, and we find only one appliance showing +4 flame under the most severe condition of adjustment and pressure with both the 20and 25-percent mixtures. This is clearly negligible if the committee was justified in accepting as interchangeable with the adjustment gas the four +5 and two +4 flames of gas 11-30. We should expect severe yellow tip conditions ( -5 flames) to disappear with about 24 percent of supplemental gas 13 , and we find 
seven -4 flames at 25 percent and six of the same at 20 percent. We should expect to find some incomplete combustion with the higher percentages of gas 13 , but not much since we are just under the percentage of air in propane that would be exactly interchangeable with the adjustment gas; and we should expect only a little change in the tendency toward incomplete combustion with diminishing percentages of the supplemental gas because we have assumed some of the appliances to be rated so close to the margin permitted by approval requirements that no increase in $J_{I}$ is permissible. We find $11,12,3,2$, and 2 recorded cases of incomplete combustion respectively with mixtures containing $100,50,25,20$, and 10 percent of gas 13 , which is in good accord with the prediction.

The most outstanding point of practical importance shown by figure 35 is that whatever limits we assume as permissible for the several indexes, the addition of air must be carefully controlled if we wish to make maximum use of propane as a supplement to the fuel supply.

It is now possible to outline quite definitely the practice desirable when coke-oven gas must be supplemented with propane. Because it is desirable to maintain constant the selling price of the gaseous fuel, a 535-Btu mixture containing about 22 percent of propane and 78 percent of air should be used until the first hazard from lifting is encountered. This occurs when the demand for fuel exceeds the supply of coke oven gas by about 40 percent. When this occurs, about 8 percent by volume of the air-free gas will be propane. If the demand continues to increase, the addition of propane can be continued, but the percentage of air in the propane must be gradually reduced until the air constitutes about 65 percent of the mixture with propane and the propane constitutes about 18 percent of the air-free gas by volume and has added about 105 percent to the available fuel supply. The heating value of the propane-air mixture will then be about $890 \mathrm{Btu}$ per cubic foot and that of the gas as a whole about $676 \mathrm{Btu}$. Appliances with fixed orifice and valve settings will be delivering about 95 percent as much heat at the same pressure as with the unmixed coke-oven gas.

Some time before this mixture is reached complaints of yellow or even smoky flames may be expected, but a little smoke is preferable to lifting flames or to an inadequate fuel supply. A further increase in the use of propane will result in either lifting flames or the release of carbon monoxide unless pressure is lowered. Lowering the pressure will not, of course, prevent trouble with the appliances controlled by regulators already set at pressures materially lower than those in the mains, nor will it relieve the tendency to deposit carbon very much.

\section{Summary and Conclusions}

The conditions that determine whether one fuel gas can be satisfactorily substituted for another have been described in relation to a general diagram by the use of which the complicated subject can be ex- plained much more clearly than otherwise. All the commonly used formulas for predicting the effects of supplying one gas mixture to appliances already adjusted to burn another have been discussed and compared, and a new group of indexes (which includes some old ones) has been proposed for use. The term index is used in this case for any mathematical expression that shows approximately the relative tendencies of the two gases to give unsatisfactory results of some kind when supplied to the same appliances without readjusting them. The symbols used in the new indexes all represent properties of gas mixtures that are easily computed from their composition.

The new indexes were derived in part from theory and in part empirically from recorded observations, chiefly those made in the Laboratory of the American Gas Assn. For a substantially complete survey of the interchangeability of two gases, the following indexes are recommended

$$
J_{H}=\frac{H \sqrt{D_{a}}}{H_{a} \sqrt{D}}
$$

where $H$ stands for heating value and $D$ for density or specific gravity. The subscript $a$ indicates the gas with which the appliance was adjusted. $J_{H}$ is a well-known expression that shows quantitatively the effect of a change of composition on the rate at which heat is produced in an appliance. If $I_{a}$ is the heat input into an appliance when adjusted, $I=J_{H} I_{a}$ is the heat input after the change of gases.

$$
J_{A}=\frac{A \sqrt{D_{a}}}{A_{a} \sqrt{D}} ;
$$

$A$ stands for the number of cubic feet of air required to burn $1 \mathrm{cu} \mathrm{ft}$ of gas. $J_{A}$, also well known, shows the change in the primary air that accompanies a change of gas. If $P_{a}$ is the primary air injected into an appliance, expressed as a fraction of the volume required to burn the gas at the time of adjustment, $P=P_{a} / J_{A}$ is the primary air, expressed in the same terms, which enters the burner after the change of gases. $J_{A}$ not only provides an accurate measure of the relative conditions of supply of primary air to burn two gases but an almost accurate measure of secondary air as well, and in consequence it is a measure of the hazard of incomplete combustion in the important group of water heaters, space heaters, ovens, etc., in which flame impingement is not involved and secondary air is adjusted close to the safe minimum in order to increase thermal efficiency.

$$
J_{L}=J_{A} \underset{S_{a}^{-}}{\frac{S}{100-Q_{a}}}
$$

$S / S_{a}$ is the ratio of flame speeds in corresponding mixtures of the two gases with air, and $Q$ is the percentage of oxygen in the gas. $J_{L}$ is the new index for lifting and shows the relative tendency of flames of the two gases to lift from the burner ports. When the 
two gases are exactly interchangeable with respect to lifting, $J_{L}=1$.

$$
J_{F}=\frac{S}{S_{a}}-1.4 J_{A}+0.4
$$

$J_{F}$ shows the relative tendency for flames of the two gases to flash back into the burners. When $J_{F}=0$, there is no difference between the gases in this respect.

$$
J_{Y}=J_{A}+\frac{N-N_{a}}{110}-1 .
$$

$N$ represents the number, in 100 molecules of gas, of the carbon atoms easily liberated during combustion. It is taken to be the total number of carbon atoms in the hydrocarbons except one in each molecule of the methane (saturated) series. $J_{Y}$ is a measure of the relative tendency of the two gases to produce yellow flames and release soot. When $J_{Y}=0$ there is no difference between the gases in this respect.

$$
J_{I}=J_{A}-0.366 \frac{R}{R_{a}}-0.634 .
$$

$R$ is the ratio of the number of hydrogen atoms in the gas to the number of carbon atoms in the hydrocarbons only. $J_{I}$ is a general expression for the relative tendencies of the two gases to liberate carbon monoxide and is a correction of $J_{A}$, which would otherwise apply, to take into account the effect of flame impingement in appliances of some types. When the two gases are equally likely to liberate carbon monoxide during combustion, $J_{I}=0$.

Extensive comparisons of the last four indexes with the results of experimental studies made by the American Gas Assoc. and recorded in its Bulletin 36 and Research Report 1106 show them to give a somewhat closer representation of the observations than any other method that has been proposed. Detailed comparisons were made with the three indexes of performance developed by the Association and designated $I_{L}, I_{F}$, and $I_{Y}$, which have the same purpose as the indexes designated by $J$ with the corresponding subscripts. It is clearly shown that no single index, such as that commonly referred to as AGA "Index $C$ " and which was developed during the "mixed Gas Research" of 1927-32 can be considered useful in comparison with the use of either group $J_{L}, J_{F}, J_{Y}$, and $J_{I}$ or $I_{L}, I_{F}$, and $I_{Y}$.

It is also rather clearly shown that, for the general purpose of predicting the effect of a change of gas supply on the large number of gas appliances in service, any uncertainty as to the accuracy with which either of these sets of indexes represents the relative properties of the gases is small compared with the uncertainties connected with the initial adjustments of the appliances themselves.

Without doubt the interpretation of the observations made by the AGA is complicated (1) by the difficulty of reproducing appliance adjustments and making gas mixtures exactly to specifications; (2) by variations in the number of appliances tested; and (3) by errors of computation and plotting by the writer of this paper. All these things combine to make the indexes appear less reliable than they really are. The first two sources of difficulty have been discussed at some length, particularly in connection with tables 3,4 , and 6 . These two sources of error offer the best explanation of the fact that the agreement between the behavior of appliance burners and that of test burners was never much better and was sometimes worse than the agreement of either appliance or test burners with the somewhat theoretical "indexes". Several errors that had been made in the long computations were found, but without doubt others remain. To have eliminated them by checking all the computations would have necessitated a long delay in publication and could not have changed the picture greatly.

The writer acknowledges the assistance of John H. Eiseman, who not only helped greatly in the preparation of the present paper but whose work with fuel gases for many years supplied much of the necessary background. The paper is of course, based mainly on experiments at the Laboratory of the American Gas Assoc. whose Director, E. L. Hall, generously facilitated the work of preparation by supplying copies of the several sections of Report 1106 in advance of publication. Paul Bannar, formerly of this Bureau, did much of the burdensome computing.

\section{References}

[1] Mixed Gas Research, American Gas Association Reports 597,645 , and $689(1930,1932,1933)$.

[2] Standards for gas service, NBS Circular 405 (1934).

[3] Requirements Committee Investigation of Laboratories Test Gases and Pressures. Report Number 847, AGA Testing Laboratories (1938).

[4] Combustion experiments with liquefied petroleum gases, Frank Knoy, Gas (Los Angeles) 17, 14 to 19 (June 1941).

[5] Interchangeability of other gases with natural gases. Research Bulletin 36, American Gas Association Testing Laboratories (1946).

[6] Progress report on mixed gas research Project T L-1, J. F. Anthes. Presented at the 1948 Joint Production and Chemical Committee Conference (May 24 to 26, 1948).

[7] Interchangeability of other fuel gases with coke-oven gas. Resarch Report No. 1106-A Gas Production Research Committee, Testing Laboratories (1948).

[8] Interchangeability of other fuel gases with carburetted water gases. Research Report 1106-B. AGA Testing Laboratories (1948).

[9] Interchangeability of other fuel gases with a mixed coke-oven carburetted water gas. Research Report 1106-C. AGA Laboratories (1949).

[10] Interchangeability of carburetted water gases with a mixed natural gas-blue gas - cracked natural gasproducer gas. Research Report 1106-D. AGA Laboratories (1949).

[11] Relative usefulness of gases of different heating value and adjustments of burners for changes in heating value and specific gravity, W. M. Berry, I. V. Brumbaugh, J. H. Eiseman, G. F. Moulton, and G. B. Shawn, NBS Tech. Pap. T222 (1922).

Washington, August 31, 1950 